\title{
Formas jurídicas de contratação médica em duas organizações sociais de saúde
}

\section{Cristiane Silva Oliveira}

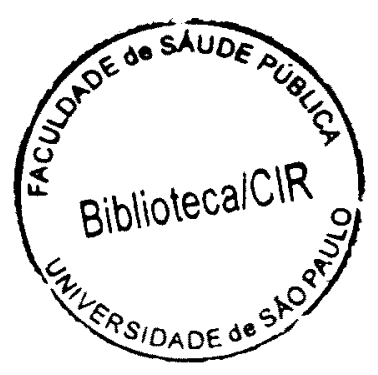

Dissertação apresentada ao Programa de Pós-Graduação em Saúde Pública da Faculdade de Saúde Pública da Universidade de São Paulo para obtenção do título de Mestre em Saúde Pública.

Área de Concentração: Serviços de Saúde Pública.

Orientador: Prof.: Dr. Olimpio J. Nogueira V. Bittar

\section{São Paulo}


“Descobri como é bom chegar quando se tem paciência.

E para se chegar, onde quer que seja, aprendi que não é preciso dominar a força, mas a razão. É preciso, antes de mais nada, querer". 


\section{DEDICATÓRIA}

Aos meus pais (Paulo e Ilza), às minhas irmãs (Adriana e Viviane), Ao meu amor (Luis) e à minha amiga (Ana).

Dedico também ao Fábio, à Heather e ao Sr. Antonio Barker . 
metodologia deve-se ao desenvolvimento de sistemas abrangentes e de alta complexidade, em conseqüência de contínuas e rápidas mudanças. As relações entre as instituições e suas motivações também são de difícil compreensão. Nessas situações, o estudo de caso permite maior proximidade para a avaliação desses sistemas. Vários são os tópicos abordados por meio de estudo de caso, dentre os quais destacam-se as inovações médicas e organizacionais (YIN apud Ferreira 2000).

São oito as características desejáveis dos estudos de caso em pesquisas de serviços de saúde propostas por (YIN apud Ferreira 2000):

1- O uso de uma definição orientada por desenho dos estudos de casos - o foco é um fenômeno único no seu contexto real. O método não é afetado pelas inúmeras variáveis do contexto externo, podendo ser usado mesmo quando os limites entre o fenômeno e seu contexto não são claros. Sua flexibilidade permite o uso em situações de incertezas, podendo o caso e o contexto mudarem ao longo do tempo;

2- Generalizações dos estudos de caso: replicações baseadas em teoria - a dificuldade em generalizar a partir de estudos de caso é considerada a maior falha deste método. O foco no desenho permite minimizar este fato. O caso deve então, ser considerado uma unidade para experimento. Desta forma, a dificuldade para generalizar é a mesma da enfrentada em experimentos, onde a hipótese e as teorias são os meios para a generalização. Utilizar 


\section{RESUMO}

Oliveira C.S. Formas Jurídicas de Contratação Médica em duas Organizações Sociais de Saúde. São Paulo, 2005. [Dissertação de MestradoFaculdade de Saúde Pública da USP]

Estudo de caso em dois hospitais caracterizados como organizações sociais de saúde que apresentam formas jurídicas de contratação médica diferentes. Um hospital com o corpo clínico próprio e o outro composto de corpo clínico terceirizado.

Objetivo: O presente trabalho tem como objetivo geral verificar os resultados dos indicadores de estrutura, produção/ produtividade, qualidade, recursos humanos e financeiros. Assim, como a relação hora médica-produção-gasto e a percepção dos diretores clínicos e administrativos das diferentes formas jurídicas de contratação dos serviços médicos de duas Organizações Sociais de Saúde.

Método: A revisão da literatura sobre o tema é seguida do estudo de caso nos dois hospitais. Os dados quantitativos correspondentes ao período de janeiro a dezembro de 2003 estão divididos da seguinte forma: Na primeira parte foram apresentados e analisados os indicadores de estrutura, produção, qualidade, recursos humanos e financeiros. Na segunda parte foi apresentada e analisada a relação hora médica-produção-gasto. Foram utilizados questionários para coleta de dados qualitativos como os diretores clínicos e administrativos dos dois hospitais.

Resultados: O Hospital Itaim Paulista possui o número de leitos $13 \%$ a mais que o Hospital Pedreira. Os percentuais de internações, saídas hospitalares e pacientes dia também foram respectivamente $19 \%, 15 \%$ e $20 \%$ superiores.

$\mathrm{Na}$ taxa de ocupação, o Hospital Pedreira apresentou $79,74 \%$, enquanto no Hospital Itaim Paulista esse percentual foi $87,88 \%$.

A média de permanência foi o item que apresentou maior disparidade entre os hospitais

No pronto socorro, o Hospital Itaim Paulista atendeu o número de consultas $16 \%$ a mais que o Hospital Pedreira e no ambulatório atendeu $44 \%$ abaixo.

Os indicadores de qualidade demonstraram melhor desempenho do Hospital Pedreira em relação ao Hospital Itaim Paulista.

Nos indicadores de recursos humanos e financeiros, foi possível observar que o Hospital Itaim Paulista possui o número de funcionários menor do que o Hospital Pedreira e também gastou menos.

Em relação à hora médica e produção, constatou-se que o número de horas trabalhadas e a produção do Hospital Itaim Paulista foram superiores ao apurado no Hospital Pedreira. 
Conclusão: O estudo mostrou que a forma de vínculo, não influenciou diretamente na diferença encontrada nos indicadores apresentados nos dois hospitais. Embora, o Hospital Itaim Paulista tenha demonstrado maior facilidade na gestão do seu corpo clínico.

Palavras Chave: organizações sociais de saúde, médicos próprios, médicos terceirizados. 


\section{SUMMARY}

Oliveira C.S. Juridical Methods for Hiring Medical Staff. [Master's Degree Dissertation - Faculdade de Saúde Pública da USP.]

Case study carried out in two hospitals characterized as social health care organizations presenting different juridical methods for hiring medical staff. One of the hospitals having its own medical staff and the other one outsourcing for its needs.

Objective: This dissertation amply aims at checking the results of hospital structure, production/productivity, quality, human resources, and finance indicators. As well as hours worked by physicians-production-expense relationship and medical and administrative directors' perception of different juridical methods for hiring medical staff at two Social Health Care Organizations.

Method: Pertaining literature review is followed by a case study of both hospitals. 2003 (January through December) quantitative data have been divided as follows: on the first part, hospital structure (such as beds available, doctor's offices etc), production (i.e. patients seen to), quality, human resources, and finance indicators have been presented and analysed; on the second, hours worked by physicians-production-expense relationship has been presented and analysed. Qualitative data have been collected through the medical and administrative directors of each hospital using questionnaires.

Results: The Hospital Itaim Paulista has $13 \%$ more beds available than the Hospital Pedreira. Percent admissions, releases, and patient/day were also $19 \%, 15 \%$, and $20 \%$ higher, respectively.

The Hospital Pedreira showed a $79.74 \%$ occupation rate against a $87.88 \%$ one of the Hospital Itaim Paulista.

Average stay was the item presenting the greatest disparity between both hospitals.

At emergency, the Hospital Itaim Paulista attended $16 \%$ more outpatients than Hospital Pedreira but $44 \%$ less at the clinic.

The Hospital Pedreira showed a higher quality indicator performance than the Hospital Itaim Paulista.

It has been detected through the human resources and finance indicators that the Hospital Itaim Paulista has a smaller number of employees than the Hospital Pedreira and has incurred less expenses.

As to hours worked by physicians and production, it has been observed that the number of hours worked and production were greater at the Hospital Itaim Paulista than those verified at the Hospital Pedreira. 
Conclusion: The study has shown that the type of bond does not downright influence the difference found in the indicators presented for both hospitals. Neverthless, the Hospital Itaim Paulista has shown greater ease of management of its medical staff.

Key words: social health care organizations, own medical staff, outsourced physicians. 


\section{LISTA DE QUADROS}

Quadro 1

A evolução da terceirização

Quadro 2

Distribuição dos médicos segundo vínculo, por gênero

Quadro 3

Inserção dos médicos nos setores públicos e privados 


\section{LISTA DE TABELAS}

Tabela 1

Número de leitos operacionais de jan a dez de 2003 nos Hospitais Pedreira e Itaim.

Tabela 2

Número de internações realizadas de jan a dez de 2003 nos Hospitais Pedreira e Itaim.

Tabela 3

Número de saídas realizadas de jan a dez de 2003 nos Hospitais Pedreira e Itaim.

Tabela 4

Número de pacientes dia de jan a dez de 2003 nos Hospitais Pedreira e Itaim.

Tabela 5

Porcentagem de ocupação de jan a dez de 2003 nos Hospitais Pedreira e Itaim.

Tabela 6

Média de permanência de jan a dez de 2003 nos Hospitais Pedreira e Itaim.

Tabela 7

Diagnósticos de saídas mais freqüentes de jan a dez de 2003 - Clinica Médica e UTI Adulto nos Hospitais Pedreira e Itaim.

Tabela 8

Diagnósticos de saídas mais freqüentes de jan a dez de 2003 - Clinica Cirúrgica nos Hospitais Pedreira e Itaim.

Tabela 9

Diagnósticos de saídas mais freqüentes de jan a dez de 2003 - Ortopedia nos Hospitais Pedreira e Itaim. 
Diagnósticos de saídas mais freqüentes de jan a dez de 2003 - Clinica Pediátrica nos Hospitais Pedreira e Itaim.

Tabela 11

Diagnósticos de saídas mais freqüentes de jan a dez de 2003 - Unidade Neonatal nos Hospitais Pedreira e Itaim.

Tabela 12

Diagnósticos de saídas mais freqüentes de jan a dez de 2003 - Ginecologia e Obstetrícia nos Hospitais Pedreira e Itaim.

Tabela 13 66

Número de Consultas de jan a dez de 2003 - Pronto Socorro nos Hospitais Pedreira e Itaim.

Tabela 14

Diagnósticos de atendimentos mais freqüentes de jan a dez de 2003 - Clínica Médica nos Hospitais Pedreira e Itaim.

Tabela 15 68

Diagnósticos de atendimentos mais freqüentes de jan a dez de 2003 - Clínica Cirúrgica nos Hospitais Pedreira e Itaim.

Tabela 16

Diagnósticos de atendimentos mais freqüentes de jan a dez de 2003 - Ortopedia nos Hospitais Pedreira e Itaim.

Tabela 17 69

Diagnósticos de atendimentos mais freqüentes de jan a dez de 2003 - Clínica Pediátrica nos Hospitais Pedreira e Itaim.

Tabela 18 69

Diagnósticos de atendimentos mais freqüentes de jan a dez de 2003 - Ginecologia e Obstetrícia nos Hospitais Pedreira e Itaim. 
Número de consultas ambulatoriais de jan a dez de 2003 nos Hospitais Pedreira e Itaim.

Tabela 20

Taxa de Infecção Hospitalar de jan a dez de 2003 nos Hospitais Pedreira e Itaim.

Tabela 21

Taxa de Cesáreas de jan a dez de 2003 nos Hospitais Pedreira e Itaim.

Tabela 22

Avaliação dos usuários sobre o corpo clínico de jan a dez de 2003 nos Hospitais Pedreira e Itaim.

Tabela 23 73

Dados gerais sobre recursos humanos de jan a dez de 2003 nos Hospitais Pedreira e Itaim.

Tabela 24

Dados gerais sobre gastos de jan a dez de 2003 nos Hospitais Pedreira e Itaim.

Tabela 25

Dados gerais de indicadores nos Hospitais Pedreira e Itaim.

Tabela 26

Distribuição hora/médica, produção e gasto de Jan a Dez de 2003 - Clínica

Médica - Hospital Pedreira

Tabela 27

Distribuição hora/médica, produção e gasto de Jan a Dez de 2003 - Clínica

Médica - Hospital Itaim Paulista

Tabela 28 78

Relação entre valor gasto e horas médicas de jan a dez de 2003 - Clínica Médica 
Distribuição hora/médica, produção e gasto de Jan a Dez de 2003 - UTI

Adulto - Hospital Pedreira

Tabela 30

Distribuição hora/médica, produção e gasto de Jan a Dez de 2003 - UTI

Adulto - Hospital Itaim Paulista

Tabela 31

Relação entre valor gasto e horas médicas de jan a dez de 2003 - UTI Adulto

Tabela 32

Distribuição hora/médica, produção e gasto de Jan a Dez de 2003 - Clínica

Cirúrgica - Hospital Pedreira

Tabela 33

Distribuição hora/médica, produção e gasto de Jan a Dez de 2003 - Clínica

Cirúrgica - Hospital Itaim Paulista

Tabela 34

Relação entre valor gasto e horas médicas de jan a dez de 2003 - Clínica Cirúrgica

Tabela 35

Distribuição hora/médica, produção e gasto de Jan a Dez de 2003 - Clínica Pediátrica - Hospital Pedreira

Tabela 36

Distribuição hora/médica, produção e gasto de Jan a Dez de 2003 - Clínica Pediátrica - Hospital Itaim Paulista

Tabela 37 84

Relação entre valor gasto e horas médicas de jan a dez de 2003 - Clínica Pediátrica 
Distribuição hora/médica, produção e gasto de Jan a Dez de 2003 - Unidade Neonatal - Hospital Pedreira

Tabela 39 85

Distribuição hora/médica, produção e gasto de Jan a Dez de 2003 - Unidade Neonatal - Hospital Itaim Paulista

Tabela 40 86

Relação entre valor gasto e horas médicas de jan a dez de 2003 - Unidade Neonatal

Tabela 41

Distribuição hora/médica, produção e gasto de Jan a Dez de 2003 -

Ginecologia e Obstetrícia - Hospital Pedreira

Tabela 42

Distribuição hora/médica, produção e gasto de Jan a Dez de 2003 -

Ginecologia e Obstetrícia - Hospital Itaim Paulista

Tabela 43

Relação entre valor gasto e horas médicas de jan a dez de 2003 - Ginecologia e

Obstetrícia

Tabela 44

Dados gerais da relação hora médica-produção-gasto - Unidade de

Internação

Tabela 45

Distribuição hora/médica, produção e gasto de Jan a Dez de 2003 - Pronto

Socorro / Clínica Médica - Hospital Pedreira

Tabela 46

Distribuição hora/médica, produção e gasto de Jan a Dez de 2003 - Pronto Socorro / Clínica Médica - Hospital Itaim Paulista 
Relação entre consultas e horas médicas de Jan a dez de 2003 - Pronto

Socorro / Clínica Médica - Hospital Pedreira e Hospital Itaim Paulista

Tabela 48

Relação entre valor gasto e horas médicas de Jan a dez de 2003-Pronto

Socorro / Clínica Médica - Hospital Pedreira e Hospital Itaim Paulista

Tabela 49

Distribuição hora/médica, produção e gasto de Jan a Dez de 2003 - Pronto

Socorro / Clínica Cirúrgica - Hospital Pedreira

Tabela 50

Distribuição hora/médica, produção e gasto de Jan a Dez de 2003 - Pronto

Socorro / Clínica Cirúrgica - Hospital Itaim Paulista

Tabela 51

Relação entre consultas e horas médicas de Jan a dez de 2003 - Pronto

Socorro / Clínica Cirúrgica - Hospital Pedreira e Hospital Itaim Paulista

Tabela 52

Relação entre valor gasto e horas médicas de Jan a dez de 2003-Pronto

Socorro / Clínica Cirúrgica - Hospital Pedreira e Hospital Itaim Paulista

Tabela 53

Distribuição hora/médica, produção e gasto de Jan a Dez de 2003 - Pronto

Socorro / Clínica Pediátrica - Hospital Pedreira

Tabela 54

Distribuição hora/médica, produção e gasto de Jan a Dez de 2003 - Pronto Socorro / Clínica Pediátrica - Hospital Itaim Paulista 
Relação entre consultas e horas médicas de Jan a dez de 2003 - Pronto

Socorro / Clínica Pediátrica - Hospital Pedreira e Hospital Itaim Paulista

Tabela 56

Relação entre valor gasto e horas médicas de Jan a dez de 2003- Pronto

Socorro/Clínica Pediátrica - Hospital Pedreira e Hospital Itaim Paulista

Tabela 57

Distribuição hora/médica, produção e gasto de Jan a Dez de 2003 - Pronto

Socorro/Ginecologia e Obstetrícia - Hospital Pedreira

Tabela 58

Distribuição hora/médica, produção e gasto de Jan a Dez de 2003 - Pronto

Socorro / Ginecologia e Obstetrícia - Hospital Itaim Paulista

Tabela 59

Relação entre consultas e horas médicas de Jan a dez de 2003 - Pronto

Socorro/Ginecologia e Obstetrícia - Hospital Pedreira e Hospital Itaim

Paulista

Tabela 60

Relação entre valor gasto e horas médicas de Jan a dez de 2003-Pronto

Socorro / Ginecologia e Obstetrícia - Hospital Pedreira e Hospital Itaim

Paulista

Tabela 61

Dados gerais da relação hora médica-produção-gasto - Pronto Socorro

Tabela 62

Distribuição hora/ médica, produção e gasto de jan a dez de 2003 Ambulatório Hospital Pedreira e Hospital Itaim Paulista 
Relação entre consultas e horas médicas de Jan a dez de 2003 - Ambulatório Hospital Pedreira e Hospital Itaim Paulista

Tabela 64 100

Relação entre valor gasto e horas médicas de Jan a dez de 2003 -

Ambulatório Hospital Pedreira e Hospital Itaim Paulista

Tabela 65

Distribuição hora/médica e produção de jan a dez de 2003 - Unidade de Internação / Ortopedia - Hospital Pedreira

Tabela 66

Distribuição hora/médica e produção de jan a dez de 2003 - Unidade de Internação / Ortopedia - Hospital Itaim Paulista

Tabela 67

Distribuição hora/médica e produção de jan a dez de 2003 - Pronto Socorro

/ Ortopedia - Hospital Pedreira

Tabela 68

Distribuição hora/médica e produção de jan a dez de 2003 - Pronto Socorro

/ Ortopedia - Hospital Itaim Paulista

Tabela 69

Relação entre consultas e horas médicas de jan a dez de 2003 - Pronto

Socorro / Ortopedia - Hospital Pedreira e Hospital Itaim

Tabela 70

Dados gerais da relação hora médica-produção-gasto - Hospital Pedreira e Hospital Itaim Paulista 
Remuneração líquida por tipo de vínculo

\section{LISTAS DE SIGLAS}

\begin{tabular}{|c|c|}
\hline Siglas & Nome \\
\hline CLT & Consolidação das Leis do Trabalho \\
\hline CPDC & Código de Proteção de Defesa do Consumidor \\
\hline CREMESP & Conselho Regional de Medicina do Estado de São Paulo \\
\hline DOE & Diário Oficial do Estado de São Paulo \\
\hline DP & Departamento Pessoal \\
\hline FSP & Faculdade de Saúde Pública \\
\hline MARE & Ministério da Administração Federal e Reforma do Estado \\
\hline OSS & Organizações Sociais de Saúde \\
\hline PDRAE & Plano Diretor do Aparelho do Estado \\
\hline PROAHSA & $\begin{array}{l}\text { Programa de Estudos Avançados em Administração Hospitalar e de } \\
\text { Sistemas de Saúde }\end{array}$ \\
\hline SAU & Serviço de Atendimento ao Usuário \\
\hline $\mathrm{SCIH}$ & Serviço de Controle de Infecção Hospitalar \\
\hline SES & Secretaria de Estado da Saúde \\
\hline SPP & Serviço de Prontuário do Paciente \\
\hline SUS & Sistema Único de Saúde \\
\hline
\end{tabular}




\section{ÍNDICE}

1.1-Reforma da Administração Pública e a Constituição das Organizações Sociais

1.2 - Organizações Sociais de Saúde 03

1.3-Terceirização de Profissionais e Serviços 05

1.3.1-Terceirização no Setor Saúde 06

1.3.2- A terceirização no contexto atual 08

1.4 -Formas de Contratação Médica 12

$\begin{array}{ll}\text { 1.4.1 Médicos Próprios } & 14\end{array}$

$\begin{array}{ll}\text { 1.4.2 Cooperativa Médica } & 20\end{array}$

$\begin{array}{ll}\text { 1.4.3 Empresas Médicas } & 22\end{array}$

1.5 - A Responsabilidade Civil Médica 24

1.6- Indicadores 35

$\begin{array}{ll}\text { 2.JUSTIFICATIVA } & 37\end{array}$

3. OBJETIVOS 39 
4.1-Estudo de Caso

4.2-O processo de Pesquisa de Campo

4.3- Período do Estudo

4.4- Coleta de Dados

5- RESULTADOS e DISCUSSÃO

PRIMEIRA PARTE

5.1-Unidades de Internação

5.1.1-Número de Leitos Operacionais

5.1.2-Internações

5.1.3-Saídas Hospitalares

5.1.4-Pacientes /Dia

5.1.5-Porcentagem de Ocupação Operacional (média mensal) 60

5.1.6-Média de Permanência

5.1.7 Perfil de Morbidade nas Unidades de Internação

5.2.1 Perfil de Morbidade no Pronto Socorro

5.4- Indicadores de Qualidade

5.4.1 - Taxa de Infecção Hospitalar

5.4.2-Taxa de Cesáreas

5.4.3- Avaliação dos usuários sobre o corpo clínico 
$\begin{array}{ll}\text { SEGUNDA PARTE } & 75\end{array}$

5.7-Relação hora médica-produção-gasto $\quad 77$

5.7.1-Unidades de Internação $\quad 77$

$\begin{array}{lr}\text { 5.7.2-Pronto Socorro } & 90\end{array}$

5.7.3-Ambulatório 99

5.7.4-Ortopedia - Unidade de Internação 101

5.7.5-Ortopedia - Pronto Socorro 102

5.7.6- Formas de Remuneração Médica 105

5.7.7 A Percepção dos Diretores Clínicos e Administrativos 107

5.7.8 Comparação com a literatura 115

6. CONCLUSÃo 121 


\section{INTRODUÇÃo}

\section{REVIS Ã O DA LITERATURA}

\section{1-Reforma da Administração Pública e a Constituição das Organizações Sociais.}

O Plano Diretor da Reforma do Aparelho do Estado-PDRAEMinistério da Administração Federal e Reforma do Estado-MARE traçou a trajetória dos modelos de administração pública no Brasil, justificando a reforma proposta, definindo e conceituando o Aparelho do Estado, os Setores de Estado e as Formas de Propriedade e de Administração. Nesse Plano, a saúde por ser um Serviço Não Exclusivo poderia ser transferida à iniciativa privada sem fins lucrativos.

Segundo o texto produzido pelo PDRAE o Estado é uma organização burocrática que possui o poder de legislar e tributar sobre a população de um determinado território. O Estado é, portanto, a única estrutura organizacional que possui o "poder extroverso", ou seja, o poder de constituir unilateralmente obrigações para terceiros, com extravasamento dos seus próprios limites.

Para entendermos a classificação do setor saúde como um Serviço Não Exclusivo no PDRAE é preciso distinguir no aparelho de Estado quatro setores:

- Núcleo Estratégico: Corresponde aos Poderes Legislativos, ao Ministério Público e, no poder executivo, ao Presidente da 
República, aos ministros e seus auxiliares e assessores diretos, responsáveis pelo planejamento e formulação das políticas públicas.

- Atividades Exclusivas: São serviços em que se exerce o poder extroverso do Estado, o poder de regulamentar, fiscalizar e fomentar. Ex.: cobrança e fiscalização dos impostos, a polícia, a previdência básica, etc.

- Serviços não Exclusivos: Corresponde ao setor onde o Estado atua simultaneamente com outras organizações públicas não estatais e privadas. As entidades desse setor não possuem o poder de Estado. Este, entretanto, está presente porque os serviços envolvem direitos humanos fundamentais, como os da educação e da saúde, ou porque possuem "economias externas" relevantes, na medida que produzem ganhos que não podem ser apropriados por esses serviços através do mercado. As economias produzidas imediatamente se espalham para o resto da sociedade, não podendo ser transformadas em lucros. São exemplos deste setor: as universidades, os hospitais, os centros de pesquisa e os museus.

- Produção de bens e serviços para o mercado: Corresponde a área de atuação das empresas. É caracterizado pelas atividades econômicas voltadas para o lucro que ainda permanecem no aparelho do Estado seja porque faltou capital ao setor privado para realizar o investimento, seja porque as atividades 
naturalmente monopolistas, nas quais o controle via mercado não é possível, tornando-se necessário no caso de privatização, a regulamentação rígida.

Além dessas questões o PDRAE aponta três projetos básicos que permitirão a implantação da administração pública gerencial no serviço público brasileiro. Em um plano horizontal, temos o projeto de Avaliação Estrutural, que examinará de forma global a estrutura do Estado. Nas atividades exclusivas de Estado, temos operando de forma vertical, em maior profundidade, o projeto das Agências Autônomas e nos serviços não-exclusivos, o projeto das Organizações Sociais acompanhado pelo processo de publicização.

No PDRAE o processo de publicização é a transferência dos serviços não exclusivos do Estado, do setor estatal, para o público não estatal, onde assumirão a forma de Organizações Sociais.

\section{2 - Organizações Sociais de Saúde}

A Organização Social criada pelo Governo Federal que utilizou o Plano Diretor da Reforma do Aparelho do Estado-PDRAE foi caracterizada como “... entidade de interesse social e de utilidade pública, associação civil sem fins lucrativos". Foi objeto da medida provisória n..$^{\circ} 1.591$, de Outubro de 1.997, visando a reforma do Estado, resgatando sua autonomia financeira e sua capacidade de implementar políticas públicas(Sá, 1998). 
Nas Organizações Sociais, o Governo transfere as funções de órgãos públicos para entidades da sociedade civil. Com isso, ele reduz gasto público, ganha agilidade na gestão de pessoal, de recursos humanos e nos procedimentos de contratação( Vaz, 1999).

No Estado de São Paulo, a Organização Social surgiu como medida de gestão estratégica e modernização do serviço público, através da Lei Complementar 846 de 04 de Junho de 1998 que a qualificou como pessoa jurídica de direito privado sem fins lucrativos, cujas atividades sejam dirigidas à saúde e à cultura.

$\mathrm{Na}$ área da saúde, definiu-se o modelo de gestão com base na Lei Complementar 846 , bem como seus direitos e deveres perante a Secretaria de Saúde do Estado de São Paulo e os demais órgãos de fiscalização e criou uma Comissão de Avaliação que analisa mensalmente as metas e os contratos (DOE - SP 5/6/1998).

O Contrato de Gestão é o instrumento utilizado para garantir o gerenciamento entre o poder público e a organização social (DOE -SP $5 / 6 / 1998)$.

As instituições qualificadas como organizações sociais têm como competência atender com seus recursos humanos e técnicos aos usuários do SUS - Sistema Único de Saúde, oferecendo, segundo o grau de complexidade de sua assistência e sua capacidade operacional, os serviços de saúde. Tendo ainda, autonomia de gestão referente a aquisição de materiais, medicamentos (sem licitação e através de 
cotações) e financeiramente, podem fazer aplicações bancárias, desde que os lucros obtidos com os investimentos sejam utilizados nas próprias organizações. Podem também se utilizar desta autonomia para realizar contratos assistenciais e desenvolver parcerias com terceiros (cooperativa de médicos, laboratórios de análises clínicas, serviços de diagnóstico por imagem e outros), objetivando alcançar as metas estabelecidas no Contrato de Gestão.

A própria Emenda Constitucional $\mathrm{n}^{\circ} 19$, de 04.06 .98 (federal) deixa uma abertura oficializada quando reafirma sua disposição em permitir a associação por consórcios públicos e convênios de cooperação com outras entidades.

\section{3-Terceirização de Profissionais e Serviços}

Terceirização (cujo termo em inglês, outsourcing, é formado pelas palavras out e source, ou seja, fonte externa) é uma abordagem de gestão que permite delegar a um agente externo a responsabilidade operacional por processos ou serviços até então realizados na empresa (Francesschini, Galetto, Varetto e Pignatelli, 2004).

Os principais motivos que levam as empresas à opção pela terceirização são a racionalização dos custos, alcançar maior qualidade e produtividade. Ao terceirizar, as empresas podem concentrar seus esforços em seu negócio principal, nas metas de médio e longo prazo. A essência desse processo é a interface organizacional 
entre contratante e terceirizada durante todas as atividades de terceirização (Francesschini, Galetto, Varetto e Pignatelli, 2004).

A principal finalidade da terceirização seria otimizar a produção, a qualidade, o lucro e a competitividade, mediante um processo de horizontalização de atividades, simplificando-se a estrutura organizacional, a fim de que as empresas possam concentrar seus esforços na melhor metodologia para a obtenção do produto de sua atividade fím. Além disso, permite redução do preço do produto ou serviço devido à diminuição dos encargos trabalhistas e previdenciários. Outra vantagem seria a especialização de empresas prestadoras de serviço.

\subsection{1-Terceirização no Setor Saúde}

Segundo Boletim de Indicadores do PROAHSA publicado em 1997, 49\% da mão-de-obra de hospitais de grande porte (151 a 300 leitos) eram terceirizados, $38 \%$ em hospitais com mais de 500 leitos, $10 \%$ dos de médio porte (51 a 150 leitos) e somente $3 \%$ da mão-deobra dos hospitais de pequeno porte(5 a 50 leitos). Os setores mais terceirizados são os de manutenção e conservação (limpeza, segurança, alimentação, manutenção de equipamentos e lavanderia); entre as áreas técnicas e profissionais, podemos citar a área administrativa e alguns setores médicos como laboratórios, imagem e pronto atendimento. 
Os serviços de saúde terceirizados podem ser caracterizados em três grupos (Ibanez \& Bittar, 2001):

Serviços de apoio técnico-administrativo: lavanderia, alimentação, limpeza, manutenção, segurança e transporte. Esses serviços são terceirizados pela maioria dos hospitais públicos com contratos bem definidos.

Serviços de apoio diagnóstico e terapêutico: Imagem, Banco de Sangue, laboratório clínico, anatomia patológica e anestesia. Esses serviços são terceirizados freqüentemente por hospitais privados, através de arrendamento dessas áreas a profissionais ou empresas com contratos variados.

Serviços clínicos e cirúrgicos: Esses serviços são terceirizados nos hospitais privados através de contratos baseados na tabela AMB Associação Médica Brasileira - e contratos com empresas e cooperativas.

Segundo artigo publicado em outubro de 2004 na Gazeta Mercantil, a terceirização nos hospitais tem sido opção muitas vezes econômica sem perder a qualidade. Isso ocorre em função de setores que antes relegados a um segundo plano, ocupam lugar de destaque na gestão de empresas especializadas. Mário Hélio Souza Ramos, diretor executivo do Hospital Edmundo Vasconcelos, diz que "Com a terceirização correta, a empresa ganha qualidade e tempo, vantagens que se somam à redução de custos, mas o maior resultado é a 
possibilidade de melhorar a qualidade do serviço oferecido ao paciente".

Numa pesquisa realizada pelo mesmo hospital em 145 hospitais privados, com 200 a 300 leitos, revelou que o índice de terceirização no país ainda é pequeno. Na região norte não foi encontrado nenhum hospital com serviço terceirizado, $4 \%$ na região sul, $10 \%$ na região nordeste, $14 \%$ na região centro-oeste e $30 \%$ na região sudeste.

\subsection{2- A terceirização no contexto atual}

A terceirização tradicional que objetivava apenas cortar custos e envolvia basicamente serviços não essenciais das empresas, permitindo que os gestores pudessem concentrar os seus esforços no negócio principal tem dado lugar a chamada terceirização estratégica que foca ganhar rapidez, flexibilidade e eficiência, em que a empresa terceiriza várias atividades, exceto aquelas específicas que lhe podem gerar uma vantagem competitiva(Francesschini, Galetto, Varetto e Pignatelli, 2004).

Nesse processo de terceirização estratégica, o contratante deve ter um modelo específico de análise e gestão do terceirizado. Ele precisa monitorar e administrar o terceirizado em todas as etapas que requerem tomadas de decisão. (Francesschini, Galetto, Varetto e Pignatelli, 2004). 
Para seguir o modelo proposto é necessário passar por quatro etapas principais:

1-Benchmarking interno: O contratante controla seus processos, avalia a própria eficiência e define o que deve terceirizar.

2- Benchmarking externo: Aborda todas as relações entre contratante e contratado, desde a seleção até a estratégia de gestão do relacionamento entre ambos.

3-Negociação de contrato: É a conseqüência dessas análises e decisões prévias.

4-Gerenciamento da terceirização: É a medição dos processos terceirizados planejados. (Francesschini, Galetto, Varetto e Pignatelli, 2004).

Um estudo realizado pela Consultoria Accenture mostra que inúmeras empresas no mundo estão utilizando a terceirização para alcançar uma melhoria rápida e sustentável no desempenho da empresa como um todo. Trata-se da terceirização transformacional, que vem sendo conhecida no mundo inteiro como BTO (business transformation outsourcing). $\mathrm{O}$ terceirizado assume o papel de parceiro, compartilhando riscos com a empresa contratante, aceitando fazer acordos flexíveis e empreendendo o automonitoramento. A contratante por sua vez, muda sua abordagem, trocando o controle pela transparência e compartilhando com os parceiros os benefícios. 
$O$ estudo foi realizado em entrevistas com executivos envolvidos com as experiências de 26 empresas. Destas, $65 \%$ estão sediadas nos Estados Unidos e 35\% na Europa ou na Ásia. A maior parte, $73 \%$ é do setor privado (Linders, Cole e Jacobson, 2004) 
Quadro 1: A evolução da terceirização

\begin{tabular}{|c|c|c|c|}
\hline & $\begin{array}{l}\text { Terceirização } \\
\text { convencional }\end{array}$ & $\begin{array}{l}\text { Terceirização } \\
\text { colaborativa }\end{array}$ & $\begin{array}{c}\text { Terceirização } \\
\text { transformacional }\end{array}$ \\
\hline Objetivo & 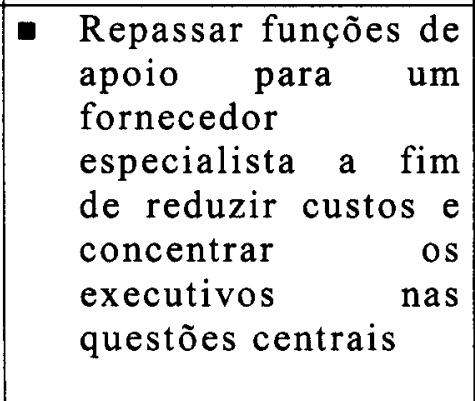 & $\begin{array}{l}\text { Atualizar processos } \\
\text { não-centrais com o } \\
\text { objetivo de reduzir } \\
\text { despesas e propiciar } \\
\text { maior flexibilidade } \\
\text { para responder às } \\
\text { constantes mudanças } \\
\text { do negócio }\end{array}$ & $\begin{array}{l}\text { Transformar a } \\
\text { maneira pela qual a } \\
\text { empresa funciona, } \\
\text { de forma a alcançar } \\
\text { uma melhoria do } \\
\text { desempenho } \\
\text { drástica } \\
\text { sustentável por toda } \\
\text { a empresa. }\end{array}$ \\
\hline \begin{tabular}{|l} 
Papel do \\
parceiro
\end{tabular} & $\begin{array}{l}\text { - Executar a função } \\
\text { de apoio }\end{array}$ & $\begin{array}{l}\text { Responsabilizar-se } \\
\text { pelo redesenho e pelo } \\
\text { gerenciamento dos } \\
\text { processos } \\
\text { centrais não- }\end{array}$ & $\begin{array}{llr}\text { - Colaborar } & \text { para } \\
\text { transformar } & \text { o } \\
\text { negócio } & \end{array}$ \\
\hline$\overline{\text { Abo }}$ & \begin{tabular}{|l} 
- \\
Serviços \\
padronizados \\
- Taxa de serviço \\
baseado r em \\
transações \\
- \\
Escala e escopo de \\
serviços reduzidos
\end{tabular} & 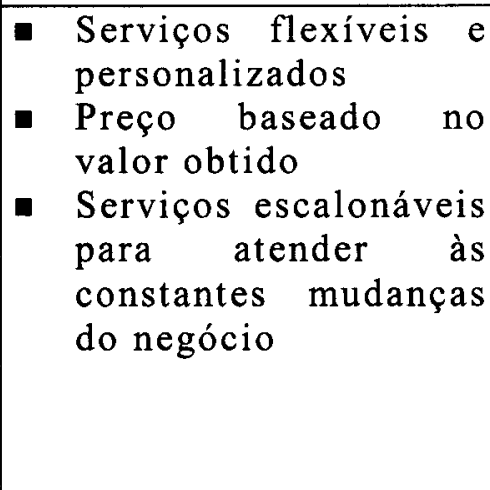 & $\begin{array}{l}\text { - } \text { Serviços integrados } \\
\text { para mudar o } \\
\text { negócio } \\
\text { radicalmente } \\
\text { - Estrutura financeira } \\
\text { baseada em } \\
\text { resultados; } \\
\text { compartilhamento } \\
\text { de riscos } \\
\text { Prestação de serviço } \\
\text { acelerada }\end{array}$ \\
\hline $\begin{array}{l}\text { Be } \\
\text { típ }\end{array}$ & 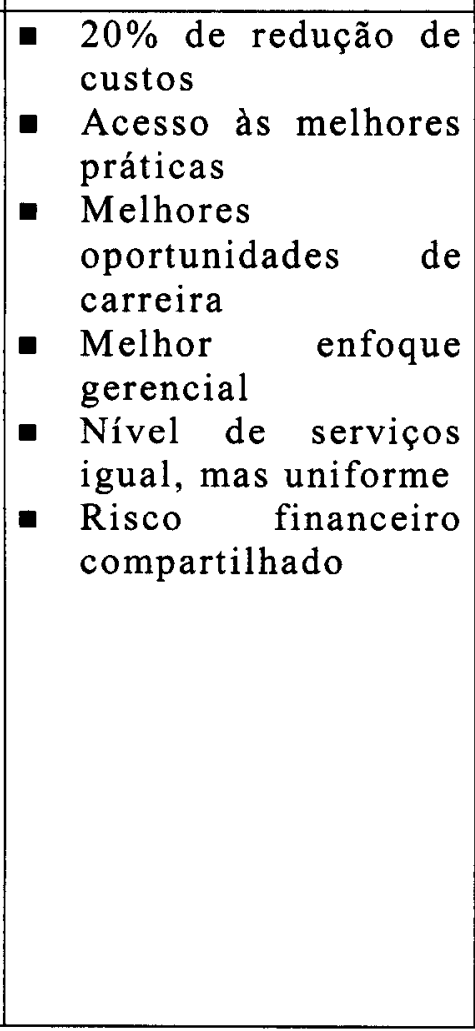 & 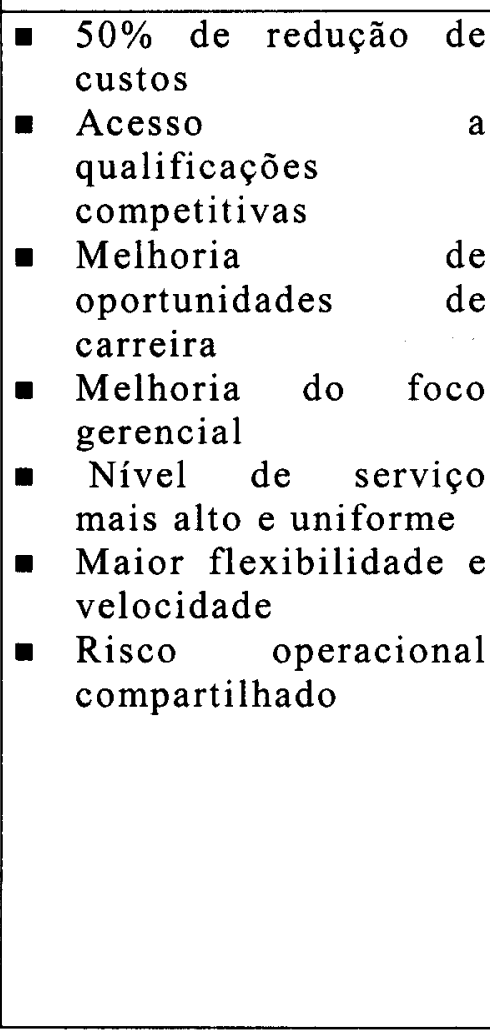 & $\begin{array}{l}\text { - } \begin{array}{l}50 \% \text { de redução de } \\
\text { custos } \\
\text { Acesso } \\
\text { qualificações } \\
\text { críticas } \\
\text { Melhores } \\
\text { oportunidades de } \\
\text { carreira } \\
\text { - Melhor enfoque } \\
\text { gerencial } \\
\text { Nivel de serviço } \\
\text { superior e uniforme } \\
\text { - Maior flexibilidade } \\
\text { e velocidade } \\
\text { - Risco estratégico } \\
\text { compartilhado } \\
\text { - } 50 \% \text { de aumento de } \\
\text { participação } \\
\text { mercado no } \\
\text { - } \begin{array}{l}\text { Duplicação } \\
\text { receita de }\end{array} \\
\text { Mudança na base de } \\
\text { concorrência }\end{array} \\
\end{array}$ \\
\hline
\end{tabular}

Fonte: HSM Management 42 janeiro-fevereiro 2004 


\section{4 -Formas de Contratação Médica}

Dados obtidos em 1999 a partir da Pesquisa Nacional de Amostragem por Domicílios-(PNAD) do IBGE, além Rais-Caged', demonstrou que as principais formas de inserção no mercado de trabalho paulista são assalariadas com carteiras assinadas (CLT), públicos estatutários e empregados sem carteiras assinadas (Quadro 2).

Quadro 2- Distribuição dos médicos segundo vínculo, por gênero.

São Paulo -1999

\begin{tabular}{|l|c|c|}
\hline \multicolumn{1}{|c|}{ Posição na Ocupação } & Homens & Mulheres \\
\hline Empregado com carteira assinada & $29,7 \%$ & $40,4 \%$ \\
\hline Funcionário público estatutário & $17,2 \%$ & $21,0 \%$ \\
\hline Empregado sem carteira assinada & $10,9 \%$ & $15,8 \%$ \\
\hline Autônomo (trabalha por conta própria) & $23,4 \%$ & $17,5 \%$ \\
\hline Empregador & $15,6 \%$ & $3,5 \%$ \\
\hline
\end{tabular}

Fonte: IBGE. Pesquisa Nacional por Amostra de Domicílios, 1999.

\footnotetext{
${ }^{1}$ Rais: Criada pelo decreto 76.900/75, do Ministério do Trabalho e Emprego, a Relação Anual de Informações Sociais permite a obtenção de informações anuais referentes ao estoque e à movimentação de mão-de-obra forma da economia (empregados CLT, estatutários e outros vínculos regulamentados).

Caged: Cadastro Geral de Empregados e Desempregados, criado pelo Governo Federal por meio da Lei 4.923/65, que instituiu o registro permanente de admissões e dispensa de empregados sob o regime da CLT.
} 
O número de médicos empregados nos setores público e privado era equilibrado, mas as instituições estaduais tinham um peso maior em São Paulo (Quadro 3).

Quadro 3- Inserção dos Médicos nos setores público e privado. São Paulo -1999

\begin{tabular}{|l|c|}
\hline \multicolumn{1}{|c|}{ Setor } & $\%$ \\
\hline Privado & 48,1 \\
\hline Público & 51,9 \\
\hline Distribuição entre os públicos & $\%$ \\
\hline Público Federal & 7,1 \\
\hline Público Estadual & 52,4 \\
\hline Público Municipal & 40,85 \\
\hline
\end{tabular}

Fonte: IBGE. Pesquisa Nacional por Amostra de Domicilios, 1999.

O Estado de São Paulo apresentou entre o início de 1999 até o final de 2000 , um crescimento importante no mercado formal do trabalho médico, segundo a pesquisa Formas Institucionais da Terceirização dos Serviços em Hospitais da Região Sudeste do Brasil, do Nescon, além do sistema Rais-Caged.

A pesquisa Niveis de Oferta e Modalidades de Contratação para Especialidades Médicas, outras profissões de Saúde e Serviços de Apoio Diagnóstico e Terapêutico na Rede Hospitalar do Estado de São Paulo-(Nescon 2001), foram levantadas as informações relativas a 360 hospitais em todas as regiões de abrangência das 27 delegacias 
regionais do Cremesp, demonstrou que a maioria das contratações de médicos se dá na condição de autônomos. Mais de $60 \%$ dos hospitais paulistas contratavam dessa forma, cirurgiões, anestesistas, cardiologistas, obstetras, clínicos gerais, pediatras e ortopedistas.

Nesse item serão apresentadas as formas de contratação médica usadas no estudo para melhor entendimento: médicos próprios, contratados através da Consolidação das Leis do Trabalho(CLT), e médicos cooperados e contratados por empresas médicas.

\subsection{1-Médicos Próprios}

Esses profissionais seguem as mesmas etapas de contratação de outros funcionários conforme a política de recursos humanos de cada hospital e é também seguido o Acordo em Dissídio Coletivo firmado entre os sindicatos dos Médicos de São Paulo e a Federação das Santas Casas de Misericórdia e Hospitais Filantrópicos do Estado de São Paulo .

Seguem as principais determinações que os hospitais devem seguir quando possuem médicos próprios.

\section{- Reajuste salarial}

\section{- Piso Salarial}

\section{- Garantias na admissão}


O médico admitido em substituição a outro, dispensado sem justa causa, terá o direito ao mesmo salário pago ao do médico de menor salário na função, sem considerar vantagens pessoais, não será admitido o contrato de experiência, quando da readmissão para a mesma função.

\section{- Plantão a Distância}

O médico que permanecer à disposição do empregador, cumprindo jornada de plantonista à distância, receberá para cada hora o equivalente $1 / 3$ (um terço) do valor da sua hora normal de trabalho.

\section{- Ausências Justificadas}

Além das hipóteses legais, os médicos poderão faltar ao serviço e terão suas ausências abonadas até 3 (três) dias consecutivos em caso de falecimento do cônjuge, ascendentes, descendente, irmão ou a pessoa que, declarada em sua Carteira Profissional de Trabalho e Previdência Social, viva sob sua dependência econômica e por 5(cinco) dias consecutivos em virtude de casamento.

\section{- Horas Extras}

Concessão de $100 \%$ (cem por cento) de sobretaxa para as horas extraordinárias prestadas pelo trabalhador.

Fica facultada aos empregadores a utilização do sistema do banco de horas, através do qual o excesso de horas trabalhadas 
em um dia poderá ser compensado pela correspondente diminuição em outro dia, de maneira que não exceda, no período máximo de um ano, a referida compensação. $O$ empregador poderá optar pela compensação no período destinado à concessão de férias, adicionando aos dias de férias, os correspondentes à compensação prevista nesta cláusula.

$\mathrm{Na}$ hipótese de rescisão de contrato de trabalho, ou após o decurso do prazo supra estabelecido, sem que tenha havido a compensação integral da jornada extraordinária, o trabalhador fará jus ao pagamento das horas extras não compensadas, calculadas sobre o valor da remuneração na data da rescisão ou do efetivo pagamento.

\section{- Adicional Noturno}

O adicional incidente sobre as horas noturnas trabalhadas, assim consideradas as compreendidas entre as 22 horas de um dia e às 5 horas do dia seguinte, será $40 \%$ (quarenta por cento), sobre o valor da hora normal.

\section{- Estabilidade do Acidentado}

Os médicos vitimados por acidente do trabalho ou moléstia profissional gozarão de estabilidade no emprego, nos termos da legislação previdenciária em vigor. 


\section{- Estabilidade da gestante}

Fica garantida a estabilidade provisória à empregada gestante desde o início da gravidez até 60 (sessenta) dias após o término da licença compulsória.

\section{- Estabilidade às vésperas da aposentadoria}

Fica assegurada aos médicos que estiverem a um máximo de 24 (vinte e quatro) meses da aquisição do direito à aposentadoria, especial ou não e que contém com um mínimo de três anos de trabalho na mesma empresa, a garantia de emprego ou salário.

Aos médicos que estiverem a um máximo de 36(trinta e seis) meses da aquisição do direito à aposentadoria, especial ou não, e que contém com, um mínimo de 5(cinco) anos de trabalho na mesma empresa, ficam igualmente garantidos o emprego ou salário.

Os médicos se obrigam a notificar o empregador por escrito de que possuem tais condições, no ato da aquisição do direito à aposentadoria.

Adquirido o direito à aposentadoria, especial ou não, cessa o direito à estabilidade. 
- Preservação da Saúde do Médico

Os empregadores garantirão a vacinação contra a hepatite "B" aos médicos que assim solicitarem, mediante avaliação do médico do trabalho.

\section{- Assistência Hospitalar}

Os hospitais, dentro de sua especialidade, concederão a todo empregado, assistência hospitalar, com direito a internação em enfermaria, ressalvada as entidades que mantenham convênio hospitalar para seus empregados, sendo possível à participação dos trabalhadores no custeio da assistência médica.

\section{- Auxílio Alimentação e Cesta Básica}

Lanche Noturno: fornecimento gratuito de lanche aos médicos que laboram em jornada noturna.

Cesta Básica: Os empregadores concederão, mensalmente, uma cesta básica de alimentos, com a mesma composição da fornecida à categoria preponderante e, nos mesmos prazos fixados pela mesma.

\section{- Auxílio-Creche}

Os empregadores que não possuírem creches próprias ou convênio equivalente pagarão o auxílio creche aos médicos, conforme o valor e forma definidos pela categoria preponderante. 


\section{- Aviso prévio}

Será concedido, além do prazo legal, aviso prévio de 1(um) dia por ano de serviço prestado ao empregador. Para os médicos com mais de 45(quarenta e cinco) anos de idade e mais de 1 (um) ano de emprego, será concedido aviso prévio de 45 (quarenta e cinco) dias.

Os primeiros 30 (trinta) dias do aviso prévio serão trabalhados, se assim desejar o empregador. Os dias excedentes a 30(trinta) dias serão sempre indenizados.

Para efeito de cálculo das verbas rescisórias, será computado o reflexo do aviso prévio somente em relação aos primeiros $30($ trinta) dias.

\section{- Participação em Congressos}

Serão concedidos aos médicos 5(cinco) dias úteis por ano, consecutivos ou não, sem prejuízo dos salários, para reciclagem e atualização profissional, participação em congressos, simpósios, seminários ou outros eventos ligados a atividade científica, desde que previamente acordado com a direção da empresa e comprovação posterior.

\section{- Comissões Científicas}

Fica assegurada a continuidade das Comissões Científicas de médicos, desde que sem ônus para o empregador. 


\subsection{2 -Cooperativa Médica}

\section{Conceito de Cooperativas Médicas}

Segundo Blanco (1983), "entre os precursores do cooperativismo médico encontra-se James Peter Warbasse, graduado em 1882 pela Universidade de Columbia. Ele difundiu os princípios cooperativistas publicando seus trabalhos no "American Journal of Surgery" e "New York State Journal of Medicine" e cativou para o movimento cooperativista Eleonor Roosevelt com dois artigos: "Democracia Cooperativista" e "Paz Cooperativa".

Em 1934 um grupo de cirurgiões de Bilbao (Espanha) formou uma sociedade capaz de oferecer as famílias de recursos limitados uma cobertura às hospitalizações por doenças cirúrgicas; buscavam a proteção do exercício profissional liberal, defendiam a livre escolha e o pagamento do trabalho médico sem qualquer intermediação.

Também na Espanha, em Barcelona, a Sociedade Cooperativa Lavinia conta com 14.815 médicos associados participando de uma cooperativa "compradora" de serviços médicos.

Por iniciativa do Dr. Edmundo Castilho, foi criada a primeira cooperativa médica brasileira, em Santos no dia 12 de novembro de 1965. Chamou-se UNIMED (União dos Médicos) e teve sua ata de fundação inscrita no INCRA em 28 de agosto de 1968. Estava regulamentada, com muita luta e sacrifício, em plena época da ditadura militar, uma cooperativa de trabalho com forte base ética, 
preocupada com o usuário e sem o objetivo do lucro (UNIMED do Brasil, 1992, v.1). A Assembléia geral realizou-se em 18 de dezembro de 1967, data habitualmente consignada como de sua fundação.

\section{A Origem das Cooperativas Médicas}

O decreto-1ei 66, de 22 de novembro de 1966, associou os Institutos de Aposentadoria e Pensões, criando o INPS - Instituto Nacional de Previdência Social, atualmente INSS-Instituto Nacional de Seguridade Social, estabeleceu que todos os previdenciários urbanos, a partir daí, teriam direito a uma assistência médicohospitalar integral.

Como o INPS não tinha recursos próprios capazes de absorver a demanda da massa de usuários procurou resolver o problema por meio do chamado convênio empresa, através do qual as empresas retinham $10 \%$ do salário mínimo por empregado e por dependente, responsabilizando-se pela assistência médico-hospitalar de seus funcionários e dependentes, desobrigando a Previdência dessa incumbência.

As organizações acrescentavam algum dinheiro aos $10 \%$ retidos e terceirizavam a assistência médico-hospitalar aos chamados grupos mercantilistas, que empregavam mão-de-obra mais acessível como: doutorandos, residentes e médicos, para o atendimento em ambulatórios, por uma remuneração aviltante e sem nenhuma garantia 
trabalhista. Os serviços eram prestados não pela necessidade dos doentes, mas no limite que não comprometesse o lucro.

Com nascimento das UNIMEDs, abriram-se as portas dos consultórios médicos particulares para uma grande parcela da população, a um custo acessível e com livre escolha do médico cooperado da preferência do cliente.

Igualmente, as Cooperativas nasceram como um imperativo ético, partindo do princípio que não necessita haver intermediário na relação médico-paciente e que esta relação é um vínculo único, exclusivo, que não permite interferências de qualquer espécie.

A primeira Cooperativa Médica fundada no país foi a UNIMED de Santos, São Paulo, no dia 18/12/1967. Nos primeiros três anos de cooperativismo médico, foram fundadas 90 Cooperativas Médicas no Brasil, incentivadas e apoiadas pelo idealizador do sistema, Dr.Edmundo Castilho, que na época da implantação da nova alternativa de assistência médica, era Presidente do Sindicato Médico de Santos - SP.

\subsection{3-Empresas Médicas}

"As sociedades médicas são definidas como sociedades civis de caráter econômico, sem a prática de atos de comércio, uma vez que não se pode desvirtuar o fim para o qual a medicina existe- a prestação de serviço em prol do ser humano e da coletividade, 
observando os artigos $9^{\circ}, 98^{\circ}$ e $99^{\circ}$ do Código de Ética Médica".(CREMESP 2003).

Podem ser classificadas como sociedades simples - aquelas que são formadas por profissionais liberais que visam, exclusivamente, a prestação de serviço médico ou sociedades empresariais - aquelas onde os médicos podem formar sociedade empresária quando a sua maior contribuição for, não a prestação de serviços médicos, mas a organização de empresa.

As sociedades simples são inscritas no cartório de Registro Civil das Pessoas Jurídicas de sua jurisdição no prazo de 30 dias da data de sua constituição, já as sociedades empresárias devem ser inscritas na junta Comercial de sua jurisdição, de acordo com o artigo 1.150 do novo Código Civil.

Para efetuar registro da empresa no Conselho Regional de Medicina de sua jurisdição, o médico responsável técnico deverá solicitar o registro em requerimento próprio.

A retirada e/ou exclusão dos sócios da sociedade deve ser comunicada ao Conselho Regional no prazo de 30 dias, a contar da data de sua ocorrência, sob pena de instauração de procedimento disciplinar envolvendo o médico responsável técnico.

O novo Código Civil prevê a dissolução total e a resolução da sociedade em relação a um sócio - antes denominada dissolução parcial, também pode ser dissolvida extrajudicial ou judicialmente - 
nesta hipótese deve-se recorrer ao Poder Judiciário para que o juiz determine a dissolução em sentença. A dissolução parcial da sociedade pode ocorrer por acordo entre os sócios, por morte de sócio, retirada de sócio e exclusão de sócio.

\section{5 - A Responsabilidade Civil Médica}

\section{Conceito de Erro Médico}

O Erro médico é o mau resultado ou resultado adverso decorrente de ação ou da omissão do médico. O erro médico pode se verificar por três vias principais.

A primeira delas é o caminho da imperícia decorrente da "falta de observação das normas técnicas", "por despreparo prático" ou "insuficiência de conhecimento" como aponta o autor Veloso (2001). É mais freqüente na iniciativa privada por motivação mercantilista.

A segunda é o caminho é o da imprudência e daí nasce o erro quando o médico por ação ou omissão assume procedimentos de risco para o paciente sem respaldo científico ou, sobretudo, sem esclarecimentos à parte interessada.

A terceira é o caminho é o da negligência, quando o profissional negligencia, trata com descaso ou pouco interesse os deveres e compromissos éticos com o paciente e até com a instituição. O erro médico pode também se realizar por vias escusas quando decorre do 
resultado adverso da ação médica, do conjunto de ações coletivas de planejamento para prevenção ou combate às doenças.

Cabe ao médico lidar com o bem mais precioso para a espécie humana: a vida, com as múltiplas funções de órgãos vitais, com a honra do ser humano e seus valores mais caros e íntimos e ainda com o patrimônio afetivo das pessoas, incluídos seus entes mais queridos. Isso somente bastaria para conceder à medicina um incômodo privilégio entre as ciências humanas e criar sobre ela uma extraordinária expectativa, sem lhe oferecer, por outro lado, recursos operacionais adequados. Tudo the é cobrado.

O dano decorrente do erro médico é quase sempre de caráter irreparável, significa tudo ou nada para quem o sofre. Nada ou quase nada para a espécie humana, mas tudo ou quase tudo para o próprio indivíduo. Isto torna o erro médico grave, sempre grave; o erro médico como reverso da expectativa de quem busca reparar parte ou função do próprio organismo, ou seja, é a antítese da cura pretendida.

\section{Classificação do Erro Médico}

A Justiça brasileira considera a natureza do contrato entre médico e paciente como um contrato de meios e não de fins, onde o primeiro se obriga a tratar e não a curar o segundo, utilizando todo seu conhecimento técnico-científico para sua recuperação. Para tal, o 
médico precisa se esmerar ao máximo e, obrigatoriamente, ter uma atualização constante.

Erro médico é a falha do médico no exercício da profissão, é o mau resultado ou resultado adverso decorrente da ação ou omissão, por inobservância de conduta técnica, desde que o profissional esteja no pleno exercício de suas faculdades mentais. Excluem-se as limitações impostas pela própria natureza da doença, bem como as lesões produzidas deliberadamente pelo médico para tratar um mal maior.

Observa-se que todos os casos de erro médico julgados nos Conselhos de medicina ou na Justiça, em que o médico foi condenado, o foi por erro culposo.

O erro médico pode ocorrer por:

- Imperícia: decorrente da falta de observação das normas técnicas, por despreparo prático ou por insuficiência de conhecimentos. Considerar um médico imperito é discutível, tratando-se de um profissional longamente treinado nas escolas médicas e nos programas de residência médica, com no mínimo 8 até um máximo de 11 anos de estudos e prática. É uma premissa que, não sendo aceita, torna-se um agravante;

- Imprudência: quando o médico assume riscos para o paciente sem respaldo científico para seu procedimento. 
- Negligência: quando o médico trata o paciente com descaso ou pouco interesse.

- Falha Técnica: esta depende da competência e da dedicação do médico mas também da resposta do paciente que pode falhar, agravada por doença ou situação desconhecida.

- Erro doloso: é aquele cometido voluntariamente, sendo inadmissível que um médico o venha a cometer. Trata-se, pois, de um crime.

- Erro diagnóstico: o diagnóstico para ser exato deve ser genérico, pois são desconhecidas as causas de $25 \%$ a $30 \%$ das doenças conhecidas.

- Erro de conduta: o médico não pode errar a conduta. Esta deve ser ajustada a cada momento, seguindo a evolução clínica (diagnóstica ou terapêutica) e de acordo com as respostas a cada momento. Tudo deve ser corrigido passo a passo, em tempo real, para que o desvio seja o menor possivel e o retorno ao caminho certo seja mais fácil, rápido e com as menores seqüelas.

- Erro deliberado: é aquele realizado para tratar mal maior.

- Erro profissional: a Justiça assim considera aquele decorrente de falha não imputável ao médico, e que depende das naturais limitações da medicina que não possibilitam sempre e com certeza o estabelecimento de um diagnóstico exato. A omissão 
de dados e informações pelo paciente também contribuem para este tipo de erro médico.

- Erro técnico: refere-se a erro do médico procedente de falhas estruturais, quando os meios (falta de equipamentos) ou as condições de trabalho na instituição por ocasião do atendimento médico são insuficientes ou ineficazes para uma resposta satisfatória. São comuns as falhas dos esfigmomanômetros, das autoclaves, dos aparelhos de raios-X, dos aparelhos de anestesia, dos aparelhos para ventilação mecânica, das ambulâncias, nas condições que podem propiciar infecção hospitalar, etc.

\section{Conceito e Origem da Responsabilidade Civil Médica}

Existem no Brasil apenas estimativas sobre haver aumento do número de processos contra conduta médica, com índices eventualmente publicados na imprensa leiga, já que a especializada médica ou jurídica, apenas aborda aspectos técnicos em seus respectivos campos de atuação.

O erro médico é um dos mais palpitantes e polêmicos assuntos em todas as camadas sociais, sendo freqüentemente tratado de forma sensacionalista pelos meios de comunicação de massa que se arvoram em polícia, promotor, juiz e carcereiro, condenando antes de julgar e causando danos irreparáveis não só ao médico acusado, mas também à 
instituição e aos pacientes, que em geral perdem a confiança e a credibilidade em ambos, médico e hospital.

"O fundamento da responsabilidade civil está na alteração do equilibrio social produzida por um prejuizo causado a um dos seus membros. O dano sofrido por um indivíduo preocupa todo o grupo porque, egoisticamente, todos se sentem ameaçados pela possibilidade de, mais cedo ou mais tarde, sofrerem os mesmos danos, menores, iguais e até maiores" Alcântara (1971).

A primeira vista, responder alguém por danos que tenha causado sem culpa parece uma grave injustiça. Também não seria menor injustiça deixar a vítima sujeita a sua própria sorte, arcando sozinha com seus prejuízos. A solidariedade é o maior sentimento de justiça. Reparar todo e qualquer dano seria o ideal da própria solidariedade humana.

Morin, citado por (Lima, 1963) assegura: "Se a noção de responsabilidade materializou-se no sentido de não procurar o elemento moral subjetivo, não desprezou, entretanto, os princípios de uma elevada moral social, dentro de um sistema solidarista que não enxerga individuos justapostos e isolados, mas um organismo de humanidade no qual todos os membros são solidários". Esse é o princípio da responsabilidade sem culpa.

Indenizar o dano produzido sem culpa é mais uma garantia que propriamente uma responsabilidade. E não se pense que os "reparados" 
pelo dano tirem vantagem disso. Os danos são sempre maiores que a reparação.

A responsabilidade civil do médico sempre provocou varias controvérsias, não apenas pela sua inclusão ora no campo contratual, ora no campo extracontratual; mas, principalmente, pela maneira mais circunstancial em que a profissão é exercida. A tendência é colocá-la na forma contratual, até mesmo no atendimento gratuito.

É claro que o médico, ao exercer suas atividades junto ao paciente, sua intenção é beneficiá-lo. Mesmo assim o dano pode surgir. Isso o obriga, pela teoria objetiva da responsabilidade, a reparar o prejuízo, pois uma vontade honesta e a mais cuidadosa das atenções não eximem o direito de outrem. O certo é que os tribunais até a algum tempo somente caracterizavam a responsabilidade médica diante de um erro grosseiro ou de uma forma indiscutível de negligência. Hoje a tendência é outra: apenas a inexistência de nexo de causalidade, de força maior, de atos de terceiros ou de culpa do próprio paciente isentariam o médico da responsabilidade.

Não e fácil estabelecer a responsabilidade penal do médico, sua responsabilidade civil começa a sofrer profundas modificações. Seus aspectos se voltam exclusivamente para o caráter político-econômico, tendo como princípio mais aceito o da repartição dos danos, caracterizado por uma exigência econômica em decorrência da qual qualquer dano deve ser repartido entre os envolvidos. O que se pretende na responsabilidade civil - quase ilimitada - é tão-somente 
assegurar o equilíbrio social, quando um prejuízo produzido poderia causar dano a um dos membros do grupo.

Beviláqua (1929) afirmava: "O Direito Penal vê, por trás do crime, o criminoso e o considera um ente anti-social, ao passo que o Direito Civil vê, por trás do ato ilicito, não simplesmente o agente, mas principalmente a vitima, e vem em socorro dela, a fim de, tanto quanto lhe for permitido, restaurar seu direito violado, constituindo a eurritmia social refletida no equilibrio dos patrimônios e das relações pessoais, que se formam no circulo do direito privado".

A responsabilidade civil do médico (C.C., artigo 1.545), na qualidade de profissional liberal, consoante o que dispõe o art. 14, parágrafo $4^{\circ}$, do CPDC, será apurada mediante verificação da culpa. Isto é, será avaliada de acordo com o maior ou menor grau de previsibilidade de dano. Ainda: o médico, nas relações de consumo com seus clientes, não está obrigado a um resultado, pois entre eles existe um contrato de meios e não de fins. Seu compromisso é utilizar todos os meios e esgotar as diligências ordinariamente exercidas. Em suma: usar de prudência e diligenciar normalmente a prestação do serviço. Haverá inadimplência se a atividade for exercida de forma irregular, atípica ou imprudente, e se na prestação do serviço venha ocorrer um acidente de consumo, o médico terá sua responsabilidade civil apurada dentro dos limites da má prática. Discute-se tal conceito, no que se refere aos contratos de meios ou de resultados, na 
anestesiologia, na cirurgia plástica, na radiologia e na patologia clínica.

Quando se tratar de assistência médica prestada pelo hospital, como fornecedor de serviços, a apuração da responsabilidade independe da existência de culpa (princípio da responsabilidade sem culpa). Basta o nexo causal e o dano sofrido. O fornecedor de serviços responde, independentemente da existência da culpa, pela reparação do dano causado aos consumidores por defeitos relativos à prestação dos serviços, bem como por informações insuficientes ou inadequadas sobre a fruição e riscos (artigo 14, caput, do CPDC). A não ser que exista culpa exclusiva do consumidor ou de terceiros não prepostos, representantes ou empregados do fornecedor ou prestador de serviços. Nesse particular, só há culpa in eligendo ou in vigilando.

O terceiro de que trata a presente lei é aquele sem qualquer relação jurídica com o fornecedor. No que diz respeito aos médicos que tenham vínculo empregatício com pessoas jurídicas de direito público ou privado, a exemplo das clínicas e hospitais, a reparação civil por dano culposo será argüida dos respectivos estabelecimentos de saúde (C.C, artigo 1.521 , III), combinado com os artigos. $3^{\circ}$ e 14 do CPCD. Ainda assim, terão as empresas médicas direito de regresso, conforme estabelecem as Súmulas 187 e 188 do STF. Sobre o assunto, reporta-se Benjamin (1991:80): "O Código é claro ao asseverar que só para a responsabilidade pessoal dos profissionais liberais é que se utiliza o sistema alicerçado em culpa. Logo, se o médico trabalha em 
hospital, responderá apenas por culpa, enquanto a responsabilidade do hospital será apreciada objetivamente".

Assim, não existe atualmente no mundo profissão mais regulamentada que a Medicina. Seu exercício é um dos mais perigosos sob o ponto de vista legal. No campo médico, onde os mais variados fatores influem direta ou indiretamente, é lógico esperar a ocorrência de erros, não só da parte do médico, mas também de todo o sistema de saúde. Isso abrange desde a falta de materiais básicos para tratamento de urgência até o modo de planejamento sanitário.

Segundo Beviláqua (1929) a responsabilidade dos profissionais "funda-se na culpa, e a disposição tem por fim afastar a escusa, que poderiam pretender invocar, de ser o dano um acidente no exercício da sua profissão; o direito exige que esses profissionais exerçam sua arte segundo os preceitos que ela estabelece, e com as cautelas e precauções necessárias ao resguardo da vida e da saúde dos clientes e dos fregueses, bens inestimáveis, que se lhes confiam, no pressuposto de que os zelem; e esse dever de possuir sua arte e aplicá-la, honesta e cuidadosamente, é tão imperioso que a Lei, repressiva, lhe pune as infrações".

A responsabilidade civil do médico, na qualidade de profissional liberal, em face do disposto no Art. 14, parágrafo $4^{\circ}$, do Código de Defesa do Consumidor, será apurada mediante verificação de culpa, regra, aliás, aplicável a todos os demais profissionais liberais, cujo 
elenco está relacionado no anexo do Art. 577 da Consolidação das Leis Trabalhistas.

A competência profissional do médico caracteriza-se pela aptidão em realizar os atos com conhecimento, segurança e êxito. A cada dia o médico e eterno estudante defronta-se com situações novas, as quais deve superar, valendo-se das experiências adquiridas desde então. 


\section{6 -Indicadores}

Segundo Burmester et al., Indicadores são representações, quantitativas ou não, de resultados, ocorrências ou eventos de um sistema. Constitui um instrumento gerencial de mensuração, sem o qual é impossível a avaliação criteriosa de qualidade ou produtividade (Burmester et al apud Bittar, 1996).

Para avaliação em saúde, devem ser estabelecidos modelos adequados, como o modelo proposto por Donabedian e Fleming apud Bittar (2001) para avaliação da estrutura, processo e resultado dos serviços ou sistema de saúde.

- A estrutura é definida como a parte física de uma instituição, os seus funcionários, instrumentais, equipamentos, móveis, aspectos relativos à organização, entre outros;

- Processos são as atividades de cuidados realizados para um paciente, freqüentemente ligados a um resultado, assim como atividades ligadas à infra-estrutura para prover meios para as atividades-fins atingirem suas metas e;

- Resultados são demonstrações dos efeitos conseqüentes da combinação de fatores do meio ambiente, estrutura e processos, acontecidos ou não ao paciente, ou efeitos de operações técnicas e administrativas de uma instituição. 
Para Tanaka \& Melo(2001), o indicador é comumente representado como uma variável numérica, podendo ser um número absoluto ou uma relação entre dois eventos ou uma qualidade do evento. 


\section{2-JUSTIFICATIVA}

A Faculdade de Saúde Pública - USP (FSP) através de um convênio realizado com a Secretaria de Saúde do Estado de São Paulo (SES) avaliou as Organizações Sociais de Saúde através de relatórios de produção, resultados financeiros, morbidade hospitalar, gerenciamento de medicamentos, análise da demanda e gestão de pacientes. Durante o desenvolvimento desse trabalho a equipe responsável pelas informações e relatórios deparou-se com um aspecto novo, o da terceirização total do corpo clínico no Hospital Pedreira e alguns serviços médicos, clínicos e cirúrgicos no Hospital Itapecerica. Sendo assim, foi efetuado um estudo mais aprofundado dessa nova modalidade com o apoio das gerências SES e FSP, onde os resultados, vantagens e desvantagens foram levantados e comparados(Ibañez \& Bittar 2001).

Após a análise e discussão das variáveis, os resultados de qualidade e quantidade na produção de serviços não diferem de maneira significativa com relação ao tipo de contratação; não fícou evidente a possibilidade da terceirização do corpo clínico favorecer distorções quanto a vocação pública dos hospitais; a terceirização do Hospital Itapecerica revela um alto gasto c/ o corpo clínico, mas é no Hospital Pedreira que o gasto é maior, devido ao maior número de médicos e estes são melhor remunerados; nos hospitais Pedreira e 
Itapecerica, os critérios estabelecidos p/ admissão de médicos são de maior complexidade e exigência dos que os realizados nos hospitais de regime próprio; não há uniformidade nos assuntos técnicos e administrativos discutidos pelos corpos clínicos das diferentes OSS/SUS; a avaliação dos profissionais médicos nos hospitais é informal e seria importante os próximos contratos de gestão apresentarem cláusulas relativas à análise e acompanhamento dos contratos de terceirização, que contemplem especificações quanto às modalidades de pagamento, cobertura, abrangência, produção, produtividade e principalmente qualidade dos programas e serviços (Ibañez \& Bittar 2001).

Partindo desse princípio, surgiu o interesse em estudar os resultados das formas jurídicas de contratação médica em dois hospitais caracterizados como organizações sociais de saúde. Um hospital com o corpo clínico inteiramente contratado através de CLTConsolidação das Leis do Trabalho e o outro composto de corpo clínico terceirizado em todas as suas especialidades. 


\section{OBJETIVOS}

\section{I-Geral}

Verificar os resultados dos indicadores de estrutura, produção/ produtividade, qualidade, recursos humanos e financeiros. Assim como a relação hora médica-produção-gasto e a percepção dos diretores clínicos e administrativos das diferentes formas jurídicas de contratação dos serviços médicos de duas Organizações Sociais de Saúde. 


\section{4- MÉTODOS}

Este estudo inicia-se com a revisão bibliográfica da literatura sobre assuntos referentes ao objeto da dissertação.

Após a revisão da literatura, são apresentados os indicadores utilizados na coleta de dados.

Passada a fase da coleta de dados, os indicadores dos dois hospitais foram analisados por tipo de serviço: Unidade de internação, pronto socorro e ambulatório.

Esse trabalho é caracterizado como estudo de caso, por permitir maior proximidade na avaliação.

Após a análise dos dados e de posse dos resultados de sua tabulação, foi realizada a discussão dos mesmos, chegando à conclusão e respondendo aos objetivos propostos.

\section{1-Estudo de Caso}

Segundo YIN apud Ferreira (2000), "o estudo de caso é uma forma de se fazer pesquisa empírica, investigando um fenômeno contemporâneo dentro do contexto real; em situações em que as fronteiras entre $o$ fenômeno e o contexto não estão claramente estabelecidas; onde se utilizam múltiplas fontes de evidências".

Os métodos de estudo de caso estão sendo redescobertos nas pesquisas sobre serviços de saúde. A necessidade do uso desta 
metodologia deve-se ao desenvolvimento de sistemas abrangentes e de alta complexidade, em conseqüência de contínuas e rápidas mudanças. As relações entre as instituições e suas motivações também são de difícil compreensão. Nessas situações, o estudo de caso permite maior proximidade para a avaliação desses sistemas. Vários são os tópicos abordados por meio de estudo de caso, dentre os quais destacam-se as inovações médicas e organizacionais (YIN apud Ferreira 2000).

São oito as características desejáveis dos estudos de caso em pesquisas de serviços de saúde propostas por (YIN apud Ferreira 2000):

1- O uso de uma definição orientada por desenho dos estudos de casos - o foco é um fenômeno único no seu contexto real. O método não é afetado pelas inúmeras variáveis do contexto externo, podendo ser usado mesmo quando os limites entre o fenômeno e seu contexto não são claros. Sua flexibilidade permite o uso em situações de incertezas, podendo o caso e o contexto mudarem ao longo do tempo;

2- Generalizações dos estudos de caso: replicações baseadas em teoria - a dificuldade em generalizar a partir de estudos de caso é considerada a maior falha deste método. O foco no desenho permite minimizar este fato. O caso deve então, ser considerado uma unidade para experimento. Desta forma, a dificuldade para generalizar é a mesma da enfrentada em experimentos, onde a hipótese e as teorias são os meios para a generalização. Utilizar 
critérios de amostragem para selecionar e agregar estudos de casos individuais não é adequado. Considerando o estudo de caso uma sub investigação, a generalização pode ser feita por meio da lógica de replicação, utilizando-se assim de hipóteses ou teorias sobre os casos;

3- Identificação da unidade de análise: qual é o caso - o passo mais desafiador é a definição do caso. As proposições teóricas preliminares formuladas no desenho do estudo fornecem importante guia para a definição do caso. Exemplo: o caso é o sistema de saúde num determinado momento ou depois de sua reorganização?

O caso é a comunidade ou o local? Quais as diferenças?

4- Operacionalizando o estudo de caso - bons estudos de casos deveriam conter um formato operacional, mesmo que se enquadrem no modelo exploratório, de modo a definir as prioridades a serem exploradas;

5- Mantendo a descoberta e flexibilidade - ao longo do estudo de caso pode haver necessidade de alterações do processo. Para manter a flexibilidade e a possibilidade de descobertas evitandose produzir uma pesquisa com viés, é preciso rever todo o desenho do estudo quando de uma possível alteração, garantindo assim que, caso a formatação inicial esteja inadequada, o estudo deverá ser reformulado; 
6- O uso de explicações contraditórias como estratégia de desenho - um dilema freqüente para o investigador diante de desenhos experimentais ou quase experimentais é quando o número de casos é pequeno. O estado da arte vigente ignora este problema incluindo a análise de três casos. Uma abordagem alternativa é utilizar casos considerados concorrentes e distintos, isto é, "rivais" como parte do desenho do estudo;

7- Coletando evidências de fontes múltiplas - o estudo de caso pode envolver uma variedade de técnicas, como a condução de visitas, análise da literatura, pesquisa documental e observações de campo. Utilizando-se dessas várias fontes, o objetivo da coleta será reunir as evidências e realizar a triangulação a respeito de um determinado fato.

8- Distinguindo evidência de interpretação: a base de dados de um estudo de caso - uma característica desejável dos estudos de caso é apresentar evidências separadamente das interpretações do investigador a respeito das mesmas. Esta não é tarefa fácil, mas poderá ser feita por meio de base de dados, ou seja, que reúna os dados levantados por meio das diferentes técnicas de coleta de dados. 


\section{2-O processo de Pesquisa de Campo}

Caracterização e critério de escolha das Organizações Sociais de Saúde

Os dois hospitais qualificados como organizações sociais de saúde apresentam similaridades no tipo de atendimento oferecido à população, mas possuem formas jurídicas distintas na contratação da prestação de serviços médicos.

\section{Caracterização do Hospital Geral de Pedreira-Organização Social} de Saúde

O Hospital Geral de Pedreira iniciou suas atividades em junho de 1998, após assinatura do contrato entre Secretaria Estadual de Saúde e a Associação Congregação de Santa Catarina, entidade filantrópica que administra hospitais, creches, escolas, programas de saúde da família, centro de referência do idoso em São Paulo, Rio de Janeiro, Espírito Santo e Mato Grosso.

O hospital faz parte da micro região 4 que conta com uma área de aproximadamente $43,4 \mathrm{~km} 2$. Composta por três distritos administrativos: Campo Grande, Cidade Ademar e Pedreira. O estudo do perfil da demanda do serviço de Pronto Socorro do Hospital Geral de Pedreira de junho/2000(sub-projeto-Análise do perfil de demanda) 
mostrou que $79,2 \%$ dos atendimentos do pronto socorro eram procedentes da micro região 4 .

O Hospital Pedreira é classificado como secundário, contando com 226 leitos de internação,10 consultórios no pronto socorro e 19 consultórios no ambulatório de especialidades.

Os prestadores de atendimento médico foram contratados sob regime de cooperativa e empresas médicas.

\section{Caracterização do Hospital Geral Itaim Paulista - Organização Social de Saúde}

Em 1998 o Governo do Estado de São Paulo propôs parceria com as Irmãs da Congregação Santa Marcelina a administração de um hospital no Itaim Paulista. Assim, em 26 de junho deste mesmo ano, foi assinado o contrato de gestão entre as partes.

O Hospital Itaim Paulista está localizado na Zona Leste do município, e pertence a Administração Regional de Saúde 6, composta por três distritos administrativos: Jardim Helena, Vila Curuçá e Itaim Paulista.

O Hospital Itaim Paulista é classificado como secundário, contando com 257 leitos de internação, 10 consultórios no pronto socorro e 15 consultórios no ambulatório de especialidades.

Os prestadores de atendimento médico foram contratados sob o regime de CLT-Consolidação Leis do Trabalho, ou seja, são funcionários próprios. 


\section{3-Período do Estudo}

A coleta foi realizada no segundo semestre de 2004 e os dados referem-se ao período de janeiro a dezembro de 2003. A análise e elaboração da dissertação foram feitas em 2005.

\section{4-Coleta de Dados}

Para a obtenção dos dados propostos no estudo, foram realizados contatos com os gestores da Secretaria da Saúde do Estado de São Paulo, obtendo autorização para coleta das informações pertinentes.

Diante da anuência, foi efetuado contato com os diretores administrativos e clínicos dos dois hospitais para apresentação do estudo.

Foram desenvolvidos formulários que contemplassem informações sobre indicadores quantitativos relacionados à estrutura, produção/produtividade, qualidade, recursos humanos e financeiros; bem como dimensionamento dos profissionais médicos, carga horária médica trabalhada e gastos.

\section{Indicadores Quantitativos}

\section{Primeira Parte}

\section{- Indicadores de Estrutura:}


- Número de Leitos:

Indica o número de leitos disponíveis nos hospitais.

- Número de consultórios do Pronto Socorro:

Indica o número de salas disponíveis para a realização de consultas.

- Número de consultórios do Ambulatório:

Indica o número de salas disponíveis para a realização de consultas.

\section{- Indicadores de Produção/Produtividade}

- Número de Consultas do Pronto Socorro

Indica a quantidade de consultas realizadas no período estudado

- Número de Consultas Ambulatoriais

Indica a quantidade de consultas realizadas no período estudado.

- Número de Internações

É o número de pacientes que são admitidos para ocupar um leito hospitalar por um período igual ou superior a 24 horas.

- Número de Saídas

É o número de pacientes que saem da unidade de internação por alta, evasão, transferência externa ou óbito.

- Número de Paciente/dia

Unidade de medida que representa a assistência prestada a um paciente internado durante um dia hospitalar.

- Percentual de Ocupação Operacional 
Relação percentual entre o número de paciente dia e o número de leitos dia em determinado período.

- Média de Permanência

Relação entre o total de pacientes dia e o total de pacientes que tiveram saída do hospital em determinado período. Representa o tempo médio em dias que os pacientes ficaram internados no hospital.

\section{- Indicadores de Qualidade}

- Taxa de Infeção Hospitalar

É a relação percentual entre o número de infecções adquiridas pelo paciente durante sua permanência no hospital em determinado período e o número de pacientes saídos no mesmo periodo.

\section{- Taxa de Cesárea}

É a relação percentual entre o número de cesáreas ocorridas durante determinado período, no hospital, e o número de partos no mesmo período.

- Avaliação dos usuários sobre o corpo clínico

É a avaliação da percepção de qualidade de serviço pelos pacientes ou acompanhantes. Configurando uma importante ferramenta de gestão. 


\section{- Indicadores de Recursos Humanos}

- Número de Funcionários por Leito

Demonstra a relação entre o número total de funcionários da organização e o número de leitos operacionais.

\section{- Número total de Funcionários}

Demonstra o número de funcionários incluindo os médicos.

- Número de Médicos

Demonstra o número de médicos que prestam serviço ao hospital.

- Índice de Rotatividade

Baseado no indicador tradicional de pessoal: Turn Over.

- Índice de Absenteísmo

É o cômputo percentual das faltas e licenças médicas realizado mensalmente pelo hospital.

\section{- Indicadores Financeiros}

- Gasto total do hospital

Valor gasto pelo hospital com pessoal, materiais, medicamentos, gêneros alimentícios, contratos com terceiros e despesas gerais.

- Gasto com médicos

Valor gasto pelo hospital com a folha de pagamento dos médicos. 


\section{Segunda Parte}

Relação hora médica-produção-gasto

Detalhamento por serviço: Unidade de Internação, Pronto Socorro e Ambulatório.

Para elaboração dessa análise foram excluídas duas especialidades:

- UTI Infantil por só constar no Hospital Pedreira.

- Psiquiatria por só constar no Hospital Itaim Paulista.

As tabelas estão subdivididas da seguinte forma:

- Unidades de Internação

- Clínica Médica

- UTI Adulto.

- Clínica Cirúrgica

- Clínica Pediátrica

- Unidade Neonatal

- Clínica de Ginecologia e Obstetrícia

- Pronto Socorro

- Clínica Médica

- Clínica Cirúrgica

- Clínica Pediátrica

- Clínica de Ginecologia e Obstetrícia

- Ambulatório

- Todas as especialidades médicas 


\section{- Ortopedia}

- Terá uma análise diferenciada em função da limitação na coleta dos dados, pois o Hospital Pedreira não possuía o valor gasto por serviço.

\section{Unidades de Internação}

Para acompanhamento das tabelas seguem algumas informações para melhor entendimento:

- Número de Médicos Diaristas: Total de profissionais médicos que prestaram serviço aos pacientes internados nas unidades de internação e pronto socorro durante o mês.

- Manhã e Tarde: número de médicos que deram plantão por dia e por período.

- Horas Médicas Trabalhadas: total de horas trabalhadas .

- Pacientes Saídos: Número de pacientes que saem da unidade de internação por alta, evasão, transferência externa ou óbito.

- Valor Gasto Total:

- Cooperativa: Valor gasto total do hospital com a folha de pagamento dos médicos mais taxa administrativa de $3 \%$.

- Corpo Clínico Próprio: Total gasto pelo hospital com a folha de pagamento dos médicos incluindo encargos sociais, férias e décimo terceiro salário.

- Valor gasto/número de horas trabalhadas: Valor total gasto dividido pelo número de horas trabalhadas. 


\section{Pronto Socorro}

Usando o mesmo critério das unidades de internação seguem algumas informações para melhor entendimento das tabelas:

- Número de Médicos Plantonistas: todos os profissionais médicos que prestaram serviço ao pacientes que passaram em consulta no pronto socorro durante o mês.

- Dia e Noite: número de médicos que deram plantão por dia e por período.

- Horas Médicas Trabalhadas: Total de horas trabalhadas.

- Número de Consultas: número de consultas médicas atendidas.

- Valor gasto Total:

- Cooperativa: Total gasto pelo hospital com a folha de pagamento dos médicos mais taxa administrativa de $3 \%$.

- Corpo Clínico Próprio: Total gasto pelo hospital com a folha de pagamento dos médicos mais encargos sociais, férias e décimo terceiro salário.

- Valor gasto/número de horas trabalhadas: O valor gasto total dividido pelo número de horas trabalhadas.

- Número de consultas/ número de horas médicas trabalhadas: Número de consultas dividido pelo número de horas trabalhadas. 


\section{Ambulatório}

Usando o mesmo critério das unidades de internação seguem algumas informações para melhor entendimento das tabelas:

Número de Médicos: Total de profissionais médicos que prestaram serviço aos pacientes que passam em consulta no ambulatório durante o mês.

- Horas Médicas Trabalhadas: Total de horas trabalhadas.

- Número de Consultas: Total de consultas médicas atendidas no ambulatório.

- Valor gasto Total:

- Cooperativa: Total gasto pelo hospital com a folha de pagamento dos médicos mais taxa administrativa de $3 \%$.

- Corpo Clínico Próprio: Total gasto pelo hospital com a folha de pagamento dos médicos mais encargos sociais, férias e décimo terceiro salário.

- Valor gasto/número de horas trabalhadas: Valor gasto dividido pelo número de horas trabalhadas.

- Número de consultas/ número de horas médica trabalhadas: Número de consultas dividido pelo número de horas trabalhadas. 


\section{Indicadores Qualitativos}

\section{Instrumento de Coleta}

Foram elaborados questionários dirigidos às diretorias administrativas e clinicas dos dois hospitais(anexo1). Esses questionários foram apresentados aos diretores em visitas previamente agendadas.

O questionário direcionado à diretoria administrativa teve como objetivo esclarecer os motivos que levaram cada hospital a escolher a forma jurídica de contratação médica, a forma como a administração trabalha com os médicos, as metas estabelecidas no contrato de gestão, como é realizada a gestão do corpo clínico, como é elaborada a folha de pagamento dos médicos e se há dificuldade de se recrutar esse profissional no mercado. Já o questionário direcionado à diretoria clínica, abordou os dados sobre recrutamento, seleção e integração dos médicos no hospital, relação hierárquica, reuniões para discussão e revisão de dados clínicos, bem como assuntos técnicos e administrativos, existência de protocolos clínicos, participação de comissões, existência de avaliação de desempenho e em caso afirmativo, como eles se integram aos programas de qualidade, além da opinião sobre as vantagens e desvantagens do vínculo optado pelo hospital. 


\section{5- RESULTADOS e DISCUSSÃO}

Os dados estão subdivididos de acordo com o tipo de forma jurídica de contratação médica, ou seja, hospital com corpo clínico constituído por cooperativa médica e empresas médicas - Hospital Geral de Pedreira e corpo clínico próprio - Hospital Geral de Itaim Paulista.

$\mathrm{Na}$ primeira parte serão apresentados os indicadores de estrutura, produção/produtividade por serviço: Unidades de Internação, Pronto Socorro e Ambulatório e indicadores de qualidade, recursos humanos e financeiros.

$\mathrm{Na}$ segunda parte serão apresentados os dados referentes ao dimensionamento do corpo clínico de cada hospital nos serviços de internação, pronto socorro e ambulatório. 


\section{PRIMEIRA PARTE}

\section{1-Unidades de Internação}

\section{Indicador de Estrutura}

\subsection{1-Número de Leitos Operacionais}

O Hospital Geral de Pedreira conta com 226 leitos. As clínicas médica, cirúrgica e pediátrica contam com 11,2 e 3 leitos extras respectivamente, para atender pacientes que permanecem no pronto socorro por mais de 24 horas, gerando internação hospitalar que as enfermarias não conseguem absorver.

O Hospital Itaim Paulista conta com 257 leitos e assim como o Hospital Pedreira também interna pacientes no pronto socorro.

Todos os dados referentes à Unidade de Internação contabilizam os pacientes internados no pronto socorro para efeito de estatística.

Tabela 1- Número de leitos operacionais de jan a dez de 2003.

\begin{tabular}{lcrc} 
& Hospital Pedreira & \multicolumn{2}{c}{ Itaim Paulista } \\
\hline Especialidades & \multicolumn{1}{c}{ Leitos } & \multicolumn{2}{c}{ Leitos } \\
\hline Clínica Médica & 51 & 52 \\
Clínica Cirúrgica & 40 & 41 \\
Clínica Pediátrica & 33 & 36 \\
Clínica GO & 44 & 54 \\
Clínica Ortopédica & 12 & 16 \\
UTI Adulto & 13 & 10 \\
Unidade Neonatal & 28 & 24 \\
UTI Infantil & 5 & 0 \\
Psiquiatria & 0 & 24 \\
\hline Total & $\mathbf{2 2 6}$ & $\mathbf{2 5 7}$
\end{tabular}

Fonte: SPP

As diferenças constatadas entre os dois hospitais se devem ao fato de haver a especialidade de psiquiatria no Hospital Itaim Paulista (24 leitos) e UTI Infantil (5 leitos) no Hospital Pedreira, conforme tabela 1 . 


\section{Indicadores de Produção}

\subsection{2-Internações}

Aqui, estão sendo demonstrados os dados referentes aos pacientes que foram admitidos para ocupar um leito hospitalar por um período superior a 24 horas, gerando AlH-Autorização de Internação Hospitalar e, portanto não estão sendo consideradas as transferências internas de uma unidade de internação para outra.

Tabela 2- Número de Internações realizadas de jan a dez de 2003.

Hospital Pedreira Hospital Itaim Paulista

\begin{tabular}{lcr}
\hline Especialidades & Internações & \multicolumn{2}{c}{ Internações } \\
\hline Clínica Médica & 2.782 & 2.817 \\
Clínica Cirúrgica & 2.175 & 2.694 \\
Clínica Pediátrica & 1.508 & 1.961 \\
Clínica GO & 4.015 & 6.124 \\
Clínica Ortopédica & 1.099 & 777 \\
UTI Adulto & 237 & 35 \\
Unidade Neonatal & 527 & 492 \\
UTI Infantil & 38 & - \\
Psiquiatria & - & 425 \\
\hline Total & $\mathbf{1 2 . 3 8 1}$ & $\mathbf{1 5 . 3 2 5}$ \\
\hline
\end{tabular}

Fonte: SPP

A tabela 2 mostra que o Hospital Itaim Paulista internou mais pacientes do que o Hospital Pedreira, porém, o perfil de demanda das clínicas é igual. A especialidade que mais interna é a clínica obstétrica e entre as clínicas, a maior diferença se deu na UTI adulto. O Hospital Itaim Paulista esclareceu que dificilmente um paciente é internado diretamente nessa unidade e há exceções para pacientes que vêm de outro hospital com vaga cedida. 


\subsection{3-Saidas Hospitalares}

Analisando-se as saídas por especialidade no período de jan a dez de 2003, observa-se a expressiva participação da clínica obstétrica. Sendo que no Hospital Itaim Paulista o percentual foi de $40 \%$ e no Hospital Pedreira 31\%do total de pacientes.

Tabela 3- Número de Saídas realizadas de jan a dez de 2003.

\begin{tabular}{|c|c|c|}
\hline & Hospital Pedreira & Hospital Itaim Paulista \\
\hline Especialidades & Saídas & Saídas \\
\hline Clínica Médica & 2.834 & 2.724 \\
\hline Clínica Cinúrgica & 2.201 & 2.545 \\
\hline Clínica Pediátrica & 1.500 & 1.910 \\
\hline Clínica GO & 4.091 & 6.126 \\
\hline Clínica Ortopédica & 1.119 & 816 \\
\hline UTI Adulto & 477 & 283 \\
\hline Unidade Neonatal & 663 & 505 \\
\hline UTI Infantil & 130 & - \\
\hline Psiquiatria & - & 400 \\
\hline Total & 13.015 & 15.309 \\
\hline
\end{tabular}

Fonte: SPP

O total anual de saídas hospitalares realizadas pelo Hospital Pedreira foi de 13,015 e atende a meta estipulada pela Secretaria de Saúde do Estado de São Paulo que foi de 13.008, conforme descrito no contrato de gestão para o ano de 2003.

O total anual de saídas hospitalares realizadas pelo Hospital Itaim Paulista foi de 15.309. Ficou abaixo da meta estipulada pela Secretaria de Saúde do Estado de São Paulo que foi de 15.684, mas dentro dos $15 \%$ previsto no contrato de gestão para o ano de 2003 .

A tabela 3 mostra que o perfil de demanda das especialidades é igual nos dois hospitais. 


\subsection{4-Pacientes/Dia}

Essa unidade de medida é muito importante para a gestão, pois ela é a base para cálculos da porcentagem de ocupação, média de permanência e custo das unidades de serviço. $O$ número de pacientes/dia é obtido através do censo hospitalar, que deve ser realizado todos os dias no mesmo horário.

Tabela 4- Número de Pacientes/ Dia de jan a dez de 2003.

Hospital Pedreira Hospital Itaim Paulista

\begin{tabular}{lcr}
\hline Especialidades & Pacientes Dia & Pacientes Dia \\
\hline Clínica Médica & 17.548 & 19.853 \\
Clínica Cirurgica & 10.520 & 13.351 \\
Clínica Pediátrica & 9.711 & 9.109 \\
Clínica GO & 12.987 & 16.809 \\
Clínica Ortopédica & 2.571 & 5.931 \\
UTI Adulto & 4.447 & 3.525 \\
Unidade Neonatal & 7.150 & 8.018 \\
UTI Infantil & 1.409 & - \\
Psiquiatria & - & 6.212 \\
\hline Total & $\mathbf{6 6 . 3 4 3}$ & $\mathbf{8 2 . 8 0 8}$ \\
\hline
\end{tabular}

Fonte: SPP

A clínica obstétrica teve desempenho superior nos indicadores de internação e saídas hospitalares, já no indicador de pacientes/dia, a clínica médica foi a que apresentou o maior desempenho, seguida pelas clínicas obstétrica, cirúrgica, pediátrica e unidade neonatal em ambos hospitais. O perfil de demanda foi diferente na ortopedia e na UTI Adulto.

A psiquiatria que só é encontrada no Hospital Itaim Paulista influenciou bastante no resultado que foi $20 \%$ superior ao apresentado pelo Hospital Pedreira, conforme está demonstrando a tabela 4. 


\subsection{5-Porcentagem de Ocupação Operacional (média mensal)}

Esse tipo de porcentagem de ocupação foi escolhido por representar a relação percentual entre o número de pacientes dia e o número de leitos dia em um determinado período levando em consideração os leitos extras. Se estes não fossem considerados, a porcentagem de ocupação estaria acima de $100 \%$, pois, tanto o Hospital Pedreira quanto o Hospital Itaim Paulista interna nas clínicas médica, pediátrica e cirúrgica mais pacientes do que o número de leitos operacionais comportam. Todavia, essas clínicas não apresentam $100 \%$ de ocupação, conforme tabela 5 , porque alguns leitos ficam desativados em caso de isolamento, já que cada enfermaria é composta de 2 ou 4 leitos.

Tabela 5- Porcentagem de Ocupação de jan a dez de 2003. Hospital Pedreira Hospital Itaim Paulista

\begin{tabular}{lrr}
\hline Especialidades & \% de Ocupação & \% de Ocupação \\
\hline Clínica Médica & 94,25 & 98,90 \\
Clínica Cirúrgica & 72,10 & 89,00 \\
Clínica Pediátrica & 80,50 & 69,12 \\
Clínica GO & 80,94 & 85,00 \\
Clínica Ortopédica & 58,75 & 100,00 \\
UTI Adulto & 93,77 & 97,00 \\
Unidade Neonatal & 66,57 & 92,00 \\
UTI Infantil & $\mathbf{7 7 , 2 3}$ & - \\
Psquiatria & - & 71,00 \\
Média & $\mathbf{7 9 , 7 4}$ & $\mathbf{8 7 , 7 5}$ \\
\hline
\end{tabular}

Fonte: SPP

O Hospital Itaim Paulista apresentou a porcentagem de ocupação superior ao apresentado pelo Hospital Pedreira, o perfil de demanda das clínicas difere de um hospital para o outro, como demonstra a tabela 5 . 


\subsection{6-Média de Permanência}

O Hospital Itaim Paulista apresentou na maioria das clínicas média de permanência superior a observada no Hospital Pedreira. Somente as clínicas pediátrica e ginecológica apresentaram médias inferiores. Pode-se notar também que a psiquiatria, com média de permanência de 15,53 dias influenciou bastante na média geral, conforme tabela 6 .

Tabela 6 -Média de Permanência de jan a dez de 2003.

\begin{tabular}{lcc} 
Clínica Médica & 6,26 & 7,00 \\
Clínica Cirúrgica & 4,87 & 5,00 \\
Clínica Pediátrica & 6,55 & 5,00 \\
Clínica GO & 3,23 & 3,00 \\
Ortopedia & 2,31 & 7,00 \\
UTI Adulto & 5,99 & 13,00 \\
Unidade Neonatal & 10,67 & 17,00 \\
UTI Infantil & 5,59 & - \\
Média (sub-total) & $\mathbf{5 , 6 8}$ & $\mathbf{8 , 1 4}$ \\
Psiquiatria & - & 15,53 \\
\hline Média & $\mathbf{5 , 6 8}$ & $\mathbf{9 , 0 7}$ \\
\hline
\end{tabular}

Fonte: SPP

A média de permanência geral do Hospital Pedreira no ano de 2003 foi de 5,68, variando de 2,31 dias na ortopedia e 10,67 na unidade neonatal.

O Hospital Itaim Paulista apresentou média de permanência geral de 9,67, variando de 3,0 dias na ginecologia e obstetricia e 17,00 na unidade neonatal.

Em seguida, será apresentado o perfil de morbidade das unidades de internação, com o objetivo de demonstrar os diagnósticos de saídas mais freqüentes nos dois hospitais e justificar as diferenças encontradas na média de permanência. 


\subsubsection{Perfil de Morbidade nas Unidades de Internação dos}

Hospitais Pedreira e Itaim Paulista relacionada à média de permanência

Para a análise do perfil de morbidade hospitalar foram solicitados aos setores de faturamento dos hospitais Pedreira e Itaim Paulista os diagnósticos mais freqüentes constatados nos prontuários faturados por clínicas básicas no período de jan a dez de 2003.

Tabela 7 -Diagnósticos de saídas mais freqüentes de jan a dez de 2003.

Clínica Médica e UTI Adulto

\begin{tabular}{ll}
\hline \multicolumn{1}{c}{ Hospital Pedreira } & \multicolumn{1}{c}{ Diagnósticos mais frequentes nos dois hospitais Itaim Paulista } \\
\hline Acidente Vascular Cerebral & Acidente Vascular Cerebral \\
não especificados como & não especeficados como \\
hemorrágico ou isquêmico & hemorrágico ou isquêmico \\
Diabetes Mellitus & Diabetes Mellitus \\
Hipertensão Arterial & Hipertensão Arterial \\
Insuficiência cardíaca & Insuficiência cardíaca \\
Outràs anemias & Outras anemias \\
Outros transtornos do trato urinário & Outros transtornos do trato urinário \\
Pneumonia por microorganismos & Pneumonia por microorganismos \\
não especificadas & não especificadas \\
\hline
\end{tabular}

Diagnósticos mais frequentes apenas em um dos hospitais

Angina Pectoris

Diarréia e gastroenterite de origem Caquexia

Hepatite viral crônica

infecciosa presumivel

Doença alcoólica do figado Infarto agudo do miocardio

Hepatite viral não especificada Insuficiência renal crônica

Meningite viral Insuficiência respiratória

Nefrite Tubulo- Intersticial Aguda

Neoplasia

Outras arritmias cardíacas

Fonte: Faturamento

Pelo exposto na tabela 7, pode-se deduzir que o Hospital Itaim Paulista apresentou média de permanência maior, possivelmente, pela diferença e maior gravidade das patologias. 
Em relação aos diagnósticos mais freqüentes na clínica cirúrgica, conforme tabela 8 , pode-se observar que a maioria das patologias é semelhante, assim como sua gravidade. Isso justifica a média de permanência bem parecida entre os hospitais.

Tabela 8 -Diagnósticos de saídas mais freqüentes de jan a dez de 2003.

\section{Clínica Cirúrgica}

\begin{tabular}{ll}
\hline \multicolumn{1}{c}{ Hospital Pedreira } & \multicolumn{1}{c}{ Hospital Itaim Paulista } \\
\hline \multicolumn{1}{c}{ Diagnósticos mais frequentes nos dois hospitais } \\
\hline Apendicite aguda & Apendicite aguda \\
Coleletiase & Coleletiase \\
Colicistite & Colicistite \\
Erisipela & Erisipela \\
Hérnia inguinal & Hérnia inguinal \\
Outras hérnias abdominais & Outras hérnias abdominais \\
Pancreatite aguda & Pancreatite aguda \\
Peritonite & Peritonite \\
\hline \multicolumn{1}{c}{ Diagnósticos mais frequentes apenas em um dos hospitais } \\
\hline Trombose venosa profunda & Flebite e tromboflebite \\
Hemorragia digestiva alta & Neoplasia \\
Hemorróida & Ferimento envolvendo muitas \\
Traumatismo craneo encefálico & regiões do corpo \\
\hline
\end{tabular}

Fonte: Faturamento

$\mathrm{Na}$ ortopedia, os diagnósticos de maior freqüência apresentam similaridades na gravidade e, possivelmente, a conduta médica pode ter interferido na média de permanência.

Tabela 9 -Diagnósticos de saídas mais freqüentes de jan a dez de 2003.

Ortopedia

\begin{tabular}{ll}
\hline \multicolumn{1}{c}{ Hospital Pedreira } & \multicolumn{1}{c}{ Hospital Itaim Paulista } \\
\hline \multicolumn{2}{c}{ Diagnósticos mais frequentes nos dois hospitais } \\
\hline Artroplastia de quadril & Ferimento de quadril e coxa \\
Fratura de úmero & Fratura de antebraço \\
Fratura de ossos do braço & Fratura de ombro e do braço \\
Fratura de fêmur & Fratura de perna \\
\hline Fon
\end{tabular}

Fonte: Faturamento 
A clínica pediátrica assim como a clínica cirúrgica apresentou patologias semelhantes e como o mesmo perfil de gravidade, justificando a média de permanência bem parecida entre os hospitais.

Tabela 10 -Diagnósticos de saídas mais freqüentes de jan a dez de 2003. Clínica Pediátrica

\begin{tabular}{|c|c|}
\hline Hospital Pedreira & Hospital Itaim Paulista \\
\hline \multicolumn{2}{|c|}{ Diagnósticos mais frequentes nos dois hospitais } \\
\hline Pneumonia & Pneumonia \\
\hline Infecção urinária & Infecção urinária \\
\hline Dor abdominal & Dor abdominal \\
\hline Crise asmática & Crise asmática \\
\hline \multicolumn{2}{|c|}{ Diagnósticos mais frequentes apenas em um dos hospitais } \\
\hline Desidratação & $\begin{array}{l}\text { Dor pélvica } \\
\text { Apendicite aguda }\end{array}$ \\
\hline
\end{tabular}

Fonte: Faturamento

Na unidade neonatal, o Hospital Itaim Paulista apresentou média de permanência maior do que a do Hospital Pedreira, possivelmente, porque $60 \%$ dos partos foram de gestantes de alto risco, $18 \%$ dos nascimentos foram de recém nascidos prematuros e desse percentual $51 \%$ nasceram abaixo de 2.500 gramas. As patologias são iguais nos dois hospitais.

Tabela 11 -Diagnósticos de saídas mais freqüentes de jan a dez de 2003.

Unidade Neonatal

\begin{tabular}{ll}
\hline \multicolumn{1}{c}{ Hospital Pedreira } & \multicolumn{1}{c}{ Hospital Itaim Paulista } \\
\hline \multicolumn{1}{c}{ Diagnósticos mais frequentes nos dois hospitais } \\
\hline Desconforto respiratório & Desconforto respiratório \\
Icterícia neonatal & Icterícia neonatal \\
Infecção neonatal & Infecção neonatal \\
Prematuridade & Prematuridade \\
\hline
\end{tabular}

Fonte: Faturamento 
Em relação aos diagnósticos mais freqüentes na ginecologia e obstetrícia, pode-se observar que as patologias são semelhantes, assim como a gravidade. Isso justifica a média de permanência bem parecida entre um hospital e outro, conforme tabela 12 .

Tabela 12 -Diagnósticos de saídas mais freqüentes de jan a dez de 2003.

Ginecologia e Obstetrícia

Hospital Pedreira

Hospital Itaim Paulista

Diagnósticos mais frequentes nos dois hospitais

Aborto não especificado

Aborto não especificado

Infecção Puerperal

Infecção Puerperal

Parto único espontâneo

Parto único espontâneo

Parto único por cesareana

Parto único por cesareana

Diagnósticos mais frequentes apenas em um dos hospitais

Parto múltiplo

Parto pré termo

Fonte: Faturamento 


\section{2-Pronto Socorro}

O pronto socorro do Hospital Pedreira conta com 10 consultórios médicos e atendeu uma média mensal de 22.898 consultas/mês, número inferior ao contratado pela Secretaria de Saúde do Estado de São Paulo que foi de $23.000 /$ mês, mas dentro dos $15 \%$ aceitável em contrato.

O pronto socorro do Hospital Itaim Paulista conta com 10 consultórios e atendeu uma média mensal de 24.412 consultas/mês, número superior ao contratado pela Secretaria de Saúde do Estado de São Paulo que foi de $23.416 /$ mês.

Tabela 13- Número de Consultas de jan a dez de 2003.

Hospital Pedreira

\begin{tabular}{lrlr}
\hline Especialidades & Consultas & Especialidades & Consultas \\
\hline Clínica Médica & 106.183 & Clínica Médica & 113.102 \\
Clínica Cirúrgica & 25.578 & Clínica Cirúrgica & 21.428 \\
Clínica Pediátrica & 70.621 & Clínica Pediátrica & 82.178 \\
Clínica GO & 31.143 & Clínica GO & 34.138 \\
Clínica Ortopédica & 41.246 & Clínica Ortopédica & 42.100 \\
\hline Total & $\mathbf{2 7 4 . 7 7 1}$ & Total & $\mathbf{2 9 2 . 9 4 6}$ \\
\hline
\end{tabular}

Fonte: SPP

Pelo exposto pode-se entender porque os dois hospitais tiveram que investir em infra-estrutura, para atender demandas tão intensas. Foram construídas recepções maiores para acomodar melhor os pacientes e acompanhantes.

As clínicas médica e pediátrica são as mais procuradas, seguidas pela ortopedia, ginecologia e cirúrgica nos dois hospitais, conforme descrito na tabela 7 . 


\subsubsection{Perfil de Morbidade no Pronto Socorro dos Hospitais}

\section{Pedreira e Itaim Paulista}

Para a análise do perfil de morbidade no pronto socorro foram solicitados aos Setores de Faturamento dos Hospitais Pedreira e Itaim Paulista os diagnósticos mais freqüentes constatados nas Fichas de Atendimento do pronto socorro faturadas por especialidades no período de jan a dez de 2003.

Tabela 14 -Diagnósticos de atendimentos mais freqüentes de jan a dez de 2003.

\section{Clínica Médica}

\begin{tabular}{ll}
\hline \multicolumn{1}{c}{ Hospital Pedreira } & \multicolumn{1}{c}{ Dospital Itaim Paulista } \\
\hline \multicolumn{1}{c}{ Diagnósticos mais frequentes nos dois hospitais } \\
\hline Acidente vascular cerebral & Acidente vascular cerebral \\
Amigdalite & Amigdalite \\
Cefáéia & Cefaléia \\
Diabetes Mellitus & Diabetes Mellitus \\
Diarréia e gastroenterite & Diarréia e gastroenterite \\
Dor abdominal e pélvica & Dor abdominal e pélvica \\
Dor torácica & Dor torácica \\
Epigastralgia & Epigastralgia \\
Infecção das vias aéreas superiores & Infeç̧ão das vias aéreas superiores \\
Infecção do trato urinário & Infeção do trato urinário \\
Hipertensão Arterial & Hipertensão arterial \\
Pneumonia & Pneumonia \\
\hline \multicolumn{1}{c}{$\quad$ Diagnósticos mais frequentes apenas em um dos hospitais } \\
\hline Alergia & Angina estável \\
Cólica nefrética & Calculose renal \\
Dispepsia & Derrame pleural \\
Gripe & Gastrite e duodenite \\
Sinusite & pielonefrite \\
\hline
\end{tabular}

Fonte: Faturamento

Como hospitais secundários, ambos atendem patologias de média gravidade na especialidade de clínica médica.

$\mathrm{Na}$ clínica cirúrgica chama atenção o grande número de atendimentos causados por acidente, características de hospitais "porta 
aberta" e na ortopedia a gravidade é considerada mediana nos dois hospitais, conforme demonstram as tabelas 15 e 16 .

Tabela 15 -Diagnósticos de atendimento mais freqüentes de jan a dez de 2003.

Clínica Cirúrgica

\begin{tabular}{lc}
\hline \multicolumn{1}{c}{ Hospital Pedreira } & Hospital Itaim Paulista \\
\hline \multicolumn{1}{c}{ Diagnósticos mais frequentes nos dois hospitais } \\
\hline Agcesso & Abcesso \\
A tropelamento & Agressão \\
Corpo estranho deglutido & Atropelamento \\
Ferimento na cabeça & Corpo estranho deglutido \\
Ferimento por arma de fogo & Ferimento na cabeça \\
Hemorróida & Ferimento por arma de fogo \\
Politrauma & Hemorróida \\
Traumatismo crâneo encefálico & Politrauma \\
\hline \multicolumn{2}{c}{ Diagnósticos mais frequentes apenas em um dos hospitais } \\
\hline Queda da própria altura & Traumatismo crâneo encefálico \\
Queda de escada & \\
Queda de laje & \\
\hline Fonte: Faturamento &
\end{tabular}

Tabela 16-Diagnósticos de atendimento mais freqüentes de jan a dez2003.

Ortopedia

\begin{tabular}{|c|c|}
\hline Hospital Pedreira & Hospital Itaim Paulista \\
\hline \multicolumn{2}{|c|}{ Diagnósticos mais frequentes nos dois hospitais } \\
\hline Artralgia & Artralgia \\
\hline Artrose & Artrose \\
\hline Contusão mão/punho & Contusão mão/punho \\
\hline Contusão ombro/braço & Contusão ombro/braço \\
\hline Contusão pé & Contusão pé \\
\hline Entorse de pé & Entorse de pé \\
\hline Entorse de tornozelo & Entorse de tornozelo \\
\hline Fratura antebraço & Fratura antebraço \\
\hline Fratura de perna & Fratura de perna \\
\hline Fratura dedo da mão & Fratura dedo da mão \\
\hline Lombalgia & Lomboalgia \\
\hline Lombociatalgia & Lombociatalgia \\
\hline Sinovite & Sinovite \\
\hline \multicolumn{2}{|c|}{ Diagnósticos mais frequentes apenas em um dos hospitais } \\
\hline Fratura de mão & Fratura da tíbia \\
\hline Mialgia & Fratura de mão \\
\hline Tendinite & Fratura do calcâneo \\
\hline
\end{tabular}

Fonte: Faturamento 
A clínica pediátrica apresenta a mesma semelhança de patologias e gravidade, conforme tabela 17.

Tabela 17 -Diagnósticos de atendimento mais freqüentes de jan a dez de 2003.

Clínica Pediátrica

\begin{tabular}{|c|c|}
\hline Hospital Pedreira & Hospital Itaim Paulista \\
\hline \multicolumn{2}{|c|}{ Diagnósticos mais frequentes nos dois hospitais } \\
\hline Amigdalite & Amigdalite \\
\hline Bronquite & Bronquite \\
\hline Crise asmática & Crise asmática \\
\hline Febre & Febre \\
\hline Infeç̧ão das vias aéreas superiores & Infecção das vias aéreas superiores \\
\hline Infecção do trato urinário & Infecção do trato urinário \\
\hline Pneumonia & Pneumonia \\
\hline Sinusite & Sinusite \\
\hline \multicolumn{2}{|c|}{ Diagnósticos mais frequentes apenas em um dos hospitais } \\
\hline Brocoespasmo & Broncopneumonia \\
\hline $\begin{array}{l}\text { Desidratação } \\
\text { Otite }\end{array}$ & Desconforto respiratório \\
\hline
\end{tabular}

A ginecologia e obstetrícia, assim como a pediatria, também apresentou a mesma semelhança de patologias e gravidade. Chamam atenção os diagnósticos de aborto incompleto e ameaça de aborto dentre outros, sugerindo deficiência na educação da população com relação ao uso de métodos contraceptivos.

Tabela 18 -Diagnósticos de atendimento mais freqüentes de jan a dez de 2003.

Ginecologia e Obstetricia

\begin{tabular}{lc}
\hline \multicolumn{1}{c}{ Hospital Pedreira } & \multicolumn{1}{c}{ Hospital Itaim Paulista } \\
\hline Aborto incompleto & Aborto incompleto \\
Ameaça de aborto & Ameaça de aborto \\
Falso trabalho de parto & Falso trabalho de parto \\
Gestação em curso & Gestação em curso \\
Gravidez não confirmada & Gravidez não confirmada \\
Infecção do trato urinário & Infecção do trato urinário \\
Sangramento Vaginal & Sangramento Vaginal \\
\hline
\end{tabular}




\section{3-Ambulatório}

Os ambulatórios dos Hospitais Pedreira e Itaim Paulista contam respectivamente com 19 e 15 consultórios e atendes as especialidades médicas conforme demonstra a tabela 19 .

Tabela 19 -Número de consultas ambulatoriais de jan a dez de 2003.

\begin{tabular}{lrr}
\hline \multicolumn{1}{c}{ Especialidades } & Hospital Pedreira & Hospital Itaim Paulista \\
\hline Cardiologia & 8.983 & 1.425 \\
Cirurgia & 6.674 & 12.304 \\
Dermatologia & 6.816 & - \\
Endocrinologia & 2.407 & - \\
Ginecologia & 5.463 & 4.767 \\
Gastroenterologia & 3.897 & 1.276 \\
Neurologia & 5.287 & 538 \\
Oftalmologia & 8.342 & - \\
Ortopedia & 8.937 & 5.577 \\
Otorrinolaringologia & 6.087 & - \\
Neonatologia & 879 & 1.357 \\
Hematologia & - & 203 \\
Anestesiologia & - & 342 \\
Mastologia & - & 254 \\
Psiquiatria & - & 1.290 \\
Total & $\mathbf{6 3 . 7 7 2}$ & $\mathbf{2 9 . 3 3 3}$ \\
\hline
\end{tabular}

Fonte: SPP

Pôde-se observar que o Hospital Pedreira apresentou quantidade de atendimento bem superior de atendimento em relação ao Hospital Itaim Paulista. 


\section{4- Indicadores de Qualidade}

\subsection{1- Taxa de Infecção Hospitalar}

A taxa de infecção hospitalar encontrada no Hospital Pedreira variou de $2,15 \%$ no mês de outubro a $3,30 \%$ no mês de dezembro, e a média mensal foi de $2,9 \%$.

A taxa de infecção hospitalar encontrada no Hospital Itaim Paulista variou de $2,2 \%$ no mês de fevereiro a $4,6 \%$ no mês de dezembro, e a média mensal foi de $3,1 \%$, conforme tabela 20 .

Tabela 20 - Taxa de Infeção Hospitalar de jan a dez de 2003.

\section{Hospital Pedreira Hospital Itaim Paulista}

\begin{tabular}{lcc}
\hline Taxa de Infeç̧̃̃o Hospitalar & $\%$ & $\%$ \\
\hline Média Mensal & 2,9 & 3,1 \\
\hline Fonte: SCIH &
\end{tabular}

\subsection{2-Taxa de Cesáreas}

A taxa de cesárea encontrada no Hospital Pedreira variou de $16,46 \%$ no mês de fevereiro a $23,39 \%$ no mês de outubro, e a média mensal foi de $19,20 \%$.

A taxa de cesárea encontrada no Hospital Itaim Paulista variou de $17,7 \%$ no mês de junho a $34,9 \%$ no mês de outubro, e a média mensal foi de $26,3 \%$, conforme tabela 21 .

Tabela 21- Taxa de Cesáreas de jan a dez de 2003.

Hospital Pedreira Hospital Itaim Paulista

Taxa de Cesáreas \% $\%$

$\begin{array}{lrr}\text { Média Mensal } & 19,20 & 26,3\end{array}$

Fonte: SPP 


\subsection{3- Avaliação dos usuários sobre o corpo clínico}

A tabela 22 apresenta os dados retirados da pesquisa de satisfação da Secretaria de Saúde do Estado de São Paulo. A pesquisa é realizada mensalmente e é respondida por pacientes internados ou acompanhantes.

Embora haja uma diferença de $26 \%$ entre o número de entrevistados, o Hospital Pedreira apresentou uma discreta vantagem na avaliação de satisfação dos usuários em relação ao Hospital Itaim Paulista.

Tabela 22- Avaliação dos usuários sobre o corpo clínico de jan a dez de 2003.

\section{Hospital Pedreira: 1725 entrevistados}

\begin{tabular}{lcccrr}
\hline Quesitos & Péssimo & Ruim & Regular & Bom & \multicolumn{2}{c}{ Excelente } \\
\hline Respeito e educação no tratamento ao paciente & $0 \%$ & $0 \%$ & $1 \%$ & $5 \%$ & $94 \%$ \\
Interesse do médico e qualidade do exame físico & $0 \%$ & $0 \%$ & $1 \%$ & $5 \%$ & $94 \%$ \\
Explicações fornecidas pelo médico & $0 \%$ & $0 \%$ & $1 \%$ & $5 \%$ & $94 \%$ \\
\hline
\end{tabular}

\section{Hospital Itaim Paulista: 2.347 entrevistados}

\begin{tabular}{|c|c|c|c|c|c|}
\hline Quesitos & Péssimo & Ruim & Regular & Bom & Excelente \\
\hline Respeito e educação no tratamento ao paciente & $0 \%$ & $0 \%$ & $2 \%$ & $8 \%$ & $90 \%$ \\
\hline Interesse do médico e qualidade do exame físico & $1 \%$ & $0 \%$ & $3 \%$ & $12 \%$ & $84 \%$ \\
\hline Explicações fornecidas pelo médico & $0 \%$ & $0 \%$ & $4 \%$ & $11 \%$ & $85 \%$ \\
\hline
\end{tabular}

Fonte: SAU 


\section{5- Indicadores de Recursos Humanos}

Para calcular o número de funcionários por leito do Hospital Pedreira, foi somado o total de funcionários próprios com o número de médicos terceirizados que trabalham no pronto socorro, unidades de internação e ambulatório e dividido pelo total de leitos operacionais. Os índices de rotatividade e absenteísmo não são acompanhados pelo hospital, por isso não puderam ser disponibilizados.

Para calcular o número de funcionários por leito do Hospital Itaim Paulista, foi usado o total de funcionários próprios dividido pelo total de leitos operacionais, não sendo considerados os funcionários terceirizados.

$O$ indice de rotatividade do corpo clínico foi de 18,26. E para os outros funcionários do hospital foi de 16,19.

O total de dias perdidos em função da apresentação de atestados médicos para todos os funcionários do Hospital Itaim Paulista foi de 5.666. Deste total o corpo clínico apresentou uma perda de 287 dias, gerando um índice de absenteísmo de 5,06\%.

Os indicadores de recursos humanos foram focados no corpo clínico, conforme tabela 23 .

Tabela 23 -Dados gerais sobre recursos humanos de jan a dez de 2003.

Hospital Pedreira Hospital Itaim Pauilista

\begin{tabular}{lcc}
\hline \multicolumn{1}{c}{ Recursos Humanos } & \\
\hline $\mathrm{N}^{\circ}$ de funcionários por Leito & $\mathbf{5 , 8}$ & $\mathbf{4 , 2}$ \\
$\mathrm{N}^{\circ}$ de Funcionários + Médicos- Média Mensal & $\mathbf{1 . 3 2 0}$ & $\mathbf{1 . 0 9 4}$ \\
$\mathrm{N}^{\circ}$ de Médicos- Média Mensal & $\mathbf{3 8 4}$ & $\mathbf{2 5 7}$ \\
Índice de Rotatividade dos médicos & $\mathrm{N} / \mathbf{D}$ & $\mathbf{1 8 , 2 6}$ \\
\hline Indice de Absenteísmo dos médicos & $\mathrm{N} / \mathrm{D}$ & $\mathbf{5 , 0 6}$ \\
\hline Fonte: DP & & \\
$\mathrm{N} / \mathrm{D}:$ Não disponível & &
\end{tabular}




\section{6-Indicadores Financeiros}

A tabela 24 demonstra o gasto total do hospital e o gasto com médicos nos Hospitais Pedreira e Itaim Paulista.

Tabela 24 -Dados gerais sobre gastos de jan a dez de 2003.

\begin{tabular}{lcc} 
& Hospital Pedreira & Hospital Itaim Paulista \\
\hline Recursos Financeiros & RS & RS \\
\hline Gasto Total do Hospital & $\mathbf{4 6 . 4 6 1 . 5 7 8 , 4 6}$ & $\mathbf{4 0 . 1 3 7 . 4 2 0 , 9 6}$ \\
Gasto com Médicos & $\mathbf{9 . 2 5 5 . 6 6 9 , 9 8}$ & $\mathbf{9 . 1 5 1 . 6 4 8 , 2 6}$ \\
\hline
\end{tabular}

Fonte: Financeiro

Nota-se que o Hospital Pedreira direcionou $20 \%$ do total do valor gasto para as especialidades médicas, enquanto que o Hospital Itaim Paulista destinou 22\%. Em valores reais, o Hospital Pedreira gastou R\$ 104.021,72 a mais do que o Hospital Itaim Paulista. 
A tabela 25 demonstra os dados sintéticos encontrados no estudo dos indicadores dos Hospitais Pedreira e Itaim Paulista.

Tabela 25- Dados gerais de Indicadores.

\begin{tabular}{|c|c|c|}
\hline & Hospital Pedreira & Hospital Itaim Paulista \\
\hline Tipo do Hospital & Secundário & Secundário \\
\hline \multicolumn{3}{|l|}{ Estrutura } \\
\hline $\mathrm{N}^{\circ}$ de leitos & 226 & 258 \\
\hline $\mathrm{N}^{\circ}$ de Consultórios - Pronto Socorro & 10 & 10 \\
\hline $\mathrm{N}^{\circ}$ de Consultórios- Ambulatório & 19 & 15 \\
\hline \multicolumn{3}{|l|}{ Producão/Produtividade } \\
\hline $\mathrm{N}^{\mathrm{o}}$ de Consultas- Pronto Socorro & 274.771 & 292.946 \\
\hline $\mathrm{N}^{\mathrm{o}}$ de Consultas- Ambulatório & 63.772 & 29.333 \\
\hline $\mathrm{N}^{\circ}$ de Internações & 12.381 & 15.325 \\
\hline $\mathrm{N}^{\circ}$ de Saídas & 13.015 & 15.309 \\
\hline $\mathrm{N}^{\circ}$ de Pacientes Dia & 66.343 & 82.808 \\
\hline Taxa de Ocupação-Média mensal & $79,74 \%$ & $87,88 \%$ \\
\hline Média de Permanência- Média mensal(dias) & 5,68 & 9,67 \\
\hline \multicolumn{3}{|l|}{ Qualidade } \\
\hline Taxa de Infecção Hospitalar- Média Mensal & 2,9 & 3,1 \\
\hline Taxa de Cesáreas- Média Mensal & $19,2 \%$ & $26,3 \%$ \\
\hline Respeito e educação no tratamento ao paciente & 94\% Excelente & 90\% Excelente \\
\hline Interesse do médico e qualidade do exame físico & 94\% Excelente & $84 \%$ Excelente \\
\hline Explicações fornecidas pelo médico & 94\% Excelente & $85 \%$ Excelente \\
\hline \multicolumn{3}{|l|}{ Recursos Humanos } \\
\hline $\mathrm{N}^{\circ}$ de funcionários por Leito & 5,8 & 4,2 \\
\hline $\mathrm{N}^{\circ}$ de Funcionários + Médicos- Média Mensal & 1.320 & 1.094 \\
\hline $\mathrm{N}^{\circ}$ de Médicos-Média Mensal & 384 & 257 \\
\hline Índice de Rotatividade & $\mathbf{N} / \mathbf{D}$ & 18,26 \\
\hline Índice de Absenteísmo & $\mathbf{N} / \mathbf{D}$ & 5,6 \\
\hline \multicolumn{3}{|l|}{ Financeiro } \\
\hline Gasto Total do Hospital & 46.461.578,46 & $40.137 .420,96$ \\
\hline Gasto com Médicos & $9.255 .669,98$ & $9.151 .648,26$ \\
\hline
\end{tabular}

Fonte: SPP, SCIH, SAU,DP e Financeiro 
Analisando os indicadores apresentados na primeira parte desse trabalho pôde-se observar que:

O Hospital Itaim Paulista possui o número de leitos $13 \%$ a mais que o Hospital Pedreira. Os percentuais de internações, saídas hospitalares e pacientes dia também foram respectivamente $19 \%, 15 \%$ e $20 \%$ superiores.

$\mathrm{Na}$ taxa de ocupação o Hospital Pedreira apresentou 79,74\%, enquanto no Hospital Itaim Paulista esse percentual foi $87,88 \%$.

A média de permanência foi $o$ item que apresentou maior disparidade entre os hospitais. Mesmo levantando o perfil de morbidade, ainda não foi possivel esclarecer o motivo da diferença, precisaria de um estudo mais detalhado que não coube nessa dissertação.

No pronto socorro, o Hospital Itaim Paulista atendeu o número de consultas $16 \%$ a mais que o Hospital Pedreira e no ambulatório atendeu $44 \%$ abaixo.

Os indicadores de qualidade demonstraram melhor desempenho do Hospital Pedreira em relação ao Hospital Itaim Paulista.

Nos indicadores de recursos humanos e financeiros foi possível observar que o Hospital Itaim Paulista possui o número de funcionários menor do que o Hospital Pedreira e também gastou menos. 


\section{SEGUNDA PARTE}

\section{7-Relação hora médica-produção-gasto}

\section{Clínica Médica- Unidade de Internação}

As tabelas 26 e 27 demonstram que o Hospital Pedreira em relação ao Hospital Itaim Paulista apresentou número de horas trabalhadas $35 \%$ inferior, número de pacientes saídos $3 \%$ superior e valor gasto total $33 \%$ inferior.

Tabela 26- Distribuição hora/médica, produção e gasto de Jan a Dez de 2003

Hospital Pedreira

\begin{tabular}{lcccccc}
\hline Meses & $\begin{array}{c}\text { Número de } \\
\text { Médicos } \\
\text { Diaristas }\end{array}$ & & & $\begin{array}{c}\text { Manha Tarde } \\
\text { Horas Médicas pacientes } \\
\text { Trabalhadas } \\
\text { saídos }\end{array}$ & $\begin{array}{c}\text { Gasto } \\
\text { Total Rs }\end{array}$ \\
\hline JAN & 4 & 3 & 1 & 442 & 227 & $16.446,55$ \\
FEV & 4 & 3 & 1 & 400 & 202 & $15.251,39$ \\
MAR & 4 & 3 & 1 & 440 & 211 & $16.177,07$ \\
ABR & 4 & 3 & 1 & 420 & 239 & $15.928,40$ \\
MAI & 4 & 3 & 1 & 420 & 236 & $16.073,54$ \\
JUN & 5 & 4 & 1 & 525 & 234 & $19.871,60$ \\
JUL & 5 & 4 & 1 & 569 & 209 & $21.249,03$ \\
AGO & 5 & 4 & 1 & 541 & 230 & $22.170,14$ \\
SET & 7 & 3 & 2 & 580 & 222 & $24.258,50$ \\
OUT & 7 & 3 & 2 & 685 & 277 & $25.116,18$ \\
NOV & 7 & 3 & 2 & 657 & 256 & $26.835,59$ \\
DEZ & 7 & 3 & 2 & 724 & 275 & $28.975,21$ \\
Total & & & & $\mathbf{6 . 4 0 3}$ & $\mathbf{2 . 8 1 8}$ & $\mathbf{2 4 8 . 3 5 3 , 1 7}$ \\
Média Mensal & & & & $\mathbf{5 3 4}$ & $\mathbf{2 3 5}$ & $\mathbf{2 0 . 6 9 6 , 1 0}$ \\
\hline
\end{tabular}

Fonte: SPP e Coopmed

Tabela 27- Distribuição hora/médica, produção e gasto de Jan a Dez de 2003 Hospital Itaim Paulista

\begin{tabular}{lcccccc} 
Meses & $\begin{array}{c}\text { Número de } \\
\text { Médicos } \\
\text { Diaristas }\end{array}$ & & & $\begin{array}{c}\text { Manhã Tarde } \\
\text { Horas Médicas Pacientes } \\
\text { Trabalhadas }\end{array}$ & $\begin{array}{c}\text { Proídos } \\
\text { Trastal Rs } \\
\text { Tota }\end{array}$ \\
\hline JAN & 6 & 3 & 2 & 825 & 235 & $27.319,61$ \\
FEV & 6 & 3 & 2 & 825 & 184 & $27.319,61$ \\
MAR & 6 & 3 & 2 & 825 & 198 & $27.319,61$ \\
ABR & 6 & 3 & 2 & 825 & 217 & $27.319,61$ \\
MAI & 6 & 3 & 2 & 825 & 223 & $29.309,07$ \\
JUN & 8 & 3 & 2 & 825 & 245 & $29.309,07$ \\
JUL & 8 & 3 & 2 & 825 & 247 & $29.309,07$ \\
AGO & 8 & 3 & 2 & 825 & 226 & $29.309,07$ \\
SET & 7 & 3 & 2 & 825 & 292 & $29.309,07$ \\
OUT & 7 & 3 & 2 & 825 & 235 & $39.220,87$ \\
NOV & 9 & 3 & 2 & 825 & 210 & $39.220,87$ \\
DEZ & 9 & 3 & 2 & 825 & 212 & $39.220,87$ \\
Total & & & & $\mathbf{9 . 9 0 0}$ & $\mathbf{2 . 7 2 4}$ & $\mathbf{3 7 3 . 4 8 6 , 4 0}$ \\
Média Mensal & & & & $\mathbf{8 2 5}$ & $\mathbf{2 2 7}$ & $\mathbf{3 1 . 1 2 3 , 8 7}$ \\
\hline
\end{tabular}

Fonte: SPP e DP. 
O Hospital Pedreira gastou R\$ 88,13 com honorários médicos para cada paciente que esteve internado na clínica médica. E o valor para o Hospital Itaim Paulista gastou R\$137,11.

Tabela 28-Relação entre valor gasto e horas médicas de jan a dez de 2003.

\begin{tabular}{|c|c|c|}
\hline & Hospital Pedreira & Hospital Itaim Paulista \\
\hline Meses & $\begin{array}{l}\text { Valor gasto/ } \\
\text { Número de horas médicas } \\
\text { Trabalhadas }\end{array}$ & $\begin{array}{l}\text { Valor gasto/ } \\
\text { Número de horas médicas } \\
\text { Trabalhadas }\end{array}$ \\
\hline JAN & 37,21 & 33,10 \\
\hline FEV & 38,13 & 33,10 \\
\hline MAR & 36,77 & 33,10 \\
\hline $\mathrm{ABR}$ & 37,92 & 33,10 \\
\hline MAI & 38,27 & 35,53 \\
\hline JUN & 37,85 & 35,53 \\
\hline JL & 37,34 & 35,53 \\
\hline AGO & 40,98 & 35,53 \\
\hline SET & 41,83 & 35,53 \\
\hline OUT & 36,67 & 47,54 \\
\hline NOV & 40,85 & 47,54 \\
\hline DEZ & 40,02 & 47,54 \\
\hline Média Mensal & 38,67 & 37,75 \\
\hline
\end{tabular}

Fonte: Coopmed e DP.

A tabela 28 demonstrou que o valor da hora médica trabalhada no Hospital Itaim Paulista até o mês de outubro, mês que ocorreu dissídio coletivo 2003/2004, foi inferior ao apresentado pelo Hospital Pedreira, bem como a média mensal. 


\section{UTI Adulto- Unidade de Internação}

As tabelas 29 e 30 mostram que o Hospital Pedreira em relação ao Hospital Itaim Paulista apresentou número de horas trabalhadas $19 \%$ superior, número de pacientes saídos $40 \%$ superior e valor gasto total $41 \%$ superior.

Tabela 29- Distribuição hora/médica, produção e gasto de Jan a Dez de 2003 Hospital Pedreira

\begin{tabular}{|c|c|c|c|c|}
\hline Meses & $\begin{array}{l}\mathrm{N}^{\circ} \text { de Médicos } \\
\text { Diaristas e } \\
\text { Plantonistas } \\
\end{array}$ & $\begin{array}{l}\text { Horas Médicas } \\
\text { Trabalhadas }\end{array}$ & $\begin{array}{c}\text { Produção Pacientes } \\
\text { saídos }\end{array}$ & Gasto Total RS \\
\hline$\overline{\mathrm{JAN}}$ & 17 & 1.116 & 38 & \\
\hline FEV & 16 & 1.000 & 16 & \\
\hline MAR & 19 & 1.075 & 30 & $45.323,53$ \\
\hline $\mathrm{ABR}$ & 16 & 823 & 40 & $42.042,23$ \\
\hline MAI & 17 & 1.082 & 46 & $43.231,91$ \\
\hline JUN & 17 & 1.059 & 45 & $42.070,72$ \\
\hline JUL & 17 & 1.093 & 48 & $43.203,41$ \\
\hline $\mathrm{AGO}$ & 17 & 1.095 & 38 & $43.252,79$ \\
\hline SET & 17 & 1.051 & 45 & $41.812,39$ \\
\hline OUT & 20 & 998 & 35 & $43.143,17$ \\
\hline NOV & 14 & 1.060 & 52 & $42.091,61$ \\
\hline DEZ & 16 & 1.095 & 44 & $43.268,00$ \\
\hline \multirow{2}{*}{\multicolumn{2}{|c|}{$\begin{array}{l}\text { Total } \\
\text { Média Mensal }\end{array}$}} & 12.547 & 477 & $523.297,27$ \\
\hline & & 1.046 & 40 & $43.608,11$ \\
\hline
\end{tabular}

Fonte: SPP e Coopmed

Tabela 30- Distribuição hora/médica, produção e gasto de Jan a Dez de 2003. Hospital Itaim Paulista

\begin{tabular}{|c|c|c|c|c|}
\hline Meses & $\begin{array}{l}\mathrm{N}^{\circ} \text { de Médicos } \\
\text { Diaristas e } \\
\text { Plantonistas }\end{array}$ & $\begin{array}{c}\text { Horas Médicas } \\
\text { Trabalhadas }\end{array}$ & $\begin{array}{c}\text { Produção Pacientes } \\
\text { saídos }\end{array}$ & $\begin{array}{c}\text { Gasto Total } \\
\text { R } \$\end{array}$ \\
\hline$\overline{\mathrm{JAN}}$ & 9 & 840 & 16 & $24.114,72$ \\
\hline FEV & 9 & 840 & 29 & $24.114,72$ \\
\hline MAR & 9 & 840 & 20 & $24.114,72$ \\
\hline ABR & 9 & 840 & 16 & $24.114,72$ \\
\hline MAI & 9 & 840 & 24 & $25.911,27$ \\
\hline JUN & 9 & 840 & 29 & $25.911,27$ \\
\hline JUL & 9 & 840 & 33 & $25.911,27$ \\
\hline $\mathrm{AGO}$ & 9 & 840 & 31 & $25.911,27$ \\
\hline SET & 9 & 840 & 20 & $25.911,27$ \\
\hline OUT & 9 & 840 & 20 & $27.406,38$ \\
\hline NOV & 9 & 840 & 19 & $27.406,38$ \\
\hline DEZ & 9 & 840 & 26 & $27.406,38$ \\
\hline \multirow{2}{*}{\multicolumn{2}{|c|}{$\begin{array}{l}\text { Total } \\
\text { Média Mensal }\end{array}$}} & 10.080 & 283 & $308.234,37$ \\
\hline & & 840 & 24 & $25.686,20$ \\
\hline
\end{tabular}

Fonte: SPP e DP. 
O Hospital Pedreira gastou R\$1.097,05 com honorários médicos para cada paciente que esteve internado na UTI adulto. E o valor para o Hospital Itaim Paulista gastou $\mathrm{R} \$ 1.089,16$

Tabela 31 -Relação entre o valor gasto e horas médicas de jan a dez de 2003.

\begin{tabular}{lll} 
Mospes & \multicolumn{1}{l}{$\begin{array}{l}\text { Valor gastod } \\
\text { Número de horas médicas } \\
\text { Trabalhadas }\end{array}$} & $\begin{array}{l}\text { Hospital Itaim Paulista } \\
\text { Valor gastol } \\
\text { Nómero de horas médicas } \\
\text { Trabalhadas }\end{array}$ \\
\hline JAN & 43,78 & 28,71 \\
FEV & 45,00 & 28,71 \\
MAR & 42,16 & 28,71 \\
ABR & 51,08 & 28,71 \\
MAI & 39,96 & 30,85 \\
JUN & 39,73 & 30,85 \\
JUL & 39,53 & 30,85 \\
AGO & 39,50 & 30,85 \\
SET & 39,78 & 30,85 \\
OUT & 43,23 & 32,63 \\
NOV & 39,71 & 32,63 \\
DEZ & 39,51 & 32,63 \\
Módia Mensal & 41,91 & $\mathbf{3 0 , 5 8}$ \\
\hline
\end{tabular}

Fonte: Coopmed e DP.

Nota-se que nos quatro primeiros meses, o valor da hora apresentada pelo Hospital Pedreira foi maior ao que o restante do ano. $O$ Hospital esclareceu que nesse período a especialidade contava com três coordenadores médicos. A tabela 31 demonstra que em todos os meses o valor da hora médica trabalhada no Hospital Itaim Paulista foi inferior que a do Hospital Pedreira. 


\section{Clínica Cirúrgica- Unidade de Internação}

As tabelas 32 e 33 mostram que o Hospital Pedreira em relação ao Hospital Itaim Paulista apresentou número de horas médicas trabalhadas $34 \%$ inferior, número de pacientes saídos $13 \%$ inferior e valor gasto total $14 \%$ inferior.

Tabela 32- Distribuição hora/médica, produção e gasto no período de Jan a Dez de 2003.

Hospital Pedreira

\begin{tabular}{lcccccc}
\hline Meses & $\begin{array}{l}\mathbf{N}^{\circ} \text { de Médicos } \\
\text { Diaristas }\end{array}$ & Manhã & Tarde & $\begin{array}{l}\text { Horas Médicas } \\
\text { Trabalhadas }\end{array}$ & $\begin{array}{l}\text { Produção } \\
\text { Pacientes Saídos }\end{array}$ & $\begin{array}{c}\text { Gasto Total } \\
\text { RS }\end{array}$ \\
\hline JAN & 6 & 2 & 2 & 424 & 207 & $14.382,63$ \\
FEV & 6 & 2 & 2 & 384 & 166 & $17.834,85$ \\
MAR & 6 & 2 & 2 & 392 & 161 & $18.106,22$ \\
ABR & 6 & 2 & 2 & 400 & 150 & $18.377,59$ \\
MAI & 6 & 2 & 2 & 408 & 159 & $18.648,96$ \\
JUN & 6 & 2 & 2 & 360 & 167 & $17.020,74$ \\
JUL & 6 & 2 & 2 & 392 & 166 & $18.106,22$ \\
AGO & 6 & 2 & 2 & 400 & 210 & $18.377,59$ \\
SET & 6 & 2 & 2 & 416 & 172 & $18.920,33$ \\
OUT & 6 & 2 & 2 & 408 & 260 & $18.648,96$ \\
NOV & 6 & 2 & 2 & 368 & 203 & $18.978,02$ \\
DEZ & 6 & 2 & 2 & 400 & 180 & $18.377,59$ \\
Total & & & & $\mathbf{4 . 7 5 2}$ & $\mathbf{2 . 2 0 1}$ & $\mathbf{2 1 5 . 7 7 9 , 7 0}$ \\
Média & Mensal & & & & & \\
\hline
\end{tabular}

Fonte: SPP e Coopmed

Tabela 33- Distribuição hora/médica, produção e gasto no período de Jan a Dez de 2003.

Hospital Itaim Paulista

\begin{tabular}{lcccccc}
\hline Meses & $\begin{array}{l}\mathbf{N}^{\mathbf{0}} \text { de Médicos } \\
\text { Diaristas }\end{array}$ & Manhã & Tarde & $\begin{array}{c}\text { Horas Médicas } \\
\text { Trabalhadas }\end{array}$ & $\begin{array}{c}\text { Produçáo } \\
\text { Pacientes Saídos }\end{array}$ & $\begin{array}{c}\text { Gasto Total } \\
\text { RS }\end{array}$ \\
\hline JAN & 13 & 3 & 3 & 600 & 199 & $19.799,91$ \\
FEV & 13 & 3 & 3 & 600 & 198 & $19.799,91$ \\
MAR & 13 & 3 & 3 & 600 & 212 & $19.799,91$ \\
ABR & 13 & 3 & 3 & 600 & 227 & $19.799,91$ \\
MAI & 13 & 3 & 3 & 600 & 188 & $21.229,57$ \\
JUN & 13 & 3 & 3 & 600 & 214 & $21.229,57$ \\
JUL & 14 & 3 & 3 & 600 & 213 & $21.229,57$ \\
AGO & 13 & 3 & 3 & 600 & 208 & $21.229,57$ \\
SET & 13 & 3 & 3 & 600 & 218 & $21.229,57$ \\
OUT & 14 & 3 & 3 & 600 & 238 & $22.478,36$ \\
NOV & 13 & 3 & 3 & 600 & 201 & $22.478,36$ \\
DEZ & 12 & 3 & 3 & 600 & 229 & $22.478,36$ \\
Total & & & & $\mathbf{7 . 2 0 0}$ & $\mathbf{2 . 5 4 5}$ & $\mathbf{2 5 2 . 7 8 2 , 5 7}$ \\
Média Mensal & & & & $\mathbf{6 0 0}$ & $\mathbf{2 1 2}$ & $\mathbf{2 1 . 0 6 5 , 2 1}$ \\
\hline
\end{tabular}

Fonte: SPP e DP. 
O Hospital Pedreira gastou R\$ 98,03 com honorários médicos para cada paciente que esteve internado na clínica cirúrgica. E o valor para o Hospital Itaim Paulista gastou R\$ 99,32.

Tabela 34 -Relação entre o valor gasto e horas médicas de jan a dez de 2003.

\begin{tabular}{lll} 
& Hospital Pedreira & Hospital Itaim Paulista \\
\hline Meses & $\begin{array}{l}\text { Valor gasto/ } \\
\text { Número de horas médicas } \\
\text { Trabalhadas }\end{array}$ & $\begin{array}{l}\text { Valor gasto/ } \\
\text { Número de horas médicas } \\
\text { Trabalhadas }\end{array}$ \\
\hline JAN & 33,92 & 33,00 \\
FEV & 46,44 & 33,00 \\
MAR & 46,19 & 33,00 \\
ABR & 45,94 & 33,00 \\
MAI & 45,71 & 35,38 \\
JUN & 47,28 & 35,38 \\
JUL & 46,19 & 35,38 \\
AGO & 45,94 & 35,38 \\
SET & 45,48 & 35,38 \\
OUT & 45,71 & 37,46 \\
NOV & 51,57 & 37,46 \\
DEZ & 45,90 & 37,46 \\
Média Mensal & $\mathbf{4 5 , 5 2}$ & 35,08 \\
\hline
\end{tabular}

Fonte: Coopmed e DP.

A tabela 34 demonstra que o valor da hora médica trabalhada no Hospital Itaim Paulista foi inferior que a do Hospital Pedreira em todos os meses. 


\section{Clínica Pediátrica- Unidade de Internação}

As tabelas 35 e 36 mostram que o Hospital Pedreira em relação ao Hospital Itaim Paulista apresentou número de horas trabalhadas $16 \%$ superior, número de pacientes saídos $21 \%$ inferior e valor gasto total $36 \%$ superior.

Tabela 35- Distribuição hora/médica, produção e gasto de Jan a Dez de 2003. Hospital Pedreira

\begin{tabular}{lcccccc}
\hline Meses & $\begin{array}{c}\text { Número de } \\
\text { Médicos } \\
\text { Diaristas }\end{array}$ & Manhã & Tarde & $\begin{array}{c}\text { Horas } \\
\text { Médicas } \\
\text { Trabalhadas }\end{array}$ & $\begin{array}{c}\text { Produção } \\
\text { Pacientes } \\
\text { Saídos }\end{array}$ & $\begin{array}{c}\text { Gasto } \\
\text { Total RS }\end{array}$ \\
\hline JAN & 6 & 3 & 2 & 448 & 102 & $20.091,42$ \\
FEV & 6 & 3 & 2 & 448 & 109 & $20.091,42$ \\
MAR & 6 & 3 & 2 & 448 & 128 & $20.091,42$ \\
ABR & 7 & 3 & 2 & 448 & 179 & $20.091,42$ \\
MAI & 6 & 3 & 2 & 448 & 153 & $20.091,42$ \\
JUN & 6 & 3 & 2 & 448 & 137 & $20.091,42$ \\
JUL & 6 & 3 & 2 & 448 & 106 & $20.091,42$ \\
AGO & 6 & 3 & 2 & 448 & 107 & $20.091,42$ \\
SET & 6 & 3 & 2 & 448 & 138 & $20.091,42$ \\
OUT & 6 & 3 & 2 & 448 & 119 & $20.091,42$ \\
NOV & 6 & 3 & 2 & 448 & 104 & $20.547,74$ \\
DEZ & 6 & 3 & 2 & 448 & 118 & $20.547,74$ \\
Total & & & & $\mathbf{5 . 3 7 6}$ & $\mathbf{1 . 5 0 0}$ & $\mathbf{2 4 2 . 0 0 9 , 6 6}$ \\
Média Mensal & & & & $\mathbf{4 4 8}$ & $\mathbf{1 2 5}$ & $\mathbf{2 0 . 1 6 7 , 4 7}$ \\
\hline
\end{tabular}

Fonte: SPP e Coopmed

Tabela 36- Distribuição hora/médica, produção e gasto de Jan a Dez de 2003.

Hospital Itaim Paulista

\begin{tabular}{lcccccc} 
Meses & $\begin{array}{c}\text { Número de } \\
\text { Médicos } \\
\text { Diaristas }\end{array}$ & Manhã & Tarde & $\begin{array}{c}\text { Horas } \\
\text { Médicas } \\
\text { Trabalhadas }\end{array}$ & $\begin{array}{c}\text { Produção } \\
\text { Pacientes } \\
\text { Saídos }\end{array}$ & $\begin{array}{c}\text { Gasto } \\
\text { Total RS }\end{array}$ \\
\hline JAN & 3 & 2 & 1 & 375 & 118 & $12.014,30$ \\
FEV & 3 & 2 & 1 & 375 & 114 & $12.014,30$ \\
MAR & 3 & 2 & 1 & 375 & 133 & $12.014,30$ \\
ABR & 3 & 2 & 1 & 375 & 179 & $12.014,30$ \\
MAI & 3 & 2 & 1 & 375 & 197 & $12.902,45$ \\
JUN & 5 & 2 & 1 & 375 & 187 & $12.902,45$ \\
JUL & 5 & 2 & 1 & 375 & 183 & $12.902,45$ \\
AGO & 5 & 2 & 1 & 375 & 160 & $12.902,45$ \\
SET & 5 & 2 & 1 & 375 & 151 & $12.902,45$ \\
OUT & 5 & 2 & 1 & 375 & 184 & $14.215,84$ \\
NOV & 5 & 2 & 1 & 375 & 143 & $14.215,84$ \\
DEZ & 5 & 2 & 1 & 375 & 161 & $14.215,84$ \\
Total & & & & $\mathbf{4 . 5 0 0}$ & $\mathbf{1 . 9 1 0}$ & $\mathbf{1 5 5 . 2 1 6 , 9 7}$ \\
Média Mensal & & & & $\mathbf{3 7 5}$ & $\mathbf{1 5 9}$ & $\mathbf{1 2 . 9 3 4 , 7 5}$ \\
\hline
\end{tabular}

Fonte: SPP e DP. 
O Hospital Pedreira gastou R\$161,33 com honorários médicos para cada paciente que esteve internado na clínica pediátrica. E o valor para o Hospital Itaim Paulista gastou $\mathrm{R} \$ 81,26$.

Tabela 37-Relação entre o valor gasto e de horas médicas de jan a dez de 2003.

\begin{tabular}{lcl} 
& Hospital Pedreira & Hospital Itaim Paulista \\
\hline Meses & \begin{tabular}{l} 
Valor gastol \\
Número de horas médicas \\
\multicolumn{2}{c}{ Trabalhadas }
\end{tabular} & $\begin{array}{l}\text { Valor gastol } \\
\text { Nímero de horas médicas } \\
\text { Trabalhadas }\end{array}$ \\
\hline JAN & 44,85 & 32,04 \\
FEV & 44,85 & 32,04 \\
MAR & 44,85 & 32,04 \\
ABR & 44,85 & 32,04 \\
MAI & 44,85 & 34,41 \\
JUN & 44,85 & 34,41 \\
JUL & 44,85 & 34,41 \\
ACO & 44,85 & 34,41 \\
SET & 44,85 & 34,41 \\
OUT & 44,85 & 37,91 \\
NOV & 45,86 & 37,91 \\
DEZ & 45,86 & 37,91 \\
Média Mensal & 45,02 & 34,50 \\
\hline
\end{tabular}

Fonte: Coopmed e DP.

A tabela 37 demonstrou que o valor da hora médica trabalhada no Hospital Itaim Paulista é inferior ao apresentado pelo Hospital Pedreira. 


\section{Unidade Neonatal- Unidade de Internação}

As tabelas 38 e 39 mostram que o Hospital Pedreira em relação ao Hospital Itaim Paulista apresentou número de horas trabalhadas $29 \%$ inferior, número de pacientes saídos $5 \%$ inferior e valor gasto total $13 \%$ inferior.

Tabela 38- Distribuição hora/médica, produção e gasto de Jan a Dez de 2003. Hospital Pedreira

\begin{tabular}{lcccc}
\hline \multicolumn{1}{c}{ Meses } & $\begin{array}{c}\text { Número de } \\
\text { Médicos }\end{array}$ & $\begin{array}{c}\text { Horas } \\
\text { Médicas } \\
\text { Trabalhadas }\end{array}$ & $\begin{array}{c}\text { Produção } \\
\text { Pacientes } \\
\text { Saídos }\end{array}$ & $\begin{array}{c}\text { Gasto } \\
\text { Total RS }\end{array}$ \\
\hline JAN & 48 & 1.964 & 90 & $81.850,62$ \\
FEV & 46 & 1.632 & 54 & $71.211,99$ \\
MAR & 46 & 1.824 & 60 & $77.516,36$ \\
ABR & 45 & 1.728 & 68 & $74.364,18$ \\
MAI & 46 & 1.800 & 63 & $76.727,91$ \\
JUN & 42 & 1.752 & 51 & $68.849,07$ \\
JUL & 42 & 1.776 & 48 & $75.940,27$ \\
AGO & 41 & 1.836 & 60 & $79.325,60$ \\
SET & 40 & 1.752 & 51 & $77.982,65$ \\
OUT & 39 & 1.800 & 56 & $79.558,75$ \\
NOV & 38 & 1.800 & 35 & $79.558,75$ \\
DEZ & 38 & 1.800 & 27 & $79.558,75$ \\
Total & & $\mathbf{2 1 . 4 6 4}$ & $\mathbf{6 6 3}$ & $\mathbf{9 2 2 . 4 4 4 , 8 9}$ \\
Média Mensal & $\mathbf{1 . 7 8 9}$ & $\mathbf{5 5}$ & $\mathbf{7 6 . 8 7 0 , 4 1}$ \\
\hline
\end{tabular}

Fonte: SPP e Coopmed

Tabela 39- Distribuição hora/médica, produção e gasto de Jan a Dez de 2003. Hospital Itaim Paulista

\begin{tabular}{lcccc}
\hline Meses & $\begin{array}{l}\text { Númerode } \\
\text { Médicos }\end{array}$ & $\begin{array}{l}\text { Horas } \\
\text { Médicas } \\
\text { Trabalhadas }\end{array}$ & $\begin{array}{l}\text { Producão } \\
\text { Pacientes } \\
\text { Saídos }\end{array}$ & $\begin{array}{l}\text { Gasto } \\
\text { Total R\$ }\end{array}$ \\
\hline JAN & 43 & 2.520 & 82 & $86.849,16$ \\
FEV & 41 & 2.520 & 62 & $86.849,16$ \\
MAR & 41 & 2.520 & 60 & $86.849,16$ \\
ABR & 40 & 2.520 & 68 & $86.849,16$ \\
MAI & 41 & 2.520 & 58 & $86.704,48$ \\
JUN & 37 & 2.520 & 51 & $86.704,48$ \\
JUL & 37 & 2.520 & 64 & $86.704,48$ \\
AGO & 36 & 2.520 & 38 & $86.704,48$ \\
SET & 35 & 2.520 & 58 & $86.704,48$ \\
OUT & 34 & 2.520 & 54 & $91.732,39$ \\
NOV & 33 & 2.520 & 62 & $91.732,39$ \\
DEZ & 33 & 2.520 & 39 & $91.732,39$ \\
Total & & $\mathbf{3 0 . 2 4 0}$ & $\mathbf{6 9 6}$ & $\mathbf{1 . 0 5 6 . 1 1 6 , 2 1}$ \\
Média Mensal & & $\mathbf{2 . 5 2 0}$ & $\mathbf{8 8 . 0 0 9 , 6 8}$ \\
\hline
\end{tabular}

Fonte: SPP e DP. 
O Hospital Pedreira gastou R\$ 1.391,31 com honorários médicos para cada paciente que esteve internado na unidade neonatal. E o valor para o Hospital Itaim Paulista gastou $\mathrm{R} \$ 1.517,40$.

Tabela 40-Relação entre o valor gasto e horas médicas de jan a dez de 2003.

\begin{tabular}{lcl} 
& Hospital Pedreira & Hospital Itaim Paulista \\
\hline Meses & $\begin{array}{l}\text { Valor gasto' } \\
\text { Número de horas médicas } \\
\text { Trabalhadas }\end{array}$ & $\begin{array}{l}\text { Valor gasto' } \\
\text { Número de horas médicas } \\
\text { Trabalhadas }\end{array}$ \\
\hline JAN & 41,68 & 34,46 \\
FEV & 43,63 & 34,46 \\
MAR & 42,50 & 34,46 \\
ABR & 43,03 & 34,46 \\
MAI & 42,63 & 34,41 \\
JUN & 39,30 & 34,41 \\
JUL & 42,76 & 34,41 \\
AGO & 43,21 & 34,41 \\
SET & 44,51 & 34,41 \\
OUT & 44,20 & 36,40 \\
NOV & 44,20 & 36,40 \\
DEZ & 44,20 & 36,40 \\
Média Mensal & 42,99 & 34,92 \\
\hline
\end{tabular}

Fonte: Coopmed e DP.

A tabela 40 demonstrou que o valor da hora médica trabalhada no Hospital Itaim Paulista é inferior ao apresentado pelo Hospital Pedreira. 


\section{Ginecologia e Obstetrícia- Unidade de Internação}

As tabelas 41 e 42 mostram que o Hospital Pedreira em relação ao Hospital Itaim Paulista apresentou número de horas trabalhadas $25 \%$ inferior, número de pacientes saídos $33 \%$ inferior e valor gasto total $6 \%$ inferior.

Tabela 41- Distribuição hora/médica, produção e gasto de Jan a Dez de 2003. Hospital Pedreira

\begin{tabular}{lcccccc}
\hline Meses & $\begin{array}{l}\text { Número de } \\
\text { Médicos } \\
\text { Diaristas }\end{array}$ & Manha & Tarde & $\begin{array}{l}\text { Horas } \\
\text { Médicas } \\
\text { Trabalhadas }\end{array}$ & $\begin{array}{l}\text { Produçao } \\
\text { Pacientes } \\
\text { Saídos }\end{array}$ & $\begin{array}{l}\text { Gasto } \\
\text { Total Rs }\end{array}$ \\
\hline JAN & 3 & 1 & 0 & 324 & 391 & $13.395,04$ \\
FEV & 3 & 1 & 0 & 216 & 394 & $13.395,04$ \\
MAR & 3 & 1 & 0 & 324 & 401 & $13.395,04$ \\
ABR & 3 & 1 & 0 & 216 & 363 & $13.395,04$ \\
MAI & 3 & 1 & 0 & 216 & 383 & $13.395,04$ \\
JUN & 5 & 2 & 0 & 400 & 286 & $15.973,06$ \\
JUL & 9 & 2 & 0 & 412 & 363 & $16.380,11$ \\
AGO & 7 & 2 & 0 & 404 & 344 & $16.108,74$ \\
SET & 7 & 2 & 0 & 412 & 299 & $16.380,11$ \\
OUT & 6 & 2 & 0 & 412 & 381 & $16.380,11$ \\
NOV & 7 & 2 & 0 & 388 & 253 & $15.729,05$ \\
DEZ & 3 & 1 & 0 & 324 & 233 & $14.597,30$ \\
Total & & & & $\mathbf{4 . 0 4 8}$ & $\mathbf{4 . 0 9 1}$ & $\mathbf{1 7 8 . 5 2 3 , 6 6}$ \\
Média Mensal & & & $\mathbf{3 3 7}$ & $\mathbf{3 4 1}$ & $\mathbf{1 4 . 8 7 6 , 9 7}$ \\
\hline
\end{tabular}

Fonte: SPP e Coopmed

Tabela 42- Distribuição hora/médica, produção e gasto de Jan a Dez de 2003. Hospital Itaim Paulista

\begin{tabular}{|c|c|c|c|c|c|c|}
\hline Meses & $\begin{array}{l}\text { Número de } \\
\text { Médicos } \\
\text { Diaristas }\end{array}$ & Manhã & Tarde & $\begin{array}{l}\text { Horas } \\
\text { Médicas } \\
\text { Trabalhadas }\end{array}$ & $\begin{array}{l}\text { Produção } \\
\text { Pacientes } \\
\text { Saídos }\end{array}$ & $\begin{array}{l}\text { Gasto } \\
\text { Total RS }\end{array}$ \\
\hline$\overline{\mathrm{JAN}}$ & 11 & 1 & 2 & 450 & 561 & $14.933,90$ \\
\hline FEV & 11 & 1 & 2 & 450 & 508 & $14.933,90$ \\
\hline MAR & 11 & 1 & 2 & 450 & 507 & $14.933,90$ \\
\hline $\mathrm{ABR}$ & 11 & 1 & 2 & 450 & 506 & $14.933,90$ \\
\hline MAI & 11 & 1 & 2 & 450 & 587 & $16.019,06$ \\
\hline JUN & 11 & 1 & 2 & 450 & 496 & $16.019,06$ \\
\hline JUL & 9 & 1 & 2 & 450 & 506 & $16.019,06$ \\
\hline $\mathrm{AGO}$ & 9 & 1 & 2 & 450 & 500 & $16.019,06$ \\
\hline SET & 9 & 1 & 2 & 450 & 542 & $16.019,06$ \\
\hline OUT & 9 & 1 & 2 & 450 & 546 & $16.955,66$ \\
\hline NOV & 9 & 1 & 2 & 450 & 495 & $16.955,66$ \\
\hline DEZ & 9 & 1 & 2 & 450 & 372 & $16.955,66$ \\
\hline \multirow{2}{*}{\multicolumn{4}{|c|}{$\begin{array}{l}\text { Total } \\
\text { Média Mensal }\end{array}$}} & 5.400 & 6.126 & $190.697,88$ \\
\hline & & & & 450 & 511 & $15.891,49$ \\
\hline
\end{tabular}

Fonte: SPP e DP. 
O Hospital Pedreira gastou R\$43,63 com honorários médicos para cada paciente que esteve internado na ginecologia e obstetrícia. E o valor para o Hospital Itaim Paulista gastou R 31,12 .

Tabela 43 -Relação entre o valor gasto e horas médicas de jan a dez de 2003.

Hospital Pedreira Hospital Itaim Paulista

\begin{tabular}{lcc}
\hline Meses & $\begin{array}{l}\text { Valor gastol } \\
\text { Número de horas médicas } \\
\text { Trabalhadas }\end{array}$ & $\begin{array}{l}\text { Valor gasto' } \\
\text { Número de horas médicas } \\
\text { Trabalhadas }\end{array}$ \\
\hline JAN & 41,34 & 33,19 \\
FEV & 62,01 & 33,19 \\
MAR & 41,34 & 33,19 \\
ABR & 62,01 & 33,19 \\
MAI & 62,01 & 35,60 \\
JUN & 39,93 & 35,60 \\
JUL & 39,76 & 35,60 \\
ACO & 39,87 & 35,60 \\
SET & 39,76 & 35,60 \\
OUT & 39,76 & 37,68 \\
NOV & 40,54 & 37,68 \\
DEZ & 45,05 & 37,68 \\
Média Mensal & 46,12 & 35,33 \\
\hline
\end{tabular}

Fonte: Coopmed e DP.

A tabela 43 demonstra que o valor da hora médica trabalhada no Hospital Itaim Paulista é inferior ao apresentado pelo Hospital Pedreira. Nota-se que nos meses de fevereiro, abril e maio o Hospital Pedreira apresentou valor bem superior. 
Tabela 44-Dados sintéticos da relação hora médica-produção-gasto.

Unidades de Internação

$\mathbf{N}^{0}$ de médicos

Clínica Médica (diarista)

UTI Adulto ( diarista e plantonista)

Clínica Cirúrgica (diarista)

Clínica Pediátrica (diarista)

Unidade Neonatal (diarista e plantonista)

Gonecologia e Obstetrícia (diarista)

$\mathbf{N}^{0}$ de horas trabalhadas

Clínica Médica

UTI Adulto

Clínica Cirúrgica

Clínica Pediátrica

Unidade Neonatal

Gonecologia e Obstetrícia

Total

$\mathbf{N}^{\mathbf{0}}$ de pacientes saídos

Clínica Médica

UTI Adulto

Clínica Cirúrgica

Clínica Pediátrica

Unidade Neonatal

Gonecologia e Obstetrícia

Total

Valor gasto total

Clínica Médica

UTI Adulto

Clínica Cirúrgica

Clínica Pediátrica

Unidade Neonatal

Gonecologia e Obstetrícia

Total

Valor médio anual da hora médica

Clínica Médica

UTI Adulto

Clínica Cirúrgica

Clínica Pediátrica

Unidade Neonatal

Gonecologia e Obstetrícia

Fonte: SPP, DP e Financeiro
Hospital Pedreira

Hospital Itaim Paulista

\begin{tabular}{|c|c|}
\hline $\begin{array}{l}3 \text { manhã } 2 \text { tarde } \\
\text { Cobetura } 24 \text { horas }\end{array}$ & $\begin{array}{l}3 \text { manhã/2 tarde } \\
\text { Cobetura } 24 \text { horas }\end{array}$ \\
\hline $2 \operatorname{manh} \tilde{a} / 2 \operatorname{tarde}$ & 3 manhã/3 tarde \\
\hline $\begin{array}{l}3 \text { manhã/2 tarde } \\
\text { Cobetura } 24 \text { horas }\end{array}$ & $\begin{array}{l}2 \text { manhã } / 1 \text { tarde } \\
\text { Cobetura } 24 \text { horas }\end{array}$ \\
\hline 1 manhã $/ 0$ tarde & 1 manhã/2 tarde \\
\hline
\end{tabular}

\begin{tabular}{|cc|}
\hline 6.403 & 9.900 \\
12.547 & 10.080 \\
4.752 & 7.200 \\
5.376 & 4.500 \\
21.464 & 30.240 \\
4.048 & 5.400 \\
54.590 & 67.320 \\
\hline
\end{tabular}

2.818

2.724

477

283

2.201

2.545

1.500

1.910

663

696

4.091

6.126

11.750

14.284

248353,17

373.486,40

$\mathbf{5 2 3 2 9 7 , 2 7}$

215779,70

308.234,37

252.782,57

242009,66

$155,216,97$

922444,89

1.056.116,21

178.523,66

$190.697,88$

2.330.408,35

2.181.317,43

38,67

37,75

41,91

30,58

45,52

35,08

45,02

34,50

42,99

34,92

46,12

$\mathbf{3 5 , 3 3}$ 


\section{Clínica Médica-Pronto Socorro}

As tabelas 45 e 46 mostram que o Hospital Pedreira em relação ao Hospital Itaim Paulista apresentou número de horas trabalhadas $18,44 \%$ superior, produção $6,11 \%$ inferior, valor gasto total $21,60 \%$ superior.

Tabela 45- Distribuição hora/médica, produção e gasto de Jan a Dez de 2003. Hospital Pedreira

\begin{tabular}{|c|c|c|c|c|c|c|}
\hline Meses & $\begin{array}{l}\text { N}^{0} d e \text { Médicos } \\
\text { Plantonistas }\end{array}$ & Dia & Noite & $\begin{array}{l}\text { Horas Médicas } \\
\text { Trabalhadas }\end{array}$ & $\begin{array}{l}\text { Produção } \\
N^{0} \text { de Consultas }\end{array}$ & $\begin{array}{l}\text { Gasto } \\
\text { Total RS }\end{array}$ \\
\hline JAN & 73 & 5 & 4 & 3.829 & 8.737 & $128.039,36$ \\
\hline FEV & 79 & 5 & 4 & 3.459 & 7.292 & $115.900,46$ \\
\hline MAR & 76 & 5 & 4 & 3.797 & 8.682 & $126.958,18$ \\
\hline ABR & 76 & 5 & 4 & 3.714 & 9.052 & $124.666,79$ \\
\hline MAI & 78 & 5 & 4 & 3.791 & 9.821 & $126.781,47$ \\
\hline JUN & 70 & 5 & 4 & 3.683 & 10.017 & $117.219,72$ \\
\hline JUL & 74 & 5 & 4 & 3.539 & 8.859 & $119.216,67$ \\
\hline $\mathrm{AGO}$ & 72 & 5 & 4 & 3.409 & 8.227 & $114.652,04$ \\
\hline SET & 76 & 5 & 4 & 3.421 & 8.678 & $115.342,11$ \\
\hline OUT & 75 & 5 & 4 & 3.538 & 9.506 & $119.183,84$ \\
\hline NOV & 76 & 5 & 4 & 3.526 & 8.864 & $128.024,28$ \\
\hline DEZ & 73 & 5 & 4 & 3.552 & 8.448 & $137.974,58$ \\
\hline \multirow{2}{*}{\multicolumn{4}{|c|}{$\begin{array}{l}\text { Total } \\
\text { Média Mensal }\end{array}$}} & 43.258 & 106.183 & $1.473 .959,50$ \\
\hline & & & & 3.605 & 8.849 & $122.829,96$ \\
\hline
\end{tabular}

Fonte: SPP e Coopmed

Tabela 46- Distribuição hora/médica, produção e gasto de Jan a Dez de 2003. Hospital Itaim Paulista

\begin{tabular}{|c|c|c|c|c|c|c|}
\hline Meses & $\begin{array}{l}N^{0} \text { de Médicos } \\
\text { Plantonistas }\end{array}$ & Dia & Noite & $\begin{array}{l}\text { Horas Médicas } \\
\text { Trabalhadas }\end{array}$ & $\begin{array}{l}\text { Produção } \\
N^{0} \text { de Consultas }\end{array}$ & $\begin{array}{l}\text { Gasto } \\
\text { Total RS }\end{array}$ \\
\hline JAN & 40 & 4 & 3 & 2.940 & 8.207 & $90.394,03$ \\
\hline FEV & 40 & 4 & 3 & 2.940 & 8.662 & $90.394,03$ \\
\hline MAR & 40 & 4 & 3 & 2.940 & 9.984 & $90.394,03$ \\
\hline$A B R$ & 40 & 4 & 3 & 2.940 & 10.102 & $90.394,03$ \\
\hline MAI & 40 & 4 & 3 & 2.940 & 9.998 & $97.146,15$ \\
\hline JUN & 41 & 4 & 3 & 2.940 & 10.532 & $97.146,15$ \\
\hline JUL & 41 & 4 & 3 & 2.940 & 9.537 & $97.146,15$ \\
\hline $\mathrm{AGO}$ & 41 & 4 & 3 & 2.940 & 9.147 & $97.146,15$ \\
\hline SET & 44 & 4 & 3 & 2.940 & 9.170 & $97.146,15$ \\
\hline OUT & 38 & 4 & 3 & 2.940 & 9.396 & $102.716,65$ \\
\hline NOV & 39 & 4 & 3 & 2.940 & 9.071 & $102.716,65$ \\
\hline DEZ & 41 & 4 & 3 & 2.940 & 9.296 & $102.716,65$ \\
\hline $\begin{array}{l}\text { Total } \\
\text { Média }\end{array}$ & Mensal & & & $\begin{array}{c}35.280 \\
2.940 \\
\end{array}$ & $\begin{array}{c}113.102 \\
9.425 \\
\end{array}$ & $\begin{array}{c}1.155 .456,82 \\
96.288,07 \\
\end{array}$ \\
\hline
\end{tabular}

Fonte: SPP e DP. 
O Hospital Pedreira gastou R\$ 13,68 com honorários médicos para cada consulta. E o Hospital Itaim Paulista gastou R\$ 10,21.

As tabelas 47 e 48 mostram que uma consulta na clínica médica do Hospital Pedreira é realizada em aproximadamente 24 minutos, enquanto no Hospital Itaim Paulista é realizada em 19 minutos. O valor gasto por hora médica no Hospital Itaim Paulista é inferior ao Hospital Pedreira.

Tabela 47- Relação entre consultas e horas médicas de Jan a dez de 2003. Hospital Pedreira

\begin{tabular}{lcc}
\hline Meses & Consultas/ Hora médica & Consultas/ Hora médica \\
\hline JAN & 2,28 & 2,79 \\
FEV & 2,11 & 2,95 \\
MAR & 2,29 & 3,40 \\
ABR & 2,44 & 3,44 \\
MAI & 2,59 & 3,40 \\
JUN & 2,72 & 3,58 \\
JUL & 2,50 & 3,24 \\
AGO & 2,41 & 3,11 \\
SET & 2,54 & 3,12 \\
OUT & 2,69 & 3,20 \\
NOV & 2,51 & 3,09 \\
DEZ & 2,38 & 3,16 \\
Total & & \\
Média Mensal & $\mathbf{2 , 4 5}$ & $\mathbf{3 , 1 0}$ \\
\hline
\end{tabular}

Fonte: SPP Coopmed e DP.

Tabela 48- Relação entre valor gasto e horas médicas de Jan a dez de 2003. Hospital Pedreira Hospital Itaim Paulista

\begin{tabular}{lcc} 
Meses & Valor gasto/ Horas médicas & Valor gasto/ Horas médicas \\
\hline JAN & 33,44 & 30,75 \\
FEV & 33,51 & 30,75 \\
MAR & 33,44 & 30,75 \\
ABR & 33,57 & 30,75 \\
MAI & 33,44 & 33,04 \\
JUN & 31,83 & 33,04 \\
JUL & 33,69 & 33,04 \\
AGO & 33,63 & 33,04 \\
SET & 33,72 & 33,04 \\
OUT & 33,69 & 34,94 \\
NOV & 36,31 & 34,94 \\
DEZ & 38,84 & 34,94 \\
Total & & \\
Média Mensal & $\mathbf{3 4 , 0 9}$ & $\mathbf{3 2 , 7 5}$ \\
\hline
\end{tabular}

Fonte: Coopmed e DP 


\section{Clínica Cirúrgica- Pronto Socorro}

As tabelas 49 e 50 mostram que o Hospital Pedreira em relação ao Hospital Itaim Paulista apresentou número de horas trabalhadas $12 \%$ inferior, produção $16 \%$ inferior e valor gasto total $3 \%$ superior.

Tabela 49- Distribuição hora/médica, produção e gasto de Jan a Dez de 2003. Hospital Pedreira

\begin{tabular}{lcccccc}
\hline Meses & $\begin{array}{c}\text { Número de } \\
\text { Médicos } \\
\text { Plantonistas }\end{array}$ & Dia & Noite & $\begin{array}{c}\text { Horas Médica } \\
\text { Trabalhadas }\end{array}$ & $\begin{array}{l}\text { Produção } \\
\mathbf{N}^{\circ} \text { de } \\
\text { Consultas }\end{array}$ & $\begin{array}{l}\text { Gasto } \\
\text { Total Rs }\end{array}$ \\
\hline JAN & 34 & 3 & 3 & 2.284 & 2.414 & $83.305,52$ \\
FEV & 28 & 3 & 3 & 2.020 & 2.058 & $74.278,92$ \\
MAR & 30 & 3 & 3 & 2.232 & 2.340 & $81.722,12$ \\
ABR & 31 & 3 & 3 & 2.160 & 2.186 & $79.241,05$ \\
MAI & 30 & 3 & 3 & 2.232 & 1.991 & $85.024,36$ \\
JUN & 30 & 3 & 3 & 2.172 & 2.241 & $83.296,87$ \\
JUL & 30 & 3 & 3 & 2.332 & 1.986 & $85.266,98$ \\
AGO & 32 & 3 & 3 & 2.232 & 1.991 & $85.680,62$ \\
SET & 31 & 3 & 3 & 2.160 & 1.962 & $82.764,97$ \\
OUT & 34 & 3 & 3 & 2.160 & 2.047 & $84.735,08$ \\
NOV & 32 & 3 & 3 & 2.160 & 2.128 & $88.302,12$ \\
DEZ & 31 & 3 & 3 & 2.316 & 2.234 & $97.641,86$ \\
Total & & & & $\mathbf{2 6 . 4 6 0}$ & $\mathbf{2 5 . 5 7 8}$ & $\mathbf{1 . 0 1 1 . 2 6 0 , 4 6}$ \\
Média Mensal & & & & $\mathbf{2 . 2 0 5}$ & $\mathbf{2 . 1 3 2}$ & $\mathbf{8 4 . 2 7 1 , 7 0}$ \\
\hline
\end{tabular}

Fonte: SPP e Coopmed

Tabela 50- Distribuição hora/médica, produção e gasto de Jan a Dez de 2003. Hospital Itaim Paulista

\begin{tabular}{lcccccc}
\hline Meses & $\begin{array}{l}\text { Número de } \\
\text { Médicos } \\
\text { Plantonistas }\end{array}$ & Dia & $\begin{array}{l}\text { Noite } \\
\text { Horas } \\
\text { Médicas } \\
\text { Trabalhadas }\end{array}$ & $\begin{array}{l}\text { Produção } \\
\mathbf{N}^{\circ} \text { de } \\
\text { Consultas }\end{array}$ & $\begin{array}{l}\text { Gasto } \\
\text { Total Rs }\end{array}$ \\
\hline JAN & 35 & 3 & 3 & 2.520 & 1.934 & $77.480,60$ \\
FEV & 35 & 3 & 3 & 2.520 & 1.982 & $77.480,60$ \\
MAR & 35 & 3 & 3 & 2.520 & 1.923 & $77.480,60$ \\
ABR & 35 & 3 & 3 & 2.520 & 1.786 & $77.480,60$ \\
MAI & 35 & 3 & 3 & 2.520 & 1.686 & $83.268,13$ \\
JUN & 39 & 3 & 3 & 2.520 & 1.658 & $83.268,13$ \\
JUL & 37 & 3 & 3 & 2.520 & 1.758 & $83.268,13$ \\
AGO & 38 & 3 & 3 & 2.520 & 1.587 & $83.268,13$ \\
SET & 38 & 3 & 3 & 2.520 & 1.637 & $83.268,13$ \\
OUT & 38 & 3 & 3 & 2.520 & 1.738 & $88.042,84$ \\
NOV & 35 & 3 & 3 & 2.520 & 1.728 & $88.042,84$ \\
DEZ & 34 & 3 & 3 & 2.520 & 2.011 & $88.042,84$ \\
Total & & & & $\mathbf{3 0 . 2 4 0}$ & $\mathbf{2 1 . 4 2 8}$ & $\mathbf{9 9 0 . 3 9 1 , 5 7}$ \\
Média Mensal & & & & $\mathbf{2 . 5 2 0}$ & $\mathbf{1 . 7 8 6}$ & $\mathbf{8 2 . 5 3 2 , 6 3}$ \\
\hline FOnte: &
\end{tabular}

Fonte: SPP e DP. 
O Hospital Pedreira gastou R\$39,53 com honorários médicos para cada consulta. E o Hospital Itaim Paulista gastou R\$ 46,21.

As tabelas 51 e 52 mostram que uma consulta na Clínica Cirúrgica no Hospital Pedreira é realizada em aproximadamente 62 minutos, enquanto que no Hospital Itaim Paulista é realizada em 84 minutos. O valor gasto por hora médica no Hospital Itaim Paulista é inferior ao Hospital Pedreira.

Tabela 51- Relação entre consultas e horas médicas de Jan a dez de 2003. Hospital Pedreira Hospital Itaim Paulista Meses Consultas/Hora médica Consultas/Hora médica

\begin{tabular}{lll}
\hline JAN & 1,06 & 0,77 \\
FEV & 1,02 & 0,79 \\
MAR & 1,05 & 0,76 \\
ABR & 1,01 & 0,71 \\
MAI & 0,89 & 0,67 \\
JUN & 1,03 & 0,66 \\
JUL & 0,85 & 0,70 \\
AGO & 0,89 & 0,63 \\
SET & 0,91 & 0,65 \\
OUT & 0,95 & 0,69 \\
NOV & 0,99 & 0,69 \\
DEZ & 0,96 & 0,69 \\
Total & & \\
Média Mensal & $\mathbf{0 , 9 7}$ & $\mathbf{0 , 7 1}$ \\
\hline
\end{tabular}

Fonte: SPP Coopmed e DP.

Tabela 52- Relação entre valor gasto e horas médicas de Jan a dez de 2003. Hospital Pedreira Meses Valor gasto/Horas médicas Hospital Itaim Paulista JAN 36,47

FEV 36,77

MAR

ABR

36,61

MAI

36,69

JUN

38,09

Valor gasto/Horas médicas

JUL

38,35

30,75

30,75

30,75

30,75

33,04

33,04

36,56

33,04

AGO

38,39

33,04

SET

38,32

33,04

OUT

39,23

34,94

NOV

40,88

34,94

DEZ

42,16

34,94

Total

Média Mensal

38,21

32,75

Fonte: Coopmed e DP 


\section{Clínica Pediátrica- Pronto Socorro}

As tabelas 53 e 54 mostram que o Hospital Pedreira em relação ao Hospital Itaim Paulista apresentou número de horas trabalhadas $18 \%$ inferior, produção $14, \%$ inferior, valor gasto total $12 \%$ superior.

Tabela 53- Distribuição hora/médica, produção e gasto de Jan a Dez de 2003. Hospital Pedreira

\begin{tabular}{lcccccc}
$\begin{array}{l}\text { Meses } \\
\text { Número de } \\
\text { Médicos } \\
\text { Plantonistas }\end{array}$ & Dia & Noite & $\begin{array}{c}\text { Horas } \\
\text { Médicas } \\
\text { Trabalhadas }\end{array}$ & $\begin{array}{c}\text { Produção } \\
\mathbf{N}^{\circ} \text { de } \\
\text { Consultas }\end{array}$ & $\begin{array}{c}\text { Gasto } \\
\text { Total RS }\end{array}$ \\
\hline JAN & 49 & 4 & 3 & 2.652 & 4.256 & $90.230,66$ \\
FEV & 49 & 4 & 3 & 2.352 & 4.333 & $80.380,08$ \\
MAR & 47 & 4 & 3 & 2.657 & 5.774 & $90.394,83$ \\
ABR & 44 & 4 & 3 & 2.495 & 7.741 & $85.075,52$ \\
MAI & 47 & 4 & 3 & 2.653 & 8.425 & $89.081,42$ \\
JUN & 48 & 4 & 3 & 2.582 & 8.048 & $88.417,73$ \\
JUL & 47 & 4 & 3 & 2.664 & 5.246 & $91.314,07$ \\
AGO & 42 & 4 & 3 & 2.652 & 4.752 & $90.782,17$ \\
SET & 47 & 4 & 3 & 2.556 & 5.765 & $87.629,98$ \\
OUT & 42 & 4 & 3 & 2.652 & 6.252 & $90.782,17$ \\
NOV & 46 & 4 & 3 & 2.564 & 5.355 & $94.232,03$ \\
DEZ & 48 & 4 & 3 & 2.652 & 4.674 & $103.919,64$ \\
Total & & & & $\mathbf{3 1 . 1 3 1}$ & $\mathbf{7 0 . 6 2 1}$ & $\mathbf{1 . 0 8 2 . 2 4 0 , 3 1}$ \\
Média Mensal & & & $\mathbf{2 . 5 9 4}$ & $\mathbf{5 . 8 8 5}$ & $\mathbf{9 0 . 1 8 6 , 6 9}$ \\
\hline
\end{tabular}

Fonte: SPP e Coopmed

Tabela 54- Distribuição hora/médica, produção e gasto de Jan a Dez de 2003. Hospital Itaim Paulista

\begin{tabular}{lcccccc}
\hline Meses & $\begin{array}{c}\text { Número de } \\
\text { Médicos } \\
\text { Plantonistas }\end{array}$ & Dia & Noite & $\begin{array}{c}\text { Horas } \\
\text { Médicas } \\
\text { Trabalhadas }\end{array}$ & $\begin{array}{c}\text { Produção } \\
\mathbf{N}^{\circ} \text { de } \\
\text { Consultas }\end{array}$ & $\begin{array}{c}\text { Gasto } \\
\text { Total Rs }\end{array}$ \\
\hline JAN & 41 & 4 & 4 & 3.360 & 5.314 & $103.307,46$ \\
FEV & 41 & 4 & 4 & 3.360 & 5.714 & $103.307,46$ \\
MAR & 41 & 4 & 4 & 3.360 & 7.233 & $103.307,46$ \\
ABR & 41 & 4 & 4 & 3.360 & 8.810 & $103.307,46$ \\
MAI & 41 & 4 & 4 & 3.360 & 8.681 & $111.024,17$ \\
JUN & 41 & 4 & 4 & 3.360 & 8.679 & $111.024,17$ \\
JUL & 37 & 4 & 3 & 2.940 & 6.694 & $97.146,15$ \\
AGO & 37 & 4 & 3 & 2.940 & 5.702 & $97.146,15$ \\
SET & 37 & 4 & 3 & 2.940 & 6.116 & $97.146,15$ \\
OUT & 39 & 4 & 3 & 2.940 & 6.960 & $102.716,65$ \\
NOV & 39 & 4 & 3 & 2.940 & 6.419 & $102.716,65$ \\
DEZ & 41 & 4 & 3 & 2.940 & 5.856 & $102.716,65$ \\
Total & & & & $\mathbf{3 7 . 8 0 0}$ & $\mathbf{8 2 . 1 7 8}$ & $\mathbf{1 . 2 3 4 . 8 6 6 , 5 8}$ \\
Média Mensal & & & & $\mathbf{3 . 1 5 0}$ & $\mathbf{6 . 8 4 8}$ & $\mathbf{1 0 2 . 9 0 5 , 5 5}$ \\
\hline
\end{tabular}

Fonte: SPP e DP. 
O Hospital Pedreira gastou R\$ 15,32 com honorários médicos para cada consulta. E o Hospital Itaim Paulista gastou R\$15,02.

As tabelas 55 e 56 mostram que uma consulta na Clínica Pediátrica no Hospital Pedreira é realizada em aproximadamente 26,43 minutos, enquanto que no Hospital Itaim Paulista é realizada em 27,64 minutos. O valor gasto por hora médica no Hospital Itaim Paulista é inferior ao Hospital Pedreira.

Tabela 55- Relação entre consultas e horas médicas de Jan a dez de 2003. Hospital Pedreira

\begin{tabular}{lrc}
\hline Meses & $\begin{array}{c}\text { Consultas/ } \\
\text { Hora médica }\end{array}$ & $\begin{array}{l}\text { Consultas/ } \\
\text { Hora médica }\end{array}$ \\
\hline JAN & 1,60 & 1,58 \\
FEV & 1,84 & 1,70 \\
MAR & 2,17 & 2,15 \\
ABR & 3,10 & 2,62 \\
MAI & 3,18 & 2,58 \\
JUN & 3,12 & 2,58 \\
JUL & 1,97 & 2,23 \\
AGO & 1,79 & 1,94 \\
SET & 2,26 & 2,08 \\
OUT & 2,36 & 2,37 \\
NOV & 2,09 & 2,18 \\
DEZ & 1,76 & 1,99 \\
Total & & \\
Média Mensal & $\mathbf{2 , 2 7}$ & $\mathbf{2 , 1 7}$
\end{tabular}

Fonte: SPP Coopmed e DP.

Tabela 56-Relação entre valor gasto e horas médicas de Jan a dez de 2003. Hospital Pedreira

\begin{tabular}{lcc}
\hline Meses & $\begin{array}{l}\text { Valor gasto/ } \\
\text { Horas médicas }\end{array}$ & $\begin{array}{l}\text { Valor gasto/ } \\
\text { Horas médicas }\end{array}$ \\
\hline JAN & 34,02 & 30,75 \\
FEV & 34,18 & 30,75 \\
MAR & 34,02 & 30,75 \\
ABR & 34,10 & 30,75 \\
MAI & 33,58 & 33,04 \\
JUN & 34,24 & 33,04 \\
JUL & 34,28 & 33,04 \\
AGO & 34,23 & 33,04 \\
SET & 34,28 & 33,04 \\
OUT & 34,23 & 34,94 \\
NOV & 36,75 & 34,94 \\
DEZ & 39,19 & 34,94 \\
Total & & $\mathbf{3 2 , 7 5}$ \\
Média Mensal & $\mathbf{3 4 , 7 6}$ & \\
\hline
\end{tabular}

Fonte: Coopmed e DP 


\section{Ginecologia e Obstetrícia- Pronto Socorro}

As tabelas 57 e 58 mostram que o Hospital Pedreira em relação ao Hospital Itaim Paulista apresentou número de horas trabalhadas $10 \%$ inferior, produção $9 \%$ inferior, valor gasto total $5 \%$ inferior.

Tabela 57- Distribuição hora/médica, produção e gasto de Jan a Dez de 2003. Hospital Pedreira

\begin{tabular}{lcccccc}
\hline Meses & $\begin{array}{c}\text { Número de } \\
\text { Médicos } \\
\text { Plantonistas }\end{array}$ & Dia & Noite & $\begin{array}{c}\text { Horas } \\
\text { Médicas } \\
\text { Trabalhadas }\end{array}$ & $\begin{array}{c}\text { Produção } \\
\text { No de } \\
\text { Consultas }\end{array}$ & $\begin{array}{c}\text { Gasto } \\
\text { Total Rs }\end{array}$ \\
\hline JAN & 45 & 2 & 2 & 2.832 & 3.035 & $95.393,96$ \\
FEV & 41 & 2 & 2 & 2.016 & 2.466 & $68.600,40$ \\
MAR & 42 & 2 & 2 & 2.232 & 2.820 & $75.692,81$ \\
ABR & 43 & 2 & 2 & 2.160 & 2.582 & $73.328,68$ \\
MAI & 41 & 2 & 2 & 2.232 & 2.559 & $75.997,31$ \\
JUN & 39 & 2 & 2 & 2.160 & 2.590 & $73.328,68$ \\
JUL & 40 & 2 & 2 & 2.232 & 2.548 & $75.692,81$ \\
AGO & 41 & 2 & 2 & 2.232 & 2.612 & $75.692,81$ \\
SET & 40 & 2 & 2 & 2.160 & 2.452 & $73.328,68$ \\
OUT & 36 & 2 & 2 & 2.232 & 2.658 & $75.692,81$ \\
NOV & 41 & 2 & 2 & 2.160 & 2.456 & $78.634,28$ \\
DEZ & 43 & 2 & 2 & 2.604 & 2.365 & $101.928,63$ \\
Total & & & & $\mathbf{2 7 . 2 5 2}$ & $\mathbf{3 1 . 1 4 3}$ & $\mathbf{9 4 3 . 3 1 1 , 8 7}$ \\
Média Mensal & & & & $\mathbf{2 . 2 7 1}$ & $\mathbf{2 . 5 9 5}$ & $\mathbf{7 8 . 6 0 9 , 3 2}$ \\
\hline
\end{tabular}

Fonte: SPP e Coopmed

Tabela 58- Distribuição hora/médica, produção e gasto de Jan a Dez de 2003. Hospital Itaim Paulista

\begin{tabular}{lcccccc}
\hline Meses & $\begin{array}{c}\text { Número de } \\
\text { Médicos } \\
\text { Plantonistas }\end{array}$ & Dia & Noite & $\begin{array}{c}\text { Horas } \\
\text { Médicas } \\
\text { Trabalhadas }\end{array}$ & $\begin{array}{c}\text { Produção } \\
\text { Node } \\
\text { Consultas }\end{array}$ & $\begin{array}{c}\text { Gasto } \\
\text { Total RS }\end{array}$ \\
\hline JAN & 33 & 3 & 3 & 2.520 & 3.038 & $77.480,60$ \\
FEV & 33 & 3 & 3 & 2.520 & 2.788 & $77.480,60$ \\
MAR & 33 & 3 & 3 & 2.520 & 3.103 & $77.480,60$ \\
ABR & 33 & 3 & 3 & 2.520 & 2.938 & $77.480,60$ \\
MAI & 32 & 3 & 3 & 2.520 & 2.829 & $83.268,13$ \\
JUN & 32 & 3 & 3 & 2.520 & 2.818 & $83.268,13$ \\
JUL & 32 & 3 & 3 & 2.520 & 2.911 & $83.268,13$ \\
AGO & 32 & 3 & 3 & 2.520 & 2.766 & $83.268,13$ \\
SET & 32 & 3 & 3 & 2.520 & 2.659 & $83.268,13$ \\
OUT & 31 & 3 & 3 & 2.520 & 2.859 & $88.042,84$ \\
NOV & 34 & 3 & 3 & 2.520 & 2.707 & $88.042,84$ \\
DEZ & 33 & 3 & 3 & 2.520 & 2.722 & $88.042,84$ \\
Total & & & & $\mathbf{3 0 . 2 4 0}$ & $\mathbf{3 4 . 1 3 8}$ & $\mathbf{9 9 0 . 3 9 1 , 5 7}$ \\
Média Mensal & & & & $\mathbf{2 . 5 2 0}$ & $\mathbf{2 . 8 4 5}$ & $\mathbf{8 2 . 5 3 2 , 6 3}$ \\
\hline
\end{tabular}

Fonte: SPP e DP. 
O Hospital Pedreira gastou R\$ 30,29 com honorários médicos para cada consulta. E o Hospital Itaim Paulista gastou R\$29,01.

As tabelas 59 e 60 mostram que uma consulta na Ginecologia e Obstetrícia no Hospital Pedreira é realizada em aproximadamente 52 minutos, enquanto que no Hospital Itaim Paulista é realizada em 53 minutos. O valor gasto por hora médica no Hospital Itaim Paulista é inferior ao Hospital Pedreira.

Tabela 59- Relação entre consultas e horas médicas de Jan a dez de 2003.

\begin{tabular}{lcc} 
& Hospital Pedreira & Hospital Itaim Paulista \\
\hline Meses & $\begin{array}{c}\text { Consultas/ } \\
\text { Hora médica }\end{array}$ & $\begin{array}{l}\text { Consultas/ } \\
\text { Hora médica }\end{array}$ \\
\hline JAN & 1,07 & 1,21 \\
FEV & 1,22 & 1,11 \\
MAR & 1,26 & 1,23 \\
ABR & 1,20 & 1,17 \\
MAI & 1,15 & 1,12 \\
JUN & 1,20 & 1,12 \\
JUL & 1,11 & 1,16 \\
AGO & 1,17 & 1,10 \\
SET & 1,14 & 1,06 \\
OUT & 1,19 & 1,13 \\
NOV & 1,14 & 1,07 \\
DEZ & 0,91 & 1,08 \\
Total & & 1,13 \\
Média Mensal & $\mathbf{1 , 1 5}$ &
\end{tabular}

Fonte: SPP Coopmed e DP.

Tabela 60- Relação entre valor gasto e horas médicas de Jan a dez de 2003. Hospital Pedreira

\begin{tabular}{lcc}
\hline Meses & $\begin{array}{c}\text { Valor gasto/ } \\
\text { Horas médicas }\end{array}$ & $\begin{array}{l}\text { Valor gasto/ } \\
\text { Horas médicas }\end{array}$ \\
\hline JAN & 33,68 & 30,75 \\
FEV & 34,03 & 30,75 \\
MAR & 33,91 & 30,75 \\
ABR & 33,95 & 30,75 \\
MAI & 34,05 & 33,04 \\
JUN & 33,95 & 33,04 \\
JUL & 33,91 & 33,04 \\
AGO & 33,91 & 33,04 \\
SET & 33,95 & 33,04 \\
OUT & 33,91 & 34,94 \\
NOV & 36,40 & 34,94 \\
DEZ & 39,14 & 34,94 \\
Total & & \\
Média Mensal & $\mathbf{3 4 , 5 7}$ & $\mathbf{3 2 , 7 5}$ \\
\hline
\end{tabular}

Fonte: Coopmed e DP 
Tabela 61- Dados sintéticos da relação hora médica-produção-gasto.

Hospital Pedreira

Hospital Itaim Paulista

Pronto Socorro

$\mathbf{N}^{\circ}$ de médicos

Clínica Médica

Clínica Cirúrgica

5 dia/4noite

$4 \mathrm{dia} / 3$ noite

Clínica Pediátrica

3 dia/3 noite

$4 \mathrm{dia} / 3$ noite

$3 \mathrm{dia} / 3$ noite

Ginecologia e Obstetrícia

2 dia/2 noite

$4 \mathrm{dia} / 3$ noite

$\mathbf{N}^{\circ}$ de horas trabalhadas

Clínica Médica

43.258

$3 \mathrm{dia} / 3$ noite

Clínica Cirúrgica

26.460

35.280

31.131

30.240

37.800

27.252

30.240

Ginecologia e Obstetrícia

128.101

133.560

$\mathbf{N}^{\circ}$ de consultas

Clínica Médica

106.183

113.102

Clínica Cirúrgica

25.578

21.428

Clínica Pediátrica

70.621

82.178

Ginecologia e Obstetrícia

31.143

34.138

233.525

250.846

Valor gasto total

Clínica Médica

$1.473 .959,50$

1.155.456,82

1.011.260,46

990.391,57

Clínica Cirúrgica

1.082.240,31

$1.234 .866,58$

943.311,87

$\mathbf{9 9 0 . 3 9 1 , 5 7}$

Ginecologia e Obstetrícia

4.510.772,14

4.371.106,54

Valor médio anual da hora médica

Clínica Médica

34,09

32,75

Clínica Cirúrgica

38,21

32,75

Clínica Pediátrica

34,76

32,75

Gonecologia e Obstetrícia

$\mathbf{3 4 , 5 7}$

32,75

Tempo médio de consulta (minutos)

Clínica Médica

$24 \quad 19$

Clínica Cirúrgica

$62 \quad 84$

Clínica Pediátrica

Ginecologia e Obstetrícia

52

53

Fonte: SPP, DP e Financeiro 
Ambulatório

A tabela 62 mostra que o Hospital Pedreira em relação ao Hospital Itaim Paulista apresentou número de horas trabalhadas $30 \%$ superior, produção $54 \%$ superior, valor gasto total $29,43 \%$ inferior.

Tabela 62-Distribuição hora/ médica, produção e gasto de jan a dez de 2003.

Hospital Pedreira

Hospital Itaim Paulista

\begin{tabular}{lcclccc}
\hline Meses & $\begin{array}{l}\text { Horas } \\
\text { Médicas } \\
\text { Trabalhadas }\end{array}$ & $\begin{array}{l}\text { Produção } \\
\mathbf{N}^{\mathbf{0}} \text { de } \\
\text { Consultas }\end{array}$ & $\begin{array}{l}\text { Gasto } \\
\text { Total R\$ }\end{array}$ & $\begin{array}{l}\text { Horas } \\
\text { Médicas } \\
\text { Trabalhadas }\end{array}$ & $\begin{array}{l}\text { Produção } \\
\mathbf{N}^{\mathbf{0}} \text { de } \\
\text { Consultas }\end{array}$ & $\begin{array}{l}\text { Gasto } \\
\text { Total RS }\end{array}$ \\
\hline JAN & 2.140 & 5.634 & $67.603,06$ & 2.925 & 2.559 & $95.600,87$ \\
FEV & 2.104 & 5.700 & $67.225,48$ & 2.925 & 2.166 & $95.600,87$ \\
MAR & 1.960 & 4.998 & $62.623,47$ & 2.925 & 1.979 & $95.600,87$ \\
ABR & 2.080 & 5.361 & $66.763,66$ & 2.925 & 2.359 & $95.600,87$ \\
MAI & 2.164 & 5.640 & $69.919,29$ & 2.925 & 2.347 & $95.600,87$ \\
JUN & 1.808 & 4.938 & $58.547,23$ & 3.050 & 2.226 & $99.686,38$ \\
JUL & 2.048 & 4.894 & $71.642,29$ & 2.875 & 2.553 & $93.966,67$ \\
AGO & 1.932 & 5.232 & $67.721,65$ & 2.875 & 2.746 & $93.966,67$ \\
SET & 1.920 & 5.549 & $67.850,90$ & 2.755 & 2.539 & $90.044,58$ \\
OUT & 2.024 & $\mathbf{5 . 9 5 4}$ & $71.709,12$ & 2.680 & 2.976 & $92.517,27$ \\
NOV & 1.790 & 5.277 & $62.741,20$ & 2.460 & 2.602 & $84.922,57$ \\
DEZ & 1.724 & 4.595 & $60.229,02$ & 2.690 & 2.281 & $92.862,49$ \\
Total & $\mathbf{2 3 . 6 9 4}$ & $\mathbf{6 3 . 7 7 2}$ & $\mathbf{7 9 4 . 5 7 6 , 3 8}$ & $\mathbf{3 4 . 0 1 0}$ & $\mathbf{2 9 . 3 3 3}$ & $\mathbf{1 . 1 2 5 . 9 7 0 , 9 8}$ \\
Média Mensa & $\mathbf{1 . 9 7 5}$ & $\mathbf{5 . 3 1 4}$ & $\mathbf{6 6 . 2 1 4 , 7 0}$ & $\mathbf{2 . 8 3 4}$ & $\mathbf{2 . 4 4 4}$ & $\mathbf{9 3 . 8 3 0 , 9 2}$ \\
\hline
\end{tabular}

Fonte: SPP, Coopmed e DP. 
Uma consulta ambulatorial no Hospital Pedreira é realizada em aproximadamente 22 minutos, enquanto que no Hospital Itaim Paulista é realizada em 69 minutos. O valor gasto por hora médica no Hospital Itaim Paulista é bem próximo ao do Hospital Pedreira, conforme tabelas 63 e 64 .

Tabela 63- Relação entre consultas e horas médicas de Jan a dez de 2003.

Hospital Pedreira

\begin{tabular}{lcc}
\hline Meses & Consultas/ Hora médica & Consultas/ Hora médica \\
\hline JAN & 2,63 & 0,87 \\
FEV & 2,71 & 0,74 \\
MAR & 2,55 & 0,68 \\
ABR & 2,58 & 0,81 \\
MAI & 2,61 & 0,80 \\
JUN & 2,73 & 0,73 \\
JUL & 2,39 & 0,89 \\
AGO & 2,71 & 0,96 \\
SET & 2,89 & 0,92 \\
OUT & 2,94 & 1,11 \\
NOV & 2,95 & 1,06 \\
DEZ & 2,67 & 0,85 \\
Total & & \\
Média Mensal & $\mathbf{2 , 7 0}$ & $\mathbf{0 , 8 7}$ \\
\hline
\end{tabular}

Fonte: SPP Coopmed e DP.

Tabela 64- Relação entre valor gasto e horas médicas de Jan a dez de 2003. Hospital Pedreira

\begin{tabular}{lcc} 
Meses & $\begin{array}{c}\text { Valor gasto/ } \\
\text { Horas médicas }\end{array}$ & $\begin{array}{l}\text { Valor gasto/ } \\
\text { Horas médicas }\end{array}$ \\
\hline JAN & 31,59 & 32,68 \\
FEV & 31,95 & 32,68 \\
MAR & 31,95 & 32,68 \\
ABR & 32,10 & 32,68 \\
MAI & 32,31 & 32,68 \\
JUN & 32,38 & 32,68 \\
JUL & 34,98 & 32,68 \\
AGO & 35,05 & 32,68 \\
SET & 35,34 & 32,68 \\
OUT & 35,43 & 34,52 \\
NOV & 35,05 & 34,52 \\
DEZ & 34,94 & 34,52 \\
Total & & \\
Média Mensal & $\mathbf{3 3 , 5 9}$ & $\mathbf{3 3 , 1 4}$ \\
\hline
\end{tabular}

Fonte: Coopmed e DP

\section{Hospital Itaim Paulista}

(1)

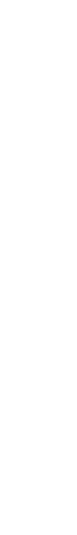




\subsection{4-Ortopedia - Unidade de Internação}

As tabelas 65 e 66 mostram que o Hospital Pedreira em relação ao Hospital Itaim Paulista apresentou número de horas trabalhadas $28 \%$ superior e produção $27 \%$ superior. O diarista do Hospital Itaim Paulista faz um horário intermediário cobrindo parte do período da manhã e parte do periodo da tarde.

Tabela 65- Distribuição hora/médica e produção de jan a dez de 2003. Hospital Pedreira

\begin{tabular}{lccccc}
\multicolumn{2}{l}{$\begin{array}{c}\text { Meses } \\
\text { N } \\
\text { Diaristas }\end{array}$} & Médicos Manhã Tarde & $\begin{array}{c}\text { Horas Médica } \\
\text { Trabalhadas }\end{array}$ & $\begin{array}{c}\text { Produçã } \\
\text { Pacientes saídos }\end{array}$ \\
\hline JAN & 1 & 1 & 0 & 88 & 91 \\
FEV & 1 & 1 & 0 & 80 & 77 \\
MAR & 1 & 1 & 0 & 76 & 91 \\
ABR & 1 & 1 & 0 & 80 & 73 \\
MAI & 1 & 1 & 0 & 84 & 88 \\
JUN & 1 & 1 & 0 & 80 & 82 \\
JUL & 1 & 1 & 0 & 92 & 104 \\
AGO & 1 & 1 & 0 & 84 & 109 \\
SET & 1 & 1 & 0 & 88 & 85 \\
OUT & 1 & 1 & 0 & 84 & 112 \\
NOV & 1 & 1 & 0 & 80 & 114 \\
DEZ & 1 & 1 & 0 & 84 & 93 \\
Total & & & & $\mathbf{1 . 0 0 0}$ & $\mathbf{1 . 1 1 9}$ \\
Média Mensal & & & $\mathbf{8 3}$ & $\mathbf{9 3}$ \\
\hline
\end{tabular}

Fonte: SPP e Financeiro.

Tabela 66- Distribuição hora/médica, produção e gasto no de jan a dez de 2003.

Hospital Itaim Paulista

\begin{tabular}{lccccc}
\multicolumn{2}{l}{$\begin{array}{l}\text { Meses No } \\
\text { Niaristas } \\
\text { Diádicos }\end{array}$} & Manhã Tarde & $\begin{array}{c}\text { Horas Médicas } \\
\text { Trabalhadas }\end{array}$ & $\begin{array}{c}\text { Produção } \\
\text { Pacientes saídos }\end{array}$ \\
\hline JAN & 1 & 1 & 1 & 60 & 69 \\
FEV & 1 & 1 & 1 & 60 & 66 \\
MAR & 1 & 1 & 1 & 60 & 70 \\
ABR & 1 & 1 & 1 & 60 & 61 \\
MAI & 1 & 1 & 1 & 60 & 78 \\
JUN & 1 & 1 & 1 & 60 & 85 \\
JUL & 1 & 1 & 1 & 60 & 63 \\
AGO & 1 & 1 & 1 & 60 & 65 \\
SET & 1 & 1 & 1 & 60 & 70 \\
OUT & 1 & 1 & 1 & 60 & 63 \\
NOV & 1 & 1 & 1 & 60 & 50 \\
DEZ & 1 & 1 & 1 & 60 & 76 \\
Total & & & & $\mathbf{7 2 0}$ & $\mathbf{8 1 6}$ \\
Média Mensal & & & $\mathbf{6 0}$ & $\mathbf{6 8}$ \\
\hline
\end{tabular}

Fonte: SPP e DP 
As tabelas 67 e 68 mostram que o Hospital Pedreira em relação ao Hospital Itaim Paulista apresentou número de horas trabalhadas $42 \%$ inferior e produção $2 \%$ inferior.

Tabela 67. Distribuiça o hora/médica e produçăo de jan a dez de 2003 .

Hospital Pedreira

\begin{tabular}{llllll}
\hline & $\begin{array}{c}\text { Médicos } \\
\text { Plantonistas }\end{array}$ & & & $\begin{array}{l}\text { Médicas } \\
\text { Trabalhadas }\end{array}$ & $\begin{array}{l}\mathbf{N}^{\circ} \text { de } \\
\text { Consultas }\end{array}$ \\
\hline JAN & 16 & 2 & 2 & 1.488 & 3.623 \\
FEV & 16 & 2 & 2 & 1.344 & 3.292 \\
MAR & 16 & 2 & 2 & 1.488 & 3.763 \\
ABR & 16 & 2 & 2 & 1.440 & 3.382 \\
MAl & 16 & 2 & 2 & 1.488 & 3.277 \\
JUN & 16 & 2 & 2 & 1.440 & 3.338 \\
JUL & 16 & 2 & 2 & 1.488 & 3.312 \\
AGO & 16 & 2 & 2 & 1.488 & 3.215 \\
SET & 16 & 2 & 2 & 1.440 & 3.462 \\
OUT & 16 & 2 & 2 & 1.488 & 3.921 \\
NOV & 16 & 2 & 2 & 1.440 & 3.451 \\
DEZ & 16 & 2 & 2 & 1.488 & 3.210 \\
Total & & & & $\mathbf{1 7 . 5 2 0}$ & $\mathbf{4 1 . 2 4 6}$ \\
Média Mensal & & & & $\mathbf{1 . 4 6 0}$ & $\mathbf{3 . 4 3 7}$ \\
\hline
\end{tabular}

Fonte: SPP e Fianceiro.

Tabela 68-Distribuiçăo hora/médica e produção de jan a dez de 2003 .

Hospital Itaim Paulista

\begin{tabular}{|c|c|c|c|c|c|}
\hline Meses & $\begin{array}{l}\text { Númerode } \\
\text { Médicos } \\
\text { Plantonistas }\end{array}$ & Dia & Noite & $\begin{array}{l}\text { Horas } \\
\text { Médicas } \\
\text { Trabalhadas }\end{array}$ & $\begin{array}{l}\text { Producăo } \\
N^{\circ} \text { de } \\
\text { Consultas }\end{array}$ \\
\hline JAN & 26 & 4 & 2 & 2.520 & 3.463 \\
\hline FEV & 26 & 4 & 2 & 2.520 & 3.580 \\
\hline M A R & 26 & 4 & 2 & 2.520 & 3.689 \\
\hline A BR & 26 & 4 & 2 & 2.520 & 3.477 \\
\hline M A I & 26 & 4 & 2 & 2.520 & 3.368 \\
\hline JUN & 26 & 4 & 2 & 2.520 & 3.370 \\
\hline JUL & 26 & 4 & 2 & 2.520 & 3.141 \\
\hline $\mathrm{AGO}$ & 26 & 4 & 2 & 2.520 & 3.307 \\
\hline SET & 26 & 4 & 2 & 2.520 & 3.573 \\
\hline OUT & 25 & 4 & 2 & 2.520 & 3.834 \\
\hline NOV & 25 & 4 & 2 & 2.520 & 3.650 \\
\hline DEZ & 25 & 4 & 2 & 2.520 & 3.648 \\
\hline \multirow{2}{*}{\multicolumn{4}{|c|}{$\begin{array}{l}\text { Total } \\
\text { Média Mensal }\end{array}$}} & 30.240 & 42.100 \\
\hline & & & & 2.520 & 3.508 \\
\hline
\end{tabular}


Uma consulta no Hospital Pedreira é realizada em aproximadamente 25 minutos, enquanto no Hospital Itaim Paulista é realizada em 43 minutos, conforme tabela 67 .

Tabela 69 -Relação entre consultas e horas médicas de jan a dez de 2003.

\begin{tabular}{lcc} 
& Hospital Pedreira & Hospital Itaim Paulista \\
\hline & $\begin{array}{c}\text { número de consultas/ } \\
\text { Número de horas médicas } \\
\text { Trabalhadas }\end{array}$ & $\begin{array}{c}\text { número de consultas/ } \\
\text { Número de horas médicas } \\
\text { Trabalhadas }\end{array}$ \\
\hline JAN & 2,43 & 1,37 \\
FEV & 2,45 & 1,42 \\
MAR & 2,53 & 1,42 \\
ABR & 2,35 & 1,46 \\
MAI & 2,20 & 1,38 \\
JUN & 2,32 & 1,34 \\
JUL & 2,23 & 1,34 \\
AGO & 2,16 & 1,25 \\
SET & 2,40 & 1,31 \\
OUT & 2,64 & 1,42 \\
NOV & 2,40 & 1,52 \\
DEZ & 2,16 & 1,45 \\
Total & & \\
Média Mensal & $\mathbf{2 , 3 6}$ & $\mathbf{1 , 3 9}$ \\
\hline Fonte: SPP, Finan
\end{tabular}

Fonte: SPP, Financeiro e DP.

A tabela 70 traz os dados gerais dos Hospitais Pedreira e Itaim Paulista em relação a hora médica-produção-gasto da ortopedia.

Tabela 70- Dados gerais da relação hora médica-produção-gasto.

\begin{tabular}{lcc} 
Ortopedia & Hospital Pedreira & Hospital Itaim Paulista \\
\hline Unidade de Internação & & 1 \\
N úmero de médicos diaristas & 1 & 720 \\
N úmero de horas trabalhadas & 1.000 & 816 \\
Número de pacientes saídos & 1.119 & \\
Pronto Socorro & & 4 dia/2noite \\
Número de médicos plantonistas & 2 dia/2 noite & 30240 \\
N úmero de horas trabalhadas & 17520 & 42100 \\
Número de Consultas & 41246 & $43 \mathrm{minutos}$ \\
Tempo médio para cada consulta & $25 \mathrm{minutos}$ & $1.013 .406,92$ \\
\hline
\end{tabular}

Fonte: SPP, Financeiro e DP. 
Após análise da segunda parte do trabalho pôde-se observar que:

Nas unidades de internação o número de horas trabalhadas pelos médicos do Hospital Itaim Paulista, assim como o número de pacientes saídos, foi maior que ao apresentado pelo Hospital Pedreira. O valor gasto foi menor.

Em relação ao valor gasto por hora médica, constatou-se que em todas as especialidades o Hospital Pedreira gastou mais que o hospital Itaim Paulista em algumas especialidades essa diferença é bastante acentuada.

No pronto socorro, O Hospital Pedreira apresentou menor número de horas médicas trabalhadas e consultas atendidas e gasto maior com os médicos em relação ao Hospital Itaim Paulista.

O valor da hora médica, assim como nas unidades de internação também apresenta a mesma diferença entre um hospital e outro.

O tempo médio por consulta apresentou diferença entre os hospitais estudados. Mas, com os dados levantados nesse estudo, não há como inferir em qual desses cenários houve melhor desempenho no atendimento prestado aos pacientes.

No ambulatório a diferença entre os dois hospitais foi muito acentuada. O Hospital Itaim Paulista produziu bem menos, apresentou número de horas médicas trabalhadas superior e gastou mais que o Hospital Pedreira. 


\subsection{6- Formas de Remuneração Médica}

Nas três formas de remuneração encontrada nos Hospitais Pedreira e Itaim Paulista, pôde-se observar que a renda líquida do profissional médico diferencia de acordo com o tipo de vínculo.

Diante desse fato, foi simulado um cenário para o cálculo do valor líquido a ser recebido pelos profissionais médicos contratados por CLT, cooperativa e empresa médica.

\section{Dados para o cálculo:}

Carga horária mês: 120 horas.

Valor da hora: $\mathrm{R} \$ 30,64$.

Total mensal gasto pelo hospital: R\$3.676,80.

Tabela 71- Remuneração líquida por tipo de vínculo.

\begin{tabular}{|c|c|c|c|}
\hline Vínculo & Gasto do Hospital & Descontos & Valor Líquido \\
\hline$\overline{\text { CLT }}$ & R\$ 3.676,80 & R\$ 1.948,74 & R\$ 1.728,06 \\
\hline Cooperativa & R\$ $3.676,80$ & R\$ 817,08 & R\$ $2.859,72$ \\
\hline Pessoa Jurídica & R\$ $\mathbf{3 . 6 7 6 , 8 0}$ & $\begin{array}{l}\text { R\$ 441,22 } \\
\text { R } \$ 551,52\end{array}$ & $\begin{array}{l}\text { R\$ 3.235,58 } \\
\text { R\$ 3.125,28 }\end{array}$ \\
\hline
\end{tabular}

Fonte:DP, Coopmed e Financeiro

Pelo exposto, pôde-se observar que o médico contratado por CLT é o que tem o salário menor, devido aos encargos trabalhistas que o hospital tem que arcar e pelos descontos realizados em folha de 
pagamento como previdência social e imposto de renda. Em compensação, ele tem todas as garantias já expostas nesse estudo, no capítulo que trata das formas de contratação médica.

O profissional médico contratado pela cooperativa médica recebe valor líquido mediano. E nesta situação sofre descontos de INSS, IR e taxa administrativa. Apesar de ter um salário superior ao do médico celetista, não dispõe das garantias previstas pela CLT.

O médico contratado através de empresa médica é o que tem a renda líquida maior, à ele caberá desconto entre $12 \%$ e $15 \%$ para tributos e despesas administrativas da empresa médica. Além disso,como pessoa física, fica isento de pagar mais imposto de renda no momento da declaração e também não dispõe das garantias trabalhistas previstas pela CLT. 


\subsection{7-A Percepção dos Diretores Clínicos e Administrativos}

Os quatro diretores responderam aos questionários (anexo1) e suas respostas desses dirigentes demonstraram as razões que levaram cada hospital a ter optado pelo tipo de vínculo médico, como são gerenciados os corpos clínicos, vantagens e desvantagens encontradas na forma jurídica de contratação escolhida pelo hospital.

\section{- Hospital Itaim Paulista- CLT}

O Hospital Itaim Paulista trabalha com corpo clínico próprio, conforme política aplicada pela Congregação Santa Marcelina.

Os médicos do hospital são selecionados e recrutados pelos coordenadores de cada especialidade e aprovados pelos diretores clínico e técnico. O critério para seleção é ter residência na especialidade, ser credenciado no CRM e ter título se for possível. A integração é realizada pelo setor de Recursos Humanos.

Segundo Sr. Sidnei, diretor administrativo, existe dificuldade em contratar médicos, pelo fato do hospital de estar localizado no extremo leste de São Paulo e a maioria dos médicos preferirem trabalhar mais próximo ao Centro. E em função disso, buscam profissionais nos municípios vizinhos.

Os médicos plantonistas e diaristas se reportam aos encarregados e coordenadores conforme descriminado a seguir: 
- Ginecologia e Obstetrícia: há um coordenador e dois encarregados.

- Clínica: há um coordenador que supervisiona também o Banco de Sangue e o Serviço de Controle de Infeç̧ão Hospitalar e dois encarregados, sendo um para UTI adulto e outro para o pronto Socorro.

- Pediatria: há um coordenador e dois encarregados, um para o pronto Socorro e outro para a Unidade Neonatal.

- Cirurgia: há um encarregado e um coordenador que supervisiona todas as especialidades cirúrgicas - infantil, urologia, geral e vascular.

- Saúde Mental: há um coordenador que supervisiona pronto socorro, ambulatório e enfermaria.

- Anestesia: há um encarregado.

As equipes médicas se reúnem para discutir casos clínicos uma vez ao mês, há reuniões quinzenais entre a administração e os coordenadores médicos para discussão de situações do cotidiano. Nesses encontros a administração orienta sobre os caminhos a seguir, sem interferir na conduta ética e profissional de cada especialidade.

As metas do contrato de gestão, são acompanhadas pelos coordenadores que recebem, diariamente, os índices de produtividade de sua clínica. 
A avaliação de desempenho do corpo clínico é realizada através das metas e objetivos colocados anualmente. A obstetrícia informa mensalmente, cada profissional sobre seu desempenho.

A ginecologia e obstetrícia e o serviço de controle de infecção hospitalar possuem protocolos médicos, sendo que os demais estão em fase de elaboração.

Os médicos participam das seguintes comissões:

- Comissão de prontuário;

- Comissão de Ética Médica;

- Comissão de Ética em Pesquisa;

- Comissão de Controle de Infecção Hospitalar,

- Comissão de Humanização;

- Comissão de Óbitos;

- Comitê de Mortalidade Materna; e

- Comissão de Acreditação.

Em relação aos programas de qualidade há participação de dois médicos na comissão de Acreditação.

Durante as férias ou licenças dos profissionais médicos, os coordenadores ou encarregados tentam substituir o colega por um profissional da equipe, caso isto não seja possível, contrata-se um profissional por tempo determinado. 
Segundo a Irmã Monique, diretora clínica, as vantagens de se ter o médico próprio é a possibilidade dele se identificar mais com a proposta da instituição. Também são melhores o gerenciamento e acompanhamento. A desvantagem é o médico se acomodar ou criar situações que o leve a ser demitido, já que assim, haveria possibilidade de receber verbas rescisórias.

\section{- Hospital Pedreira-Cooperativa e Empresa Jurídica Médica}

O Hospital Pedreira adotou a mesma linha de administração do Hospital Santa Catarina que também é pertencente à Associação Congregação de Santa Catarina, no momento de escolher o vínculo empregatício do corpo clínico.

O processo inicial de seleção das equipes em 1998 se deu com a divulgação em jornais de grande circulação de São Paulo, onde era solicitado às equipes interessadas propostas de cunho técnico e financeiro. O hospital recebeu muitas propostas e fez a seleção pensando principalmente na qualidade técnica dos profissionais.

As equipes foram montadas de forma gradativa. A partir de junho de 1998 iniciou atendimento ambulatorial nas especialidades de clínica médica, pediatria e ginecologia e obstetrícia. A partir de dezembro de 1998 começaram às internações de pacientes referenciados de outros locais, pois só em maio de 1999 foi inaugurado o pronto socorro e em julho de 1999, todas as equipes 
médicas estavam montadas. Essas equipes foram formadas por profissionais procedentes de escolas como Santa Casa, Hospital das Clínicas e UNIFESP.

Em fevereiro de 2001, as equipes de clínica médica, pediatria, cirurgia, ginecologia e obstetrícia e UTI adulto passaram de empresas jurídicas para cooperativa médica. Só a ortopedia e anestesiologia continuaram como empresas jurídicas.

Segundo Sr. Fábio Tadeo Teixeira, diretor administrativo do Hospital Pedreira, as principais razões que levaram a essa forma de contratação foram:

- Facilidade e flexibilidade na contratação de profissionais médicos, reduzindo todo o processo burocrático que envolve a contratação através de CLT;

- Possibilidade de proporcionar ao profissional melhor rendimento líquido, sem aumentar os custos com pagamento de pessoal;

- Reduzir o passivo trabalhista na eventualidade da rescisão contratual entre Entidade Gestora do Hospital e Secretaria de Saúde do Estado.

"O Hospital formaliza a contratação das equipes através de contrato. As quatro grandes clínicas, ou seja, médica, cirúrgica, pediátrica e obstetricia estão sob a égide da cooperativa e estas por sua vez, possuem coordenadores. A grande maioria das especialidades de retaguarda ou eletivas, são formalizadas através de contrato com 
pessoas juridicas. Mês a mês são definidas as flutuações de atendimento e o corpo de profissionais médicos oscila conforme a demanda. Esta flexibilidade é o grande diferencial em relação ao corpo clinico contratado". Afirma, Teixeira.

Os médicos podem ser remunerados por horas trabalhadas ou por produção. A quantidade de horas e o valor a ser pago aos médicos são registrados em planilhas e enviados à cooperativa que recebe do hospital e repassa para os seus cooperados. Todo o processo de pagamento e informes de rendimento é elaborado pela própria cooperativa. As pessoas juridicas geralmente são remuneradas por produção, ou seja, recebem um valor para determinado volume de procedimento pré-estabelecidos.

$\mathrm{Na}$ admissão, a cooperativa envia profissionais devidamente cadastrados no CRM-Conselho Regional de Medicina que tenham residência médica na área específica. Esse profissional é avalizado pelo coordenador médico da área e diretores clínico e técnico.

As equipes médicas participam mensalmente de uma reunião científica e há uma reunião bimensal do Conselho Técnico do hospital.

Os protocolos médicos já existem e estão em fase de implantação.

Nos casos de férias ou licenças médicas, o coordenador médico se responsabiliza pela cobertura dos plantões.

Não há avaliação formal do corpo clínico. 
Os médicos participam das seguintes comissões:

- Comissão de Ética Médica;

- Comissão de Ética em Pesquisa;

- Comissão de Mortalidade perinatal e materna;

- Comissão de Controle de Infecção Hospitalar,

- Comissão de Revisão de Prontuário;

- Comissão de Óbitos;

- Comissão de Hemoterapia;

- Comissão de Transplante de Órgão; e

- Núcleo de Qualidade.

Segundo Dra. Ana Lúcia Santoro, diretora clínica, o hospital trabalha o envolvimento dos médicos nos programas de qualidade, principalmente com coordenadores e diaristas em cursos direcionados para este fim e na divulgação dos benefícios que estes programas trazem para o paciente, para o corpo clínico e para a instituição. Participam da elaboração dos protocolos médicos e são estimulados a realizarem reuniões com suas equipes.

"A grande vantagem dessa forma de contratação, é poder oferecer remuneração diferenciada aos colegas, pois o hospital não tem encargos trabalhistas. A desvantagem é a ausência de vinculo, que em alguns casos determina não colaboração ou não envolvimento em alguns processos. Isto ocorre com pouca freqüencia”. Afirma, Santoro. 


\subsection{7-Comparação com a literatura}

- Reforma da administração Pública e Organizações Sociais de Saúde

Foi através do PDRAE, Plano Diretor da Reforma do Aparelho do Estado que surgiram as organizações sociais, onde o Governo transfere as funções de órgãos públicos para entidades da sociedade civil. No Estado de São Paulo as Organizações Sociais de Saúde surgiram em 1998 através da Lei Complementar 846, conforme DOESP 5/6/1998 e o contrato de gestão é o instrumento utilizado para garantir o gerenciamento entre o poder público e a organização social de saúde.

Os dois hospitais escolhidos para o estudo atendem somente pacientes do SUS - Sistema Único de Saúde e atingiram as metas propostas no Contrato de Gestão de 2003, ano em que os dados foram coletados, independentemente da forma jurídica de contratação de serviços médicos.

\section{- Terceirização}

Mesmo o Hospital Itaim Paulista que tem o seu corpo clínico próprio conta com serviços médicos terceirizados nos setores de diagnóstico por imagem, endoscopia e ecocardiograma. O Hospital Pedreira também tem esses serviços terceirizados, além do seu corpo clínico. Os dois hospitais buscam com a terceirização, assim como foi 
apresentado pela HSM Management(2004) racionalizar custo, alcançar maior qualidade e produtividade.

\section{- Formas de Remuneração Médica}

Em relação à cooperativa médica, o Hospital Pedreira se baseou na lei ${ }^{\circ} 8994 / 94$ que introduziu o parágrafo único no art. 442 da CLT frisando que não existe vínculo empregatício entre a cooperativa e seus associados, nem entre estes e os tomadores de serviços daquela, para contratar os profissionais médicos da cooperativa.

Segundo Xavier (2002), o contrato de trabalho na cooperativa é um "contrato realidade", logo não são os contratantes que determinam a existência ou não de um contrato de emprego e sim a existência ou não dos pressupostos do vínculo empregatício como pessoalidade, não eventualidade, remuneração mediante salário, dependência e subordinação.

Ainda citando Xavier (2002), somente pode ser considerado autêntico cooperativismo, aquele calcado nos princípios de adesão livre, gestão democrática, não auferimento de lucro, prestação de serviços aos associados e exercitado com ausência dos pressupostos identificadores da relação de emprego.

A jurisprudência reconhecendo a possibilidade de fraude à legislação trabalhista, onde se evidencia uma relação de caráter empregatício e não societário, afasta a aplicação do art. 442 da CLT. 
Pode-se observar através de ementas tiradas do Tribunal Regional do Trabalho de São Paulo como os juízes vêem essa questão:

"Vinculo de emprego. Médico que tem horário de trabalho, plantões a cumprir em dias certos e é subordinado aos diretores do hospital, é empregado. Presente o elemento subordinação. Vinculo reconhecido".

"Vinculo de emprego. Médico não é empregado, mas sim autônomo, o profissional que pode se fazer substituir por outro em clínica médica. Aonde a pessoalidade não é configurada, não há como presumir a subordinação jurídica".

O hospital que trabalha com médicos cooperados deve seguir as orientações do art. 442 da CLT, evitando assim a possibilidade de processos trabalhistas por parte de médicos reclamando vínculo empregatício.

O Hospital Pedreira conta com dois processos movidos por médicos da cooperativa reclamando vínculo empregatício, que estão em andamento. É um número bastante pequeno, face ao total de médicos que prestaram serviços na instituição.

Além disso, em 2003, houve mudanças na tributação tanto para a cooperativa quanto para trabalhadores autônomos. Na cooperativa até maio eram descontados da folha de pagamento dos médicos por mês, $3 \%$ de taxa de administração e 15 a $27,5 \%$ de imposto de Renda. A partir de maio, passou a ser descontado também $20 \%$ de INSS (hospital filantrópico) até o teto máximo de $\mathrm{R} \$ 205,00$. 
Esse fator fez com que muitos médicos saíssem do hospital, embora não haja registro formal da rotatividade nesse período.

\section{- Responsabilidade Civil Médica}

Filho e Souza (2001) trazem que em relação ao erro médico gerador de responsabilidade civil, o estabelecimento hospitalar responde solidariamente.

Citando Neto(2002), “...os usuários de serviços médicos, mesmo aqueles que provêm de camadas sociais menos afortunadas, principiam a ter uma idéia clara de seus direitos, enquanto pacientes... Vai-se consolidando a clara percepção do erro inescusável, da imperícia inadmissivel, da negligência criminosa, que impelem as pessoas à busca da reparação".

Os dois hospitais estudados relatam casos de processos movidos por pacientes contra médicos. Os hospitais que contratam o serviço do médico, por isso, são responsáveis por sua conduta, independente do tipo de vínculo. 


\section{- Indicadores}

No estudo, o Hospital Pedreira apresentou taxa de ocupação $79,74 \%$ e o Hospital Itaim Paulista $87,88 \%$. Esses dados estão coerentes com a literatura, pois Ibañez e Bittar (2001), encontraram uma taxa de ocupação média de $86,75 \%$, variando entre $77,00 \%$ a $96 \%$ para os hospitais administrados por organizações sociais de saúde.

Em relação à média de permanência, dados de Ibañez e Bittar (2000) relatam uma média de permanência de 5,28 dias, com amplitude entre 4,12 dias e 6,82 dias. O Hospital Pedreira apresentou média de permanência de 5,68 dias, coerente com a literatura, enquanto no Hospital Itaim Paulista a média de permanência foi 9,68 dias, acima do que foi proposto pela literatura.

Nos indicadores de recursos humanos, o número de funcionários por leito encontrado por Ibañez e Bittar(2000) nos hospitais administrados por OSS foi 4,54 funcionários por leito. O Hospital Pedreira apresentou média de 5,8 funcionários por leito, enquanto que - Hospital Itaim Paulista apresentou média de 4,2 funcionários por leito. Mas esse indicador é maior, pois só foram considerados os funcionários próprios e os médicos, os outros funcionários terceirizados não foram inseridos no estudo. 


\section{- Relação hora médica-produção-gasto}

O relatório de pesquisa do PROHASA (2000), define médico diarista como médico que cumpre sua jornada de trabalho em termos diários oferecendo atenção horizontal. E cita os parâmetros da Secretaria do Estado de Saúde para médicos diaristas /leitos.

São preconizados:

- Clínica Médica: um médico para cada dez leitos.

- Clínica Cirúrgica: um médico para cada oito leitos.

- Clínica Pediátrica: um médico para cada dez leitos.

- Ginecologia e Obstetrícia: um médico para cada dez leitos.

O Hospital Pedreira apresentou na clínica médica, um médico para cada dez leitos. Na clínica cirúrgica, idem. Na clínica pediátrica, um médico para cada sete leitos. $\mathrm{Na}$ ginecologia e obstetricia, um médico para quarenta e quatro leitos.

O Hospital Itaim Paulista apresentou na clínica médica, um médico para cada dez leitos. Na clínica cirúrgica, um médico para cada sete leitos. $\mathrm{Na}$ clínica pediátrica, um médico para cada doze leitos. Na ginecologia e obstetrícia, um médico para cada dezoito leitos.

A resolução número 74/96 co Conselho Federal de Medicina, no seu artigo $1^{\circ}$, aponta a necessidade de haver médico capacitado a 
executar manobras de reanimação e suporte vital, presente 24 horas do dia, em todas as unidades de saúde nas quais existem pacientes em regime de internação.

Nos dois hospitais, há cobertura de médicos plantonistas do pronto socorro em caso de intercorrências nas unidades de internação, quando da ausência dos médicos diaristas.

O dimensionamento de médicos do pronto socorro, segundo o relatório de pesquisa do PROHASA segue o seguinte parâmetro: dez minutos para cada consulta. No Hospital Pedreira uma consulta durou em média na clínica médica: vinte e quatro minutos, clínica cirúrgica: sessenta e dois minutos, clínica pediátrica:vinte e seis minutos, na ginecologia e obstetrícia:cinqüenta e dois minutos e na ortopedia:vinte e cinco minutos. Já o Hospital Itaim Paulista,apresentou na clínica médica:dezenove minutos,clínica cirúrgica:oitenta e quatro minutos, clínica pediátrica:vinte e sete minutos, na ginecologia e obstetrícia:cinqüenta e três minutos e na ortopedia:quarenta e três minutos.

Ainda citando o relatório de pesquisa do PROHASA, para o ambulatório, recomenda-se 15 minutos para cada consulta. O Hospital Pedreira apresentou vinte e dois minutos e o Hospital Itaim Paulista sessenta e nove minutos. 


\section{6 - CONCLUSÃo}

Em vista do que foi estudado e verificado, pôde-se concluir que:

O Hospital Itaim Paulista em relação ao Hospital Pedreira apresentou maior número de leitos, internações, saídas e pacientes dia. Assim, como taxa de ocupação e média de permanência superiores.

No que diz respeito à relação hora médica-produção-gasto, o Hospital Pedreira apresentou número de horas trabalhadas inferior ao observado no Hospital Itaim Paulista, mas gasto superior. Em todas as especialidades estudadas o valor da hora médica do Hospital Pedreira foi superior.

O pronto socorro do Hospital Itaim Paulista atendeu mais consultas que o Hospital Pedreira,gastou menos com médicos e também foi observado valor da hora médica inferior.

O ambulatório do Hospital Pedreira apresentou número de consultas $54 \%$ superior, número de horas trabalhadas $30 \%$ superior e valor gasto $29 \%$ inferior em relação ao Hospital Itaim Paulista. Todavia, o valor médio da hora médica desse hospital ainda é inferior ao observado no Hospital Pedreira.

O Hospital Itaim Paulista busca profissionais que se identifiquem com o perfil da instituição. Sua equipe tem uma estrutura hierárquica definida e tem participação atuante nas reuniões, comissões e no processo de gestão. O vínculo trabalhista propicia um melhor gerenciamento e acompanhamento, além de facilitar a 
implantação de normas e padronização de rotinas exigidas pelos processos de certificação, onde podem contar com a atuação de dois profissionais médicos. A instituição avalia o desempenho dos profissionais e estes por terem garantidos seus direitos trabalhistas.

O Hospital Pedreira por ter optado pelo regime de contratação através de cooperativa e empresa médica, não participa do processo seletivo, sendo que, os profissionais que atuam na instituição são encaminhados diretamente pelas empresas contratadas sem que haja uma integração, como a que é feita com os demais funcionários do hospital.

Em virtude da ausência de vínculo empregatício, estes profissionais se reportam diretamente a coordenadores das contratadas e estes à direção do hospital. Seu corpo clínico participa de reuniões e comissões existentes na instituição, porém não estão inseridos nos processos de benefícios, não são avaliados e nem participam de programas de desenvolvimento e treinamento. Há por parte da direção muito cuidado na relação com a cooperativa médica para não caracterizar vínculo empregatício através da pessoalidade, eventualidade, dependência e subordinação.

No início de 2005, a direção do Hospital Pedreira com a intenção de reestruturar seu corpo clínico, objetivando proporcionar aos profissionais médicos maiores benefícios, ampliar as possibilidades de envolvimento no planejamento estratégico da instituição, manter a melhoria contínua dos processos e reduzir a 
rotatividade destes profissionais; sugeriu a mudança de vínculo de cooperativa para CLT ou empresa médica. Estas propostas foram apresentadas, primeiramente, aos médicos do ambulatório. Através de um estudo, onde se evidenciava a perda do rendimento líquido nas contratações por CLT e um ganho nas contratações como empresa médica, a maioria preferiu a segunda opção.

O processo atualmente está em fase de transição e deverá ser estendido para todas as especialidades.

Constatou-se também que o número de horas trabalhadas e a produção do Hospital Itaim Paulista foram superiores ao apurado no Hospital Pedreira; ao passo que o valor gasto foi praticamente igual.

O estudo mostrou que a forma de vínculo não influenciou diretamente na diferença encontrada nos indicadores apresentados nos dois hospitais. Embora, o Hospital Itaim Paulista tenha demonstrado maior facilidade na gestão do seu corpo clínico. 


\section{7 - REFERÊNCIAS BIBLIOGRÁFICAS}

Alcântara, R. H. Responsabilidade Médica. Rio de Janeiro: José Konfino Editores, 1971.

Benjamim, V. H. A. Comentários ao Código do Consumidor. São Paulo. Editora Saraiva. 1991.

Bevilaqua, C. Teoria Geral do Direito Civil. $2^{\mathrm{a}}$ Edição, Rio de Janeiro: Editora Saraiva. 1929.

Bittar, O.J.N.V. Indicadores de qualidade e quantidade em saúde. RAS- Revista de Administração em Saúde. V. 3, nº 12, jul/set 2001.

Bittar, OJNV.,Ibanez, N. Estudo da Terceirização do Corpo Clínico nas OSS/ Itapecerica da Serra e Pedreira. São Paulo: Faculdade de Saúde Pública da USP/Secretaria de Estado da Saúde. 2001.

Bittar, O.J.N.V. Hospital: Qualidade \& Produtividade. São Paulo. Sarvier.1997. 
Blanco, J.M. O cooperativismo, algumas experiências sanitárias. In Sanidad y Cooperativismo. Zaragoza: Cenec, 1983.

Brasil. Ministério da Saúde. Padronização da nomenclatura do censo hospitalarSecretaria de Assistência à Saúde. $2^{a}$ edição. Brasília. 2002.

Brasil. Ministério da administração Federal e Reforma do Estado. Organizações Sociais. Cadernos do MARE de Reforma do Estado. Caderno 2. Brasília. 1997.

Contrato de Gestão. Coordenadoria de Serviços de saúde. Secretaria de estado da Saúde de São Paulo.

CREMESP. Mercado de Trabalho Médico no Estado de São Paulo: Núcleo de Estudos de Saúde Coletiva (Nescon)- Universidade Federal de Minas Gerais, 2002.

CREMESP. Guia de Pessoas Jurídicas na Área Médica. São Paulo. 2003.

Diário Oficial do Estado de São Paulo. 08 de janeiro de 2003. Poder Executivo. Pp 16-30. 
Filho, A.F.C.; Souza, A. P. Responsabilidade Civil Médica e Hospitalar. Belo Horizonte. Editora Del Rey. 2001.

Ferreira, J.H.G. Alianças estratégicas em hospitais provados: Estudo com oito hospitais. São Paulo. 2000. [Dissertação de Doutorado- Faculdade de Saúde Pública da Universidade de São Paulo].

Fradera,V.M.J. A Responsabilidade Civil dos Médicos. AJURIS: Revista da Associação dos Juizes do Rio Grande do Sul. Porto Alegre. 1992 v. 55.

Franceschini, F.; Galetto,M.; Varetto, M. e Pignatelli, A. Como uma empresa pode monitorar e administrar seu terceirizado em todas as etapas que requerem tomada de decisões. In: HSM Management. $N^{\circ}$ 42(1): Jan-Fev 2004.

Gazeta Mercantil 13/05/2003.

Ibañez, N.; Bittar, O.J.N.V.; Perez, M.B.V.; Silva, G.M.; Silva, R. Avaliação das Organizações Sociais de Saúde: Estudo da Gestão de pacientes nos hospitais Pedreira, Itapecerica, Pirajuçara e Itaim . São Paulo: Faculdade de Saúde Pública da USP/ Secretaria de Estado da Saúde, 2001. 
Jornal do Brasil. 06 de março de 1998 - Passo a Passo para a União.Walter Tesch. LTr, Revista vol.61, n¹, novembro de 1997.

Lima, A. Culpa e Risco, São Paulo: Editora RT, 1963.

Linders, J.; Cole, M. e Jacobson, A. Todos os aspectos da implementação da mais ousada forma de terceirização, que passa por estabelecer uma verdadeira parceria e que pode trazer recompensas significativas. Estudo Accenture. In: HSM Management. N $^{\circ}$ 42(1): Jan-Fev 2004.

Nascimento, F. R. Cooperativismo como alternativa de mudança. Rio de Janeiro: Forense. 2000.

Neto, M.K. Responsabilidade Civil do Médico. $5^{\text {a }}$ Edição. São Paulo. Editora Revista dos Tribunais. 2003.

PROAHSA. Relatório de Pesquisa. N ${ }^{\circ}$ 9, 2000.

Romeiro, V.R. Legislação Médica. Pouso Alegre. Editora NUPE.2002. 
Sá,E.N.C, Castro,C.G.J. - Organizações sociais na administração pública. Universidade de São Paulo. Faculdade de Saúde Pública.2000.

Sá, E.N.C, Yamoto, E.K.Avaliação das Organizações Sociais de Saúde: Subprojeto- Estudo do perfil da demanda do Serviço de Pronto Socorro do Hospital Geral de Pedreira: análise da demanda. São Paulo, Faculdade de Saúde Pública da USP/ Secretaria de Estado da Saúde 2000.

Sá, E.N.C, Gomes,M.C.Avaliação das Organizações Sociais de Saúde: Subprojeto- Estudo do perfil da demanda do Serviço de Pronto Socorro do Hospital Geral de Itaim Paulista: análise da demanda. São Paulo, Faculdade de Saúde Pública da USP/ Secretaria de Estado da Saúde 2002.

TANAKA, O.Y., Melo, C. Avaliação de Programas de Saúde do Adolescente. São Paulo.Edusp. 2001.

UNIMED DO BRASIL. Cooperativismo médico: a história e o êxito de um ideal. São Paulo: Cartaz Editorial, 1992.

VAZ. J.C., As Organizações Sociais no Contexto da Reforma do Estado. Debate Organizações Sociais: Público e Privado na Saúde.1998. São Paulo. Pp.11 
Veloso, F.G.; Julio, C. M. G. e José, G. F. D. - Erro Médico $3^{\text {a }}$ Ed. - Editora Edmontes. Montes Claros. 2001.

Xavier, B.A P. A terceirização por intermédio de cooperativa de trabalho. Jus Navugandi, Teresina, a.7, n.61, jan 2003. Disponível em: http:www1.jus.com.Br/doutrina/texto.asp? id=3636. Acesso em: 04 dez 2003.

\section{BIBLIOGRAFIA CONSULTADA}

Bueno, R.L.P. Análise da Eficiência Técnica dos Modelos de Gestão dos Hospitais Públicos do Estado de São Paulo no período de 2000-2001. São Paulo. 2004.[Dissertação de Mestrado - Escola de Administração de Empresas de São Paulo].

N, N.N.; Bock, D.; Aihara, T. Crescimento da medicina empresarial e mudanças na prática médica. Revista de Administração em Saúde. Abr- Jun, 2004. 23(6): 57-64.

Campomar, M.C. Do uso de "estudo de caso" em pesquisas para dissertações e teses em administração. Revista de administração. 1991. 26(3): 95-97.

Minayo,M.C.S.; Sanches, O. Quantitativo-qualitativo: oposição ou complementaridade? Caderno de Saúde Pública. 1993. 9(3): 239-48. 
Scarpi, M.J. Gestão de clínicas médicas. São Paulo. Editora Futura. 2004.

Siqueira, P.C.A. Direito Cooperativo Brasileiro. São Paulo. Editora Dialética. 2004. 
ANEXOS 


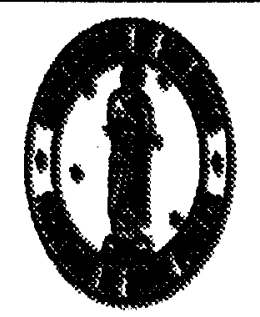

\section{Universidade de São Paulo \\ Faculdade de Saúde Pública}

\section{Entrevista com a Diretoria Administrativa}

Hospital com corpo clínico próprio

1- O que levou o hospital a escolher essa forma jurídica de contratação médica?

2- Como a administração trabalha com o corpo clínico as metas estabelecidas no contratato de gestão?

3- Como a administração acompanha o desempenho das especiliades médicas? Usa indicadores? Quais?

4- O hospital trabalha com plano de cargos, carreiras e salários?

5- O hospital encontra dificuldades para recrutar profissional médico no mercado? Em quais especialidades?

6- Qual é a ação da administração quando as metas preestabelecidas não são atingidas ou o desempenho é inadequado por parte de uma especialidade médica?

7- Por quê não terceiriza o Corpo Clínico?

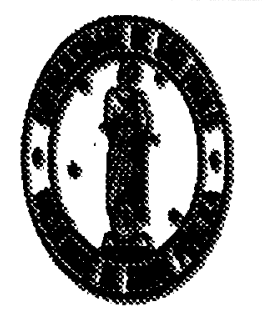

\section{Universidade de São Paulo \\ Faculdade de Saúde Pública}

\section{Entrevista com a Diretoria Administrativa}

Hospital com corpo clínico terceirizado:

1- O que levou o hospital a escolher essa forma jurídica de contratação médica?

2- Como a administração trabalha com o corpo o clínico as metas estabelecidas no contratato de gestão?

3- Como são administrados os contratos com a cooperativa e empresas médicas em relação:

a) Negociação dos contratos- jurídico, financeiro $\theta$ operacional.

b) Registro de desempenho.

c) Relacionamentos pessoais.

4- Qual é a ação da administração quando as metas preestabelecidas não são atingidas ou o desempenho é inadequado por parte de uma equipe médica?

5- Como o hospital trabalha com a impossibilidade de aplicação de punições administrativas ao médico cooperado?

6- Como é elaborada a folha de pagamento dos médicos?

7- O hospital já sofreu ação trabalhista por parte de médico reclamando vínculo empregatício? Como o hospital se prepara para essa possibilidade?

8- O hospital encontra dificuldades para recrutar profissional médico no mercado? Em quais especialidades?

9- Por quê o hospital não trabalha com o corpo clínico próprio? 


\section{Universidade de São Paulo Faculdade de Saúde Pública}

\section{Entrevista com a Diretoria Clínica}

1- Como são realizados o recrutamento, seleção, integração dos médicos no hospital?

2- Em relação a hierarquia, como os médicos se reportam a diretoria clínica $\theta$ ao hospital?

3- As equipes médicas se reunem para discussão e revisão de casos clínicos, bem como assuntos técnicos $\theta$ administrativos?

4- As equipes médicas trabalham com protocolos clínicos e cirúrgicos?

5- Como o hospital trabalha a reposição do quadro de profissionais médicos nos casos de férias e licenças?

6- Quais são as Comissões que os médicos participam?

7- Há avaliação de desempenho do corpo clínico? São usados indicadores?

8- Há alguma avaliação sobre o processo de reciclagem do profissional médico?

9- Nos programas de qualidade, como é o envolvimento dos médicos no processo?

10- Cite vantagens e desvantagens do modelo de vínculo trabalahista do profissional médico optado pelo hospital? 